\author{
Universidade de São Paulo \\ Instituto de Física
}

\title{
Estudo de Estabilidade Hidrodinâmica do Escoamento ao Redor de um Cilindro alinhado com um Fólio
}

Gustavo Alonso Patino

Orientador: Prof. Dr. Julio Romano Meneghini

Dissertação de mestrado apresentada ao Instituto de Física para a obtenção do título de Mestre em Ciências

Comissão examinadora:

Prof. Dr. Julio Romano Meneghini (POLI-USP)

Prof. Dr. Iberê Luiz Caldas (IFUSP)

Prof. Dr. José Augusto Penteado Aranha (POLI-USP)

São Paulo

2013 


\section{FICHA CATALOGRÁFICA \\ Preparada pelo Serviço de Biblioteca e Informação do Instituto de Física da Universidade de São Paulo}

Patino, Gustavo Alonso

Estudo de Estabilidade Hidrodinâmica

do Escoamento ao Redor de um Cilindro

alinhado com um Fólio - São Paulo, 2013.

Dissertação (Mestrado) — Universidade de São Paulo.

Instituto de Física

Orientador: Prof. Dr. Julio Romano Meneghini

Área de Concentração: Mecânica dos Fluidos

Unitermos: 1. Mecânica dos Fluidos; 2. Mecânica dos Fluidos Computacional ;

3. Dinâmica dos Fluidos; 4. Vórtices dos Fluidos. 



\section{Sumário}

1 Resumo 1

2 Introdução $\quad 5$

$\begin{array}{lll}3 & \text { Revisão Bibliográfica } & \mathbf{7}\end{array}$

3.1 Geração e desprendimento de vórtices em corpos cilíndricos . . 8

3.2 Separação da camada limite . . . . . . . . . . . . . . . . . 22

3.3 Geração e desprendimento de vórtices em arranjos de corpos cilíndricos . . . . . . . . . . . . . . . . 26

3.4 Geração e desprendimento de vórtices em corpos aerodinâmicos 30

3.5 Estabilidade hidrodinâmica . . . . . . . . . . . . . . 35

3.6 Teoria de estabilidade de Floquet . . . . . . . . . . . . . . 43

3.7 Método de elementos finitos espectrais . . . . . . . . . . . 45

3.8 Simulações quase tridimensionais . . . . . . . . . . . . . 47

4 Metodologia $\quad 51$

4.1 Ordem da função base . . . . . . . . . . . . . . . . . . . . 52

4.2 Tamanho lateral da malha . . . . . . . . . . . . . 54

4.3 Comprimento a jusante . . . . . . . . . . . . . . 56

4.4 Malha resultante . . . . . . . . . . . . . . 57

4.5 Malhas usadas na análise de Floquet . . . . . . . . . . . 58

5 Resultados $\quad 61$

5.1 Campos base e análise de estabilidade de um fólio isolado . . . 61

5.1.1 Simulações NACA 0012 ângulo de ataque zero grau . . 61

5.1.2 Simulações NACA 0012 ângulo de ataque dez graus . . 62

5.1.2.1 Variação do Coeficiente de Arrasto . . . . . . 64

5.1.2.2 Variação do Coeficiente de Sustentação . . . . 64

5.1.3 Simulações NACA 0012 ângulo de ataque vinte graus . 67

5.1.3.1 Variação do Coeficiente de Sustentação . . . . 68

5.1.3.2 Variação do Coeficiente de Arrasto . . . . . . 70 
5.1.3.3 Variação do número de Strouhal . . . . . . . 71

5.1.3.4 Análise de Floquet . . . . . . . . . . . . . . 72

5.2 Campos base e análise de estabilidade de um aerofólio alinhado com um cilindro . . . . . . . . . . . . . . . 76

5.2.1 Simulações cilindro com NACA 0012 ângulo de ataque zero grau . . . . . . . . . . . . . 76

5.2.1.1 Variação do Coeficiente de Arrasto . . . . . . 78

5.2.2 Simulações cilindro com NACA 0012 ângulo de ataque dez graus . . . . . . . . . . . . . . . . 79

5.2.2.1 Variação do Coeficiente de Arrasto . . . . . . 81

5.2.2.2 Variação do Coeficiente de Sustentação . . . . 83

5.2.2.3 Número de Strouhal . . . . . . . . . . . . . . 84

5.2.2.4 Análise de Floquet . . . . . . . . . . . . . 85

5.2.3 Simulações cilindro com NACA 0012 ângulo de ataque vinte graus . . . . . . . . . . . . . . 85

5.2.3.1 Variação do Coeficiente de Arrasto . . . . . . 86

5.2.3.2 Variação da Sustentação . . . . . . . . . . . . . 89

5.2.3.3 Número de Strouhal . . . . . . . . . . . . . . 90

5.2.3.4 Análise de Floquet . . . . . . . . . . . . . 90

6 Conclusões $\quad 95$

A Descrição do Método de Elementos Finitos Espectrais 105

B Aplicação do método de elementos finitos espectrais às equações incompressíveis de Navier-Stokes 


\section{Lista de Figuras}

3.1 Modelo de geração de vórtices de Gerrard ${ }^{1}$. Extraído de Meneghini $^{2} \ldots \ldots \ldots \ldots \ldots \ldots$

3.2 Escoamento ao redor de um cilindro Re $<1$. Extraído de Young $^{3}$ apud Meneghini ${ }^{2}$. . . . . . . . . . . . . 10

3.3 Vórtices estacionários ao redor de um cilindro, regime $5<$ Re $<40$. Extraído de Young ${ }^{3}$ apud Meneghini ${ }^{2}$. . . . . . . 10

3.4 Esteira oscilatória no escoamento ao redor de um cilindro, $40<\operatorname{Re}<50 \sim 70$. Extraído de Young ${ }^{3}$ apud Meneghini $^{2}$. . 10

3.5 Modo de geração e desprendimento de vórtices sem controle das condições de contorno nas bordas do cilindro (Williamson $\left.^{4}\right)$. Extraído de Meneghini ${ }^{2}$. . . . . . . . . . . . 12

3.6 Modo de geração e desprendimento de vórtices com controle das condições de contorno nas bordas do cilindro (Williamson $^{4}$ ). Extraído de Meneghini ${ }^{2}$. . . . . . . . . . . . . 12

3.7 Escoamento ao redor de um cilindro visto em planta: a) Modo A de geração de vórtices; b) Modo $\mathrm{B}$ de geração de vórtices $\left(\right.$ Williamson $^{4}$ ). Extráido de Meneghini ${ }^{2}$. . . . . . . . . . . 12

3.8 Contornos de $z$-vorticidade da esteira bidimensional no regime $\mathrm{Re}=200$. Extraído de Leweke e Williamson ${ }^{5}$. . . . . . . 13

3.9 Características físicas do escoamento principal. Extraído de Leweke e Williamson $^{5}$. . . . . . . . . . . . . . . . . 14

3.10 Linhas de corrente do escoamento ao redor de um cilindro fixo a um referencial que se move com velocidade ( $\mathrm{U} / 2$ ) (aproximadamente a velocidade do vórtice mais lento). Extraído de Leweke e Williamson ${ }^{5}$

3.11 Escoamento ao redor de um cilindro. a) Módulo do multiplicador de Floquet $|\mu|$, como função do número de onda adimensional na direção de envergadura $\beta D$, para diferentes número de Reynolds. b) Curva de estabilidade neutra do sistema. Extraído de Carmo et al. ${ }^{6}$ 
3.12 Superposição do modo crítico de Floquet na esteira de Von Kármán. Os tubos cinza são contornos de $z$-vorticidade $\mid \omega_{z}+$ $\tilde{\omega}_{z} \mid$. Conectando os vórtices de Von Kármán, se tem regiões de $x$-vorticidade $\left(\tilde{\omega}_{x}\right)$ positiva (vermelha) e negativa (azul). O modo de Floquet deforma os vórtices de Von Kármán na direção de envergadura. Extraído de Barkley e Henderson ${ }^{7}$

3.13 Contornos do Modo de Floquet de $x$-vorticidade e, linhas de $z$ vorticidade do campo base para o escoamento ao redor de um cilindro isolado. Contornos claros e linhas pontilhadas representam vorticidade negativa. Contornos escuros e linhas continuas representam vorticidade positiva. Extraído de Carmo et al. $^{6} \ldots \ldots \ldots \ldots \ldots \ldots \ldots \ldots$

3.14 Separação da camada limite e camada cisalhante próxima à superficie, regime subcrítico $\left(350<\operatorname{Re}<2^{5}\right)$. Extraído de Basu $^{8}$ apud Meneghini ${ }^{2}$. . . . . . . . . . . . 21

3.15 Separação da camada limite e camada cisalhante próxima à superficie, regime crítico $\left(2^{5}<\operatorname{Re}<7^{5}\right)$. Extraído de Basu ${ }^{8}$ apud Meneghini ${ }^{2} \ldots \ldots . \ldots . . \ldots 21$

3.16 Escoamento ao redor de um cilindro com separação (Schlichting $^{9}$ ). Extraído de Meneghini ${ }^{2}$. . . . . . . . . . . . 23

3.17 Perfil de velocidade, de sua primeira e segunda derivada em relação a $y$. Caso gradiente favorável de pressão (Schlichting $\left.{ }^{9}\right)$. Extraído de Meneghini $^{2}$. . . . . . . . . . . . . . . . 24

3.18 Perfil de velocidade, de sua primeira e segunda derivada em relação a $y$. Caso gradiente adverso de pressão (Schlichting ${ }^{9}$ ). Extraído de Meneghini ${ }^{2}$. . . . . . . . . . . . 25

3.19 Escoamento incidente sobre uma placa plana a $90^{\circ}$, a) sem e b) com outra placa plana posicionada na frente da principal. Extraído de Schlichting ${ }^{9}$ apud Meneghini ${ }^{2} \mathrm{Re}=600$. . . . . 26

3.20 Escoamento ao redor de um aerofólio a baixo ângulo de ataque. Extraído de Schlichting ${ }^{9} \ldots \ldots$. . . . . . . . . 31

3.21 Escoamento ao redor de um aerofólio a alto ângulo de ataque. Extraído de Schlichting ${ }^{9}$. . . . . . . . . . . . . 31

3.22 Multiplicadores de Floquet, caso NACA 0012 ângulo de ataque $20^{\circ}$. Extraído de Meneghini et al. ${ }^{10} \ldots$. . . . . . . . 33

3.23 Curva de estabilidade neutra, caso NACA 0012 ângulo de ataque $20^{\circ}$. Extraído de Meneghini et al. ${ }^{10} \ldots$. . . . . . . 33 
3.24 Escoamento base combinado com o modo instável de Floquet, $\beta c=11$. Superficies translúcidas correspondem a isosuperficies de $\omega_{z}$ enquanto as superficies escuras e claras correspondem a iso-superficies de $\omega_{x}$. $\operatorname{Re}=500 \alpha=20^{\circ}$. Extraído de Meneghini et al. ${ }^{10} \ldots$. . . . . . . . . . . . 34

3.25 Escoamento base combinado com o modo instável de Floquet, $\beta c=3$. Superficies translúcidas correspondem a isosuperficies de $\omega_{z}$ enquanto as superficies escuras e claras correspondem a iso-superficies de $\omega_{x}$. $\operatorname{Re}=590 \alpha=20^{\circ}$. Extraído de Meneghini et al. ${ }^{10} \ldots \ldots$. . . . . . . . 34

3.26 Curva de estabilidade neutra para camada limite bidimensional com perturbações bidimensionais. Extraído de Schlich-

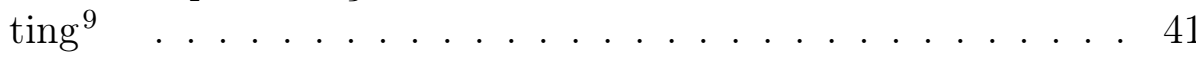

4.1 Malha usada no cálculo do campo base . . . . . . . . . . . 53

4.2 Linhas de medições do método usado no estudo de convergência da posição da fronteira a jusante. . . . . . . . . . . 56

4.3 Valores de vorticidade ao longo da distância do teste de convergência da distância da fronteira a jusante. . . . . . . . . 57

4.4 Vista detalhada da região de interferência. . . . . . . . . . . . 58

4.5 Malha utilizada para estudo de estabilidade. NACA 0012, $\alpha=20^{\circ} \ldots \ldots \ldots \ldots \ldots \ldots \ldots$

5.1 Contornos de vorticidade NACA sem ângulo de ataque, $\operatorname{Re}=600$.

Vorticidade -2 em azul a +2 em vermelho. . . . . . . . . . 62

5.2 Contornos de vorticidade NACA 0012 ângulo de ataque dez graus, $R e=600$. Vorticidade -2 em azul a +2 em vermelho . 63

5.3 Comportamento do coeficiente de arrasto e sustentação $\left(C_{d}, C_{l}\right)$ em função do tempo, $\operatorname{Re}=600, \alpha=10^{\circ} . C_{d}$ curva inferior. $\quad .63$

5.4 Comportamento dos coeficientes médios de arrasto e sustentação $\left(\overline{C_{d}}, \overline{C_{l}}\right)$ em função do Reynolds. . . . . . . . . . . . 65

5.5 Coeficientes médios de arrasto de pressão e viscoso $\left(\overline{C_{d p}}, \overline{C_{d v}}\right)$ em função do Reynolds, $\alpha=10^{\circ} \ldots$. . . . . . . . . . 65

5.6 Linhas de corrente NACA 0012 a dez graus, $R e=400 \quad \ldots \quad 65$

5.7 Linhas de corrente NACA 0012 a dez graus, $\mathrm{Re}=500$. . . . 66

5.8 Linhas de corrente NACA 0012 a dez graus, $\mathrm{Re}=600$. . . . 66

5.9 Distribuição do coeficiente de pressão $\left(C_{p}\right)$ na superficie do aerofólio em função do Reynolds. Curva inferior representa o intradorso, a superior o extradorso. $\alpha=10^{\circ}$. . . . . . . 66

5.10 Contornos de vorticidade NACA 0012 ângulo de ataque vinte graus, $\mathrm{Re}=600$. Vorticidade $-2 \mathrm{em}$ azul a +2 em vermelho . 67 
5.11 Comportamento dos coeficientes de arrasto e sustentação $\left(C_{d}, C_{l}\right)$ em função do tempo, $\operatorname{Re}=400 . \alpha=20^{\circ}, C_{d}$ curva inferior. . . 68

5.12 Comportamento dos coeficientes de arrasto e sustentação $\left(C_{d}, C_{l}\right)$ em função do tempo, $\operatorname{Re}=600 . \alpha=20^{\circ} . C_{d}$ curva inferior. . . 68

5.13 Comportamento dos coeficientes médios de arrasto e sustentação $\left(\overline{C_{d}}, \overline{C_{l}}\right)$ em função do Reynolds. NACA 0012, $\alpha=20^{\circ}$

5.14 Distribuição do coeficiente de pressão $\left(C_{p}\right)$ na superficie do aerofólio em função do Reynolds. Curva inferior representa o intradorso, a superior o extradorso . . . . . . . . . . . 69

5.15 Linhas de corrente NACA 0012 a vinte graus, $\mathrm{Re}=400 \quad$. . 70

5.16 Linhas de corrente NACA 0012 a vinte graus, $\mathrm{Re}=500$. . . 70

5.17 Linhas de corrente NACA 0012 a vinte graus, $\mathrm{Re}=600 \ldots 70$

5.18 Coeficientes médios de arrasto de pressão e viscoso $\left(\overline{C_{d p}}, \overline{C_{d v}}\right)$ em função do Reynolds, $\alpha=20^{\circ} \ldots$. . . . . . . . . . . 71

5.19 Gráfico do número de Strouhal em função do número Reynolds, $\alpha=20^{\circ}$. . . . . . . . . . . . . . . . 72

5.20 Curva do módulo dos multiplicadores de Floquet $|\mu|$ pelo número de onda $\beta$, sendo o comprimento de onda $\lambda=2 \pi / \beta$. Casos aerofólio NACA0012 isolado com ângulo de ataque $20^{\circ}$.

5.21 Curva de estabilidade neutra (instável é dentro da curva). . . . 73

5.22 Escoamento remontado a partir do campo base bidimensional e das perturbações tridimensionais. As iso-superfícies translúcidas são de $\omega_{z}$ do campo base. As iso-superfícies sólidas azuis e vermelhas representam valores negativos e positivos do modo instável $\omega_{x} . \operatorname{Re}=500, \alpha=20^{\circ}, \beta=11 \ldots \ldots$

5.23 Contornos de $\mathrm{x}$-vorticidade em cores do modo de Floquet sobrepostos as linhas de vorticidade em $z$ constante do campo base ........................ 7

5.24 Escoamento remontado a partir do campo base bidimensional e das perturbações tridimensionais. As iso-superfícies translúcidas são de $\omega_{z}$ do campo base. As iso-superfícies sólidas cinza escuras e claras representam valores de $\omega_{x}$ do modo de Floquet negativos e positivos. $\operatorname{Re}=600, \alpha=20^{\circ}, \beta=3 \quad$. . 75

5.25 Contornos de $\mathrm{x}$-vorticidade em cores do modo de Floquet sobrepostos as linhas de vorticidade em $z$ constante do campo base . . . . . . . . . . . . . . . 76

5.26 Contornos de vorticidade cilindro com NACA 0012 inclinado zero grau, $\mathrm{Re}=600$. Vorticidade $-2 \mathrm{em}$ azul a +2 em vermelho 77

5.27 Vista detalhada linhas de corrente NACA 0012 a zero grau em interferência com cilindro, $\mathrm{Re}=600 \ldots \ldots$. . . . . . 
5.28 Linhas de corrente cilindro com NACA 0012 a zero grau, $\mathrm{Re}=600$

5.29 Coeficientes médios de arrasto de pressão e viscoso $\left(\overline{C_{d p}}, \overline{C_{d v}}\right)$ do cilindro (cil) e o fólio (nac) em função do Reynolds . . . . . 79

5.30 Contornos de vorticidade cilindro com NACA 0012 a dez graus, $\mathrm{Re}=400 \ldots \ldots \ldots \ldots \ldots \ldots$

5.31 Contornos de vorticidade cilindro com NACA 0012 a dez graus, $\mathrm{Re}=500 \ldots \ldots \ldots \ldots \ldots \ldots$. . . . . . . . . . 80

5.32 Contornos de vorticidade cilindro com NACA 0012 a dez graus, $\mathrm{Re}=600 \ldots \ldots \ldots \ldots \ldots \ldots$. . . . . . . . . . 80

5.33 Comportamento do coeficiente médio de arrasto $\left(\overline{C_{d}}\right)$ em função do Reynolds para o cilindro (cil) e o fólio (nac), $\alpha=10^{\circ} .81$

5.34 Coeficientes médios de arrasto de pressão e viscoso $\left(\overline{C_{d p}}, \overline{C_{d v}}\right)$ do cilindro e o fólio em função do Reynolds, $\alpha=10^{\circ}$. . . . . 81

5.35 Linhas de corrente cilindro com NACA 0012 a dez graus, $\mathrm{Re}=600 \ldots \ldots \ldots \ldots \ldots \ldots$

5.36 Pressão média na região intersticial, $R e=400,500,600$. . . . 83

5.37 Comportamento do coeficiente médio de sustentação $\left(\overline{C_{l}}\right)$ para o cilindro e o fólio em função do Reynolds, $\alpha=10^{\circ}$. . . . . . 84

5.38 Distribuição do coeficiente de pressão $\left(C_{p}\right)$ na superficie do aerofólio em função do Reynolds. Curva inferior representa o intradorso, a superior o extradorso . . . . . . . . . . . 84

5.39 Curva do módulo dos multiplicadores de Floquet $|\mu|$ pelo número de onda $\beta$, sendo o comprimento de onda $\lambda=2 \pi / \beta$. Caso cilindro com aerofólio NACA0012 em ângulo de ataque

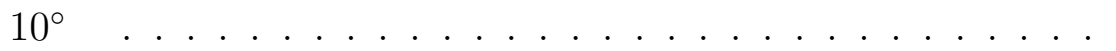

5.40 Contornos de vorticidade cilindro com NACA 0012 inclinado vinte graus, $\mathrm{Re}=600$. Vorticidade -2 em azul a +2 em vermelho.

5.41 Comportamento dos coeficientes médio de arrasto $\left(\overline{C_{d}}\right)$ do cilindro e o fólio em função do Reynolds, $\alpha=20^{\circ} \ldots$. . . . 87

5.42 Coeficientes médios de arrasto de pressão e viscoso $\left(\overline{C_{d p}}, \overline{C_{d v}}\right)$ do cilindro e o fólio em função do Reynolds . . . . . . . . . 87

5.43 Linhas de corrente cilindro com NACA 0012 a vinte graus, $\mathrm{Re}=400 \ldots \ldots \ldots \ldots \ldots$

5.44 Linhas de corrente cilindro com NACA 0012 a vinte graus, $\mathrm{Re}=500 \ldots \ldots \ldots \ldots \ldots \ldots$

5.45 Linhas de corrente cilindro com NACA 0012 a vinte graus, $\mathrm{Re}=600 \ldots \ldots \ldots \ldots \ldots$

5.46 Comportamento do coeficiente médio de sustentação $\left(\overline{C_{l}}\right)$ do cilindro e o fólio em função do Reynolds. $\alpha=20^{\circ}$. . . . . . . 89 
5.47 Distribuição do coeficiente de pressão $\left(C_{p}\right)$ na superficie do aerofólio em função do Reynolds. Curva inferior representa o intradorso, a superior o extradorso . . . . . . . . . . . 90

5.48 Gráfico do número de Strouhal cilindro com NACA 0012 em função do número Reynolds. $\alpha=20^{\circ}$. . . . . . . . . . . . . . 91

5.49 Curva do módulo dos multiplicadores de Floquet $|\mu|$ pelo número de onda $\beta$, sendo o comprimento de onda $\lambda=2 \pi / \beta$. Caso aerofólio NACA0012 em interferência com cilindro ângulo de ataque $20^{\circ}$. . . . . . . . . . . . . . . . . . . 92

5.50 Curva de estabilidade neutra (instável é dentro da curva). . . 92

5.51 Contornos de x-vorticidade em cores do modo de Floquet sobrepostos as linhas de vorticidade em $z$ constante do campo base. NACA 0012 com cilindro, $\alpha=20^{\circ}, \beta=3$. . . . . . 93

5.52 Escoamento remontado a partir do campo base bidimensional e das perturbações tridimensionais. As iso-superfícies translúcidas são de $\omega_{z}$ do campo base. As iso-superfícies sólidas azuis e vermelhas representam valores de $\omega_{x}$ negativos e positivos do modo de Floquet. $\operatorname{Re}=460, \alpha=20^{\circ}, \beta=11 \ldots . .99$

A.1 Divisão do domínio solução $\Omega$ em três elementos $\Omega^{1}, \Omega^{2}, \Omega^{3}$. Se mostram também os modos globais $\Phi_{0}(x), \Phi_{1}(x), \Phi_{2}(x)$, $\Phi_{3}(x)$ e as bases locais $\varphi_{0}(\xi), \varphi_{0}(\xi)$. Extraído de Karniadakis e Sherwin $^{11}$. . . . . . . . . . . . . . . . . 108

A.2 Coeficientes de expansão locais e globais em três domínios elementares. Extraído de Karniadakis e Sherwin ${ }^{11}$. . . . . . . . 110

A.3 Expansão modal para um polinômio de grau 5. Extraído de Karniadakis e Sherwin ${ }^{11}$. . . . . . . . . . . . . 114

A.4 Expansão nodal de modos para um polinômio de grau 5. Extraído de Karniadakis e Sherwin ${ }^{11}$. . . . . . . . . . . . . 116

A.5 Construção de uma base bidimensional a partir do produto de duas expansões unidimensionais de ordem 4. a) Expansão modal. b) Expansão nodal. Extraído de Karniadakis e Sherwin ${ }^{11}$

A.6 Definição de arranjo de índices para uma expansão tensorial bidimensional. Extraído de Karniadakis ${ }^{11}$ (1999) . . . . . . . 121

A.7 Ilustração dos esquemas de numeração local (a) e global (b) para uma região composta por dois triângulos elementares. Extraído de Karniadakis e Sherwin ${ }^{11}$. . . . . . . . . . . . 139

A.8 Forma da matriz de massa global M. Extraído de Karniadakis e Sherwin ${ }^{11}$. . . . . . . . . . . . . . . . 145 
A.9 Esquema de numeração global (a). Esquema de numeração na fronteira incluindo condições de Dirichlet (b). Ordenamento local de graus de liberdade (c). Ordenamento do sistema tal que os graus de liberdade conhecidos na fronteira de Dirichlet são listados depois dos graus desconhecidos (d). Extraído de Karniadakis e Sherwin ${ }^{11}$. . . . . . . . . . . . . . . 148

A.10 Intersecção da fronteira do elemento e com a fronteira $\partial \Omega$.

Extraído de Karniadakis ${ }^{11}$ (1999) . . . . . . . . . . . . . . . 152 



\section{Lista de Tabelas}

4.1 Influência da ordem da função base . . . . . . . . . . . . . . 54

4.2 Influência do contorno lateral da malha . . . . . . . . . . . 55

5.1 Resultados aerodinâmicos NACA 0012 isolado, ângulo de ataque dez graus. . . . . . . . . . . . . . . . 64

5.2 Resultados aerodinâmicos NACA 0012 isolado, ângulo de ataque vinte graus. . . . . . . . . . . . . . . . . 68

5.3 Resultados aerodinâmicos cilindro com NACA, sem ângulo de ataque. . . . . . . . . . . . . . . . . 78

5.4 Resultados aerodinâmicos cilindro com NACA, ângulo de ataque dez graus. . . . . . . . . . . . . . . . . . . 81

5.5 Resultados aerodinâmicos cilindro com NACA, ângulo de ataque vinte graus. . . . . . . . . . . . . 87

B.1 Coeficientes das famílias de Adams-Bashford e Adams-Moulton.

Tomada de Carmo ${ }^{12}$. . . . . . . . . . . . . . . . . . 159 



\section{Capítulo 1}

\section{Resumo}

Nesta dissertação, estuda-se a transição de esteira no escoamento ao redor de um aerofólio NACA 0012 com ângulos de ataque de zero dez e vinte graus. Dois casos são considerados: fólio isolado e fólio alinhado com um cilindro. Nas duas configurações, analisa-se a estabilidade linear em relação a perturbações tridimensionais. Tais perturbações foram estudadas usando a teoria de Floquet para um conjunto de números de Reynolds e ângulos de ataques. O escoamento base é calculado usando o método de elementos finitos espectrais para a discretização espacial. Dos resultados de estabilidade no caso do aerofólio isolado, pode-se observar dois picos de instabilidade com diferentes comprimentos de onda na envergadura. A simetria dos modos instáveis é também apresentada. Um dos modos instáveis presente na esteira do aerofólio isolado foi também observado no caso do cilindro alinhado com o fólio, enquanto o outro modo foi suprimido em tal geometria 



\section{Agradecimentos}

Inicialmente, gostaria agradecer ao Professor Iberê Caldas do Instituto de Física da USP por me contatar com meu orientador e por me apoiar durante meu processo de inscrição no mestrado.

Agradeço ao meu orientador o Professor Julio Meneghini pelo apoio brindado durante meu mestrado, por acreditar nas minhas capacidades, e por me permitir aprender junto com ele sobre temas que sempre sonhei pesquisar. Mas sobre todas essas coisas agradeço sua amizade.

Agradeço a minha mãe meu pai e minha irmã pelo amor que me brindam e por acreditar nos meus sonhos. Agradeço especialmente seu apoio moral e econômico inclusive até hoje. Espero que algum dia a vida me brinde a oportunidade de recompensar, pelo menos em parte, tudo o que eles fazem por mim.

Agradeço a meus prezados amigos David Bacca, Carlos Benavides e Ricardo Ávila por me acompanhar com carinho e alegria durante meu longo caminho fora de casa.

Agradeço aos meus colegas e amigos do NDF, Rafael Gioria, Stergios Tsiloufas, Professor Bruno Carmo e Adson Agrico, pelos ensinamentos e conselhos. Sem o apoio brindado por eles teria sido completamente impossível a 
realização deste trabalho.

Finalmente agradeço à CAPES pelo apoio econômico durante meus dois anos de mestrado, e em geral, agradeço ao Brasil por me acolher com os braços abertos. É muito grato ver que ainda existem países que acreditam no trabalho e talento de estudantes estrangeiros num mundo cheio de preconceitos e desconfiança. 


\section{Capítulo 2}

\section{Introdução}

O presente trabalho é composto por duas partes. A primeira parte consiste em estudar o escoamento incompressível ao redor de um aerofólio NACA 0012 isolado a baixos números de Reynolds. Foram adotados os trabalhos de Meneghini et al. ${ }^{10}$ e Theofilis e Sherwin ${ }^{13}$ como marco de referência na hora de avaliar alguns dos resultados obtidos nesta etapa. A segunda consiste em estudar o escoamento incompressível ao redor de um cilindro e um aerofólio fixo alinhados em relação a uma corrente uniforme.

A interferência provocada pela presença de um pequeno cilindro a montante de um aerofólio, é um fenômeno muito interessante que muda completamente as características físicas do escoamento ao redor do perfil, além de modificar as estruturas resultantes na esteira. No entanto, apesar de sua importância, não foram encontrados na literatura estudos que analisam este tipo de sistemas. Este trabalho visa suprir, em parte, o vácuo existente na literatura em relação à análise de perfis aerodinâmicos em interferência com outros corpos. 
São dois também os objetivos fundamentais deste trabalho. O primeiro deles tenta estabelecer a relação entre as características físicas do escoamento ao redor do aerofólio NACA 0012 com e sem interferência, com respeito ao número de Reynolds e o ângulo de ataque. O segundo consiste em analisar as estruturas tridimensionais que aparecem no escoamento depois da transição primária. Esta transição se dá quando o escoamento deixa de se comportar em regime permanente, para então, apresentar estruturas dependentes do tempo periódicas ou não periódicas. Para estudar tais estruturas tridimensionais foram determinados os modos e comprimentos de onda característicos.

Para cumprir com os objetivos traçados, utilizaram-se simulações numéricas diretas com o método de elementos finitos espectrais para a obtenção de um campo base bidimensional. Nesse campo foi efetuada a análise de estabilidade linear usando a teoria de Floquet. O método de elementos finitos espectrais foi escolhido dado que é um método de alta resolução espacial e alta estabilidade temporal. Com os métodos empregados é possível estudar a transição de escoamento bidimensional para tridimensional envolvidas no fluxo ao redor de um fólio com e sem interferência, usando somente simulações 2D.

O trabalho está organizado da seguinte forma: no capítulo 3 se apresenta uma revisão bibliográfica dos fenômenos estudados. Em seguida no capítulo 4 são explicadas as metodologias empregadas na obtenção dos resultados. No capítulo 5 são mostrados os resultados obtidos com as respectivas discussões. Finalmente no capítulo 6 se apresentam as conclusões. 


\section{Capítulo 3}

\section{Revisão Bibliográfica}

A seguir serão expostos os conceitos físicos e matemáticos empregados neste trabalho. Inicia-se com uma revisão do fenômeno de desprendimento de vórtices ao redor de cilindros e o fenômeno de separação da camada limite. Esta parte esta inspirada no trabalho de Meneghini ${ }^{2}$. Posteriormente se faz uma revisão do escoamento ao redor de arranjos de corpos cilíndricos e corpos aerodinâmicos. Na parte final desta revisão bibliográfica se apresentam os métodos computacionais utilizados. Essa parte esta inspirada especialmente no trabalho de Carmo $^{12}$ e na monografia de Karniadakis e Sherwin ${ }^{11}$. Com este capítulo tenta-se fazer um marco de referência apropriado para a análise dos resultados finais consignados no capítulo 5 . 


\subsection{Geração e desprendimento de vórtices em corpos cilíndricos}

Em geral os cilindros pertencem a um conjunto maior denominado corpos rombudos. Um corpo rombudo é definido como aquele que imerso numa corrente livre gera uma separação do escoamento, a qual acontece numa porção considerável de sua superfície $\left(\right.$ Meneghini $\left.^{2}\right)$. Em corpos com seções transversais, a separação faz com que se formem duas camadas cisalhantes de vorticidade oposta na região imediatamente posterior o corpo. Com certas condições, estas camadas podem se tornar instáveis representando a razão principal de desprendimento de vórtices na esteira atrás do corpo. Gerrard ${ }^{1}$ propôs uma explicação para o mecanismo físico envolvido no processo de desprendimento de vórtices num cilindro. Ele sugeriu que a interação entre as duas camadas cisalhantes de vorticidade oposta, formadas a partir do desprendimento da camada limite, constitue um ponto muito importante na formação de vórtices na esteira. Inicialmente se forma um vórtice que continuamente cresce devido à circulação proporcionada pela camada cisalhante à qual ele esta conectado, na medida em que o vórtice torna-se mais intenso, começa atrair a camada cisalhante oposta devido à velocidade que este induz sobre ela. A aproximação entre estas duas camadas de vorticidade oposta termina por interromper a alimentação de circulação do vórtice em crescimento, de maneira que ele é finalmente desconectado da camada que o alimenta e a seguir é convectado a jusante do corpo formando a esteira.

Na figura.3.1 se mostra esquematicamente o modelo de Gerrard. Ele postulou que a camada cisalhante que é atraída pelo vórtice em crescimento 


\subsection{Geração e desprendimento de vórtices em corpos cilíndricos 9}

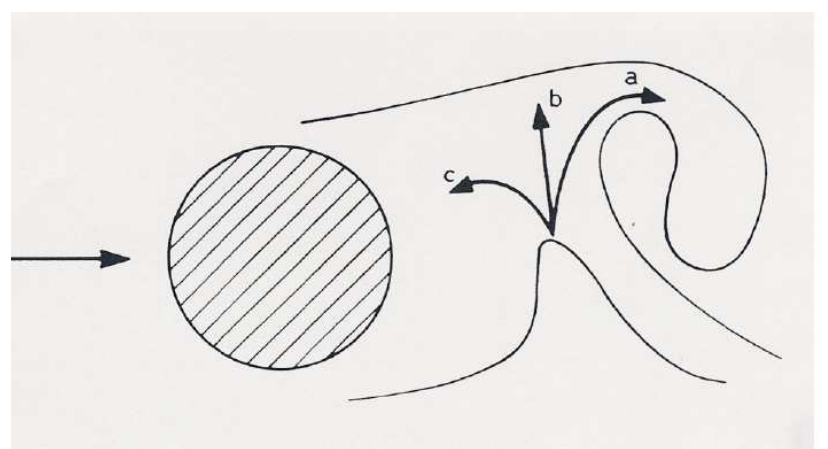

Figura 3.1: Modelo de geração de vórtices de Gerrard ${ }^{1}$. Extraído de Meneghini ${ }^{2}$

pode seguir um dos seguintes caminhos: a) eles podem seguir o caminho marcado pela seta 'a', misturando-se com o vórtice em crescimento ajudando a diminuir a circulação nele devido a que esta camada tem vorticidade oposta. Também pode continuar o caminho assinalado pela seta 'b', neste caso a camada atraída se move em direção à camada cisalhante oposta, isto em última instância causa a interrupção da alimentação de circulação para o vórtice, fazendo com que haja uma diminuição na intensidade dele. Depois da interrupção o vórtice adquire sua circulação final e se desprende da camada cisalhante à qual estava unido. Finalmente pode continuar o caminho 'c' no qual a camada voltaria para a região de esteira próxima ao corpo, neste caso colaboraria para a formação de um novo vórtice esta vez na parte inferior da esteira, fechando deste modo o ciclo de geração de vórtices. A quantidade de fluido que percorre cada um dos caminhos termina controlando a freqüência de geração e desprendimento de vórtices além de sua intensidade.

Para Reynolds muito pequenos (menores que 1) o fluido ao redor de um cilindro é aproximadamente simétrico a montante e a jusante do corpo, apresentando dois pontos de estagnação, um frontal e um traseiro (ver figura.3.2). 
Para Reynolds maiores que 5 acontece desprendimento da camada limite (fi-

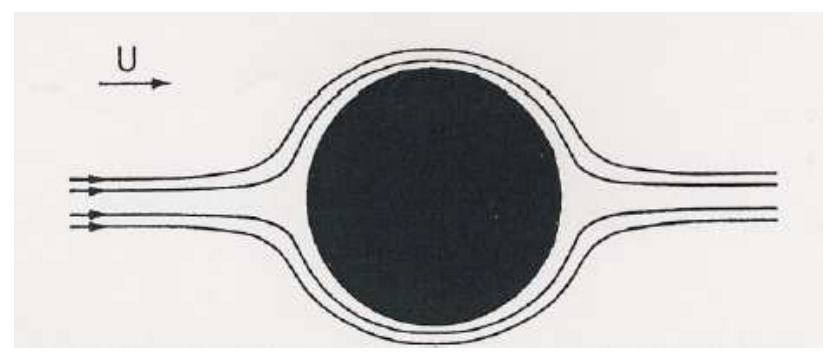

Figura 3.2: Escoamento ao redor de um cilindro Re $<1$. Extraído de Young ${ }^{3}$ apud Meneghini $^{2}$

gura.3.3), formando-se um par de vórtices estacionários. É importante ressaltar que a separação não acontece tangencial à parede. Somente com um aumento do Reynolds, a separação se torna aproximadamente tangencial a ela.

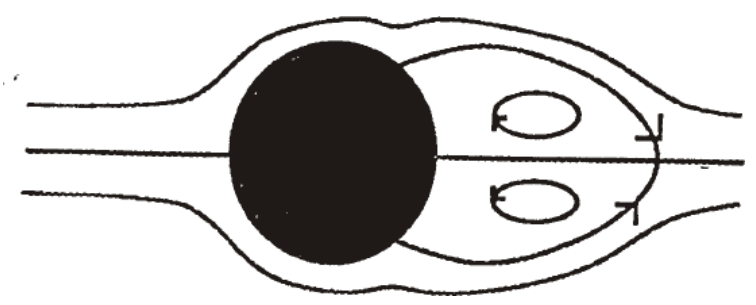

Figura 3.3: Vórtices estacionários ao redor de um cilindro, regime $5<\operatorname{Re}<40$. Extraído de Young ${ }^{3}$ apud Meneghini ${ }^{2}$

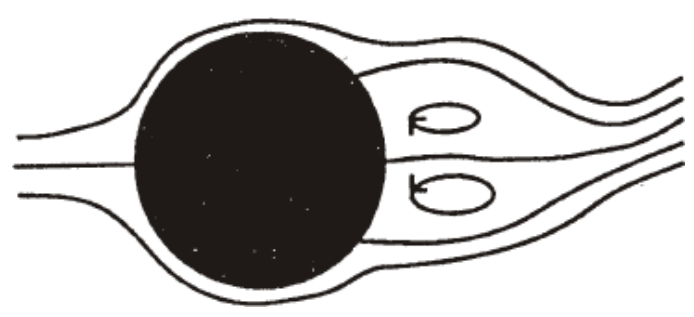

Figura 3.4: Esteira oscilatória no escoamento ao redor de um cilindro, $40<\operatorname{Re}<50 \sim$ 70. Extraído de Young ${ }^{3}$ apud Meneghini ${ }^{2}$ 


\subsection{Geração e desprendimento de vórtices em corpos cilíndricosl 1}

Acima de certo valor crítico a esteira começa a oscilar, tal como pode ser visto na figura.3.4. Tal valor crítico depende muito das perturbações externas. Para Reynolds maiores que 50-70 as camadas cisalhantes se enrolam nelas mesmas formando vórtices na esteira, gerando o fenômeno de desprendimento de vórtices, que acontece até um de Reynolds de 150-200. Nesta faixa pode se observar claramente uma esteira de Von Kármán a jusante do corpo.

Leweke e Willamson ${ }^{5}$ mostram que o primeiro passo importante na transição para turbulência no escoamento ao redor de um cilindro, é a instabilidade do escoamento estacionário que acontece ao redor de $\operatorname{Re}=47$. Neste regime o escoamento sofre uma bifurcação supercrítica de Hopf (instabilidade primária) que provoca o aparecimento de uma esteira dependente do tempo, a qual é caracterizada por uma freqüência de desprendimento de vórtices conhecida como esteira de Von Kármán. Com certas condições de fronteira os vórtices são desprendidos paralelos ao eixo do cilindro.

Outros tipos de instabilidades foram encontrados por Roshko ${ }^{14}$ a partir das descontinuidades encontradas nas curvas do número de Strouhal em função do Reynolds. Posteriormente Williamson ${ }^{4}$ encontrou que a primeira descontinuidade descoberta por $\operatorname{Roschko}^{14}$ ao redor de $\operatorname{Re}=64$, é devido a uma transição entre modos oblíquos e paralelos de geração de desprendimento de vórtices, percebendo-se um início de efeitos tridimensionais inclusive numa faixa de desprendimento laminar, uma visualização deste fenômeno é apresentada na figura.3.5 e figura.3.6.

A geração de desprendimento de vórtices oblíquos está altamente influênciada pelas condições de contorno. Williamson ${ }^{4}$ manipulou tais condições de 


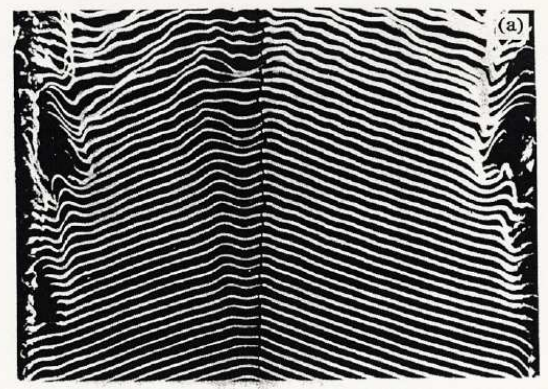

Figura 3.5: Modo de geração e desprendimento de vórtices sem controle das condições de contorno nas bordas do cilindro (Williamson $\left.^{4}\right)$. Extraído de Meneghini $^{2}$

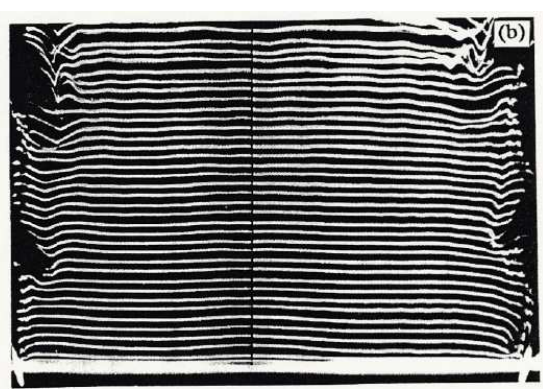

Figura 3.6: Modo de geração e desprendimento de vórtices com controle das condições de contorno nas bordas do cilindro (William$\left.\operatorname{son}^{4}\right)$. Extraído de Meneghini $^{2}$

contorno obtendo desprendimento de vórtices com linhas paralelas até um Reynolds de 200, logrando uma curva continua de Stvs Re sem dispersão. Para Reynolds mais elevados se apresentam flutuações turbulentas na esteira além de surgimento de tridimensionalidades de grande escala. Para explicar estas observações, Williamson ${ }^{4}$ propôs o aparecimento de tubos fechados de vórtices alinhados na direção do escoamento, que parecem como dedos penetrando nos vórtices alinhados com o eixo do cilindro (ver figura.3.7). São
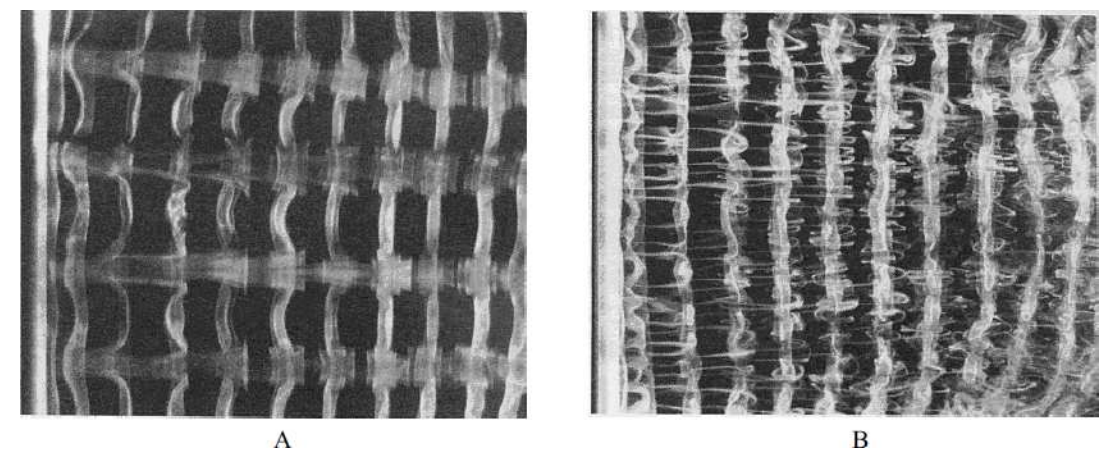

Figura 3.7: Escoamento ao redor de um cilindro visto em planta: a) Modo A de geração de vórtices; b) Modo B de geração de vórtices (Williamson ${ }^{4}$ ). Extráido de Meneghini $^{2}$. 


\subsection{Geração e desprendimento de vórtices em corpos cilíndricosl3}

justamente estes tubos os geradores de uma transição bidimensional para tridimensional. O aparecimento intermitente destes tubos é a razão pela qual acontece uma descontinuidade na curva St vs $\operatorname{Re}$ num valor de $\operatorname{Re} \approx 180$. Williamson ${ }^{4}$ chamou de A o modo de desprendimento de vórtices associado com esta primeira descontinuidade. Uma segunda descontinuidade foi observada por Williamson ${ }^{15}$ na faixa $230 \leq R e \leq 260$, e corresponde a uma mudança de menor escala nas estruturas conformadas pelos tubos de vórtices. Este modo surge da transferência gradual de energia proveniente do modo A (Williamson ${ }^{16}$ ) e foi definido por Williamson ${ }^{15}$ como modo B. Este modo tem vórtices de menor escala no plano $x-y$ com comprimento de onda de aproximadamente 1 diâmetro, tal como mostrado em Figura 3.7. Enquanto o modo A tem um comprimento de onda de aproximadamente 4D.

Leweke e Williamson ${ }^{5}$ estudaram as características físicas dos modos A e B a partir da análise da esteira bidimensional no escoamento ao redor de um cilindro num regime próximo a transição.

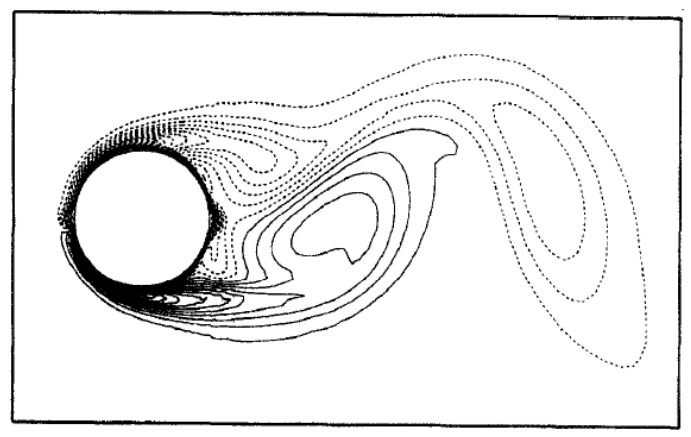

Figura 3.8: Contornos de $z$-vorticidade da esteira bidimensional no regime $\mathrm{Re}=200$. Extraído de Leweke e Williamson ${ }^{5}$

A Figura 3.8 mostra os resultados obtidos. Nela podem-se observar os contornos de $z$-vorticidade num instante do ciclo de desprendimento. Pode- 
se notar que a camada limite que se separa da parte inferior do cilindro, se enrola formando um vórtice primário aproximadamente a um diâmetro a jusante do corpo. Justo a jusante deste vórtice, percebe-se mais um vórtice primário formado da camada cisalhante desprendida da parte superior do cilindro médio ciclo de desprendimento antes. Parte da camada deste último vórtice continua ligada ao corpo formando a denominada camada cisalhante entre vórtices consecutivos (Leweke e Williamson ${ }^{5}$ ). As duas características mais importantes observadas na esteira próxima são a formação de vórtices primários, e a formação de camadas cisalhantes que os unem. Da Figura 3.9 pode-se notar que estas duas estruturas têm escalas diferentes. Os núcleos dos vórtices primários têm um diâmetro da ordem de $\delta_{\text {nucleo }}=D$, enquanto o tamanho das camadas é da ordem de $\delta_{\text {cam }}=D / 4$. O radio $\delta_{\text {nucleo }} / \delta_{\text {cam }}$ é muito próximo ao radio $\lambda_{\bmod A} / \lambda_{\operatorname{modB}}$ de comprimentos de onda na direção de envergadura entre os modos A e B. Isso sugere que existe uma conexão entre

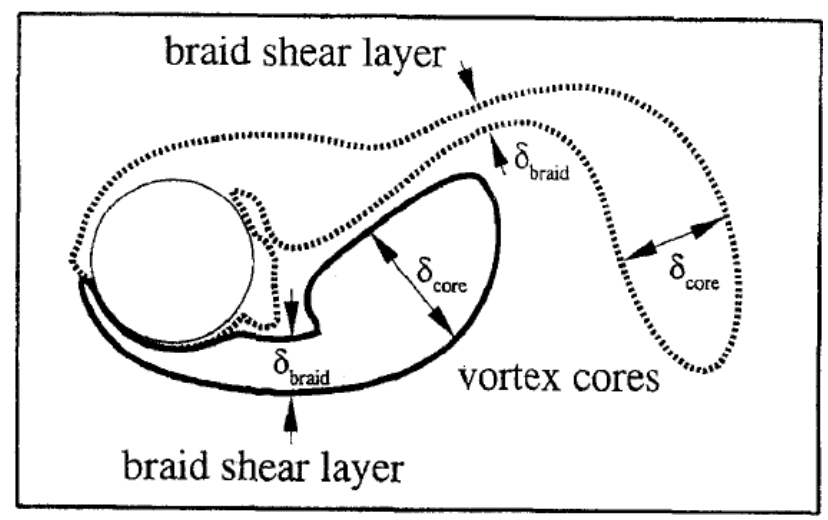

Figura 3.9: Características físicas do escoamento principal. Extraído de Leweke e Williamson $^{5}$

estas características com as instabilidades tridimensionais que conduzem a tais modos. 


\subsection{Geração e desprendimento de vórtices em corpos cilíndricosis 5}

Williamson ${ }^{17}$ propôs que o modo de instabilidade de maior comprimento de onda (modo A), estava vinculado com instabilidades de tipo elíptico que aconteciam nos núcleos dos vórtices. Para fazer estas deduções Williamson ${ }^{17}$ estudou o campo dentro dos vórtices num referencial que se movia junto com eles. Os resultados obtidos podem ser observados na Figura 3.10. Nota-se

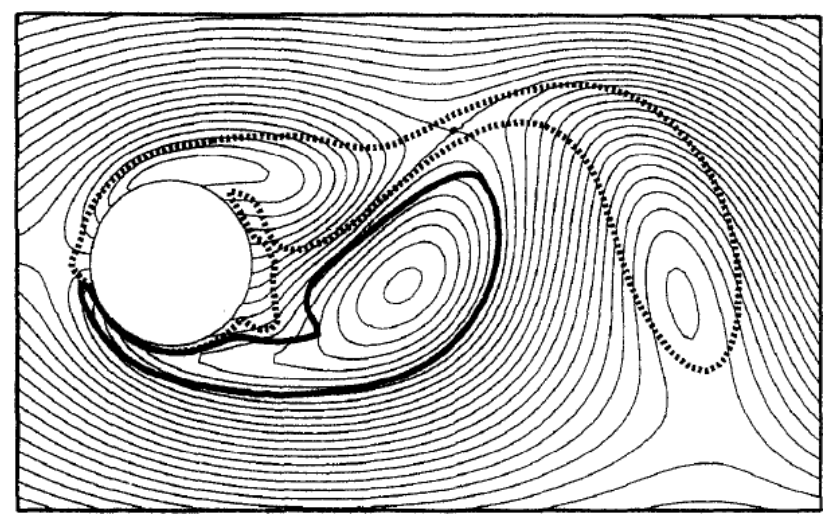

Figura 3.10: Linhas de corrente do escoamento ao redor de um cilindro fixo a um referencial que se move com velocidade $(\mathrm{U} / 2)$ (aproximadamente a velocidade do vórtice mais lento). Extraído de Leweke e Williamson ${ }^{5}$

que no núcleo dos vórtices, as linhas de corrente são aproximadamente elipses. Fluidos com linhas de corrente elípticas se originam a partir da superposição entre um fluido com rotação constante e um fluido cujas linhas de corrente são planas. A Figura 3.10, também oferece informação relacionada com o mecanismo físico que envolve as instabilidades acontecidas na camada cisalhante, pois se revela a presença de um ponto de estagnação característico de um escoamento de tipo hiperbólico. Os escoamentos hiperbólicos surgem da superposição de um escoamento plano com um em rotação. Mas contrário ao caso de fluidos elípticos, o escoamento plano domina sobre a rotação.

Barkley e Henderson ${ }^{7}$ apresentam um estudo completo de estabilidade 
de Floquet para uma esteira periódica no tempo do escoamento ao redor de um cilindro no regime de transição $140 \leq R e \leq 300$. Os cálculos computacionais apresentados nesse trabalho permitem determinar o número de Reynolds crítico e, o número de onda crítico das instabilidades secundárias na esteira de Von Kármán, adicionalmente os resultados permitem uma visualização direta da estrutura do autovalor crítico de Floquet que dirige a instabilidade. Os resultados obtidos por Barkley e Henderson ${ }^{7}$ foram reproduzidos por Carmo et al. ${ }^{6}$. Na Figura 3.11(a) se mostra o comportamento do

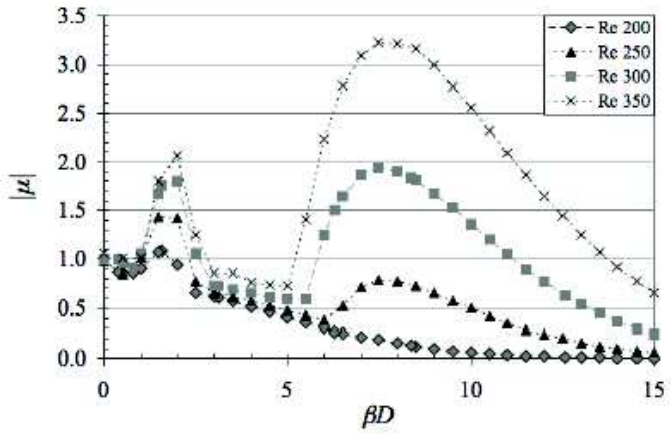

(a)

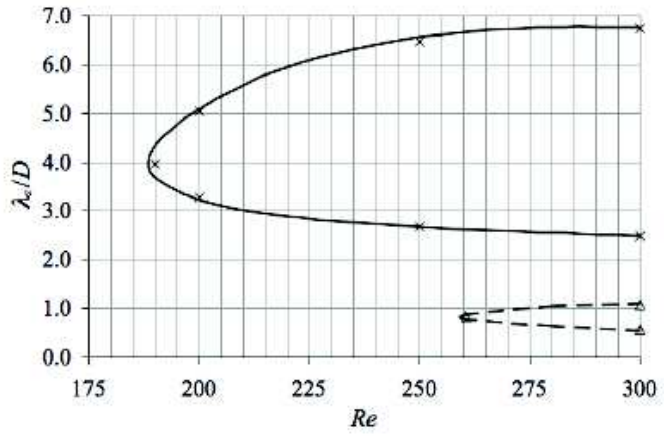

(b)

Figura 3.11: Escoamento ao redor de um cilindro. a) Módulo do multiplicador de Floquet $|\mu|$, como função do número de onda adimensional na direção de envergadura $\beta D$, para diferentes número de Reynolds. b) Curva de estabilidade neutra do sistema. Extraído de Carmo et al. ${ }^{6}$

módulo do multiplicador de Floquet $(|\mu|)$ como função do número de onda na direção de envergadura $\beta D$ para diferentes Reynolds. Dado que os ramos formados pelos multiplicadores são simétricos respeito a uma mudança do sinal do número $\beta$, só é necessário tomar a parte positiva do espectro de autovalores (Barkley e Henderson ${ }^{7}$ ). Igualmente, devido à simetria de translação temporal, há um multiplicador de Floquet $\mu=1$ em $\beta=0$ na Figura 3.11(a) que é independente do número de Reynolds. Este modo corresponde 


\subsection{Geração e desprendimento de vórtices em corpos cilíndricosl 7}

a um crescimento exponencial nulo dos modos lineares, já que por definição os multiplicadores de Floquet estão relacionados com o expoente temporal $\sigma$ pela equação $\mu=e^{(\sigma T)}$, onde T é o período da esteira. O multiplicador $\mu=1$ em $\beta=0$ aparece porque fluidos dependentes do tempo têm um modo de Floquet neutralmente estável da forma $u \propto d u / d t$ (Barkley e Henderson ${ }^{7}$ ). Fora de $\beta=0$ os multiplicadores de Floquet dependem do Reynolds tal como apresentado em Figura 3.11(a). Percebem-se dois picos de instabilidade nas curvas. Usando a nomenclatura definida por Williamson ${ }^{18}$, o modo de menor número de onda corresponde ao modo $\mathrm{A}$ de instabilidade, enquanto o modo de número de onda maior corresponde ao modo B. Adicionalmente podese observar a partir da curva de instabilidade neutra Figura 3.11(b), que o modo A torna-se instável para um $R e \approx 190$ com comprimento de onda $\lambda_{A} / D \approx 3.97$. Por outro lado o modo B se torna instável para um $R e \approx 260.5$ com comprimento de onda $\lambda_{B} / D \approx 0.825$. Para $\beta>12$ os multiplicadores tendem a zero. Uma vez que o termo viscoso começa dominar o comportamento do sistema, não é possível encontrar instabilidades a números de onda maiores a aqueles apresentados na Figura 3.11(b) (Barkley e Henderson ${ }^{7}$ ). Cabe anotar que existem mais modos de instabilidade na esteira no seu caminho para turbulência a Reynolds mais elevados, no entanto os modos A e B são muito interessantes dado que são os primeiros em ficar instáveis.

Para visualizar as instabilidades, Barkley e Henderson ${ }^{7}$ superpõem a estera bidimensional $\mathrm{U}$ com o modo crítico de Floquet $\tilde{u}$ em $\operatorname{Re}=188 \beta=1.6$. A superposição toma a forma $\mathrm{U}+\tilde{u}$ e imita o escoamento tridimensional próximo ao início da instabilidade. A Figura 3.12 mostra a esteira tridimensional resultante num instante de tempo. Se podem visualizar os contornos 


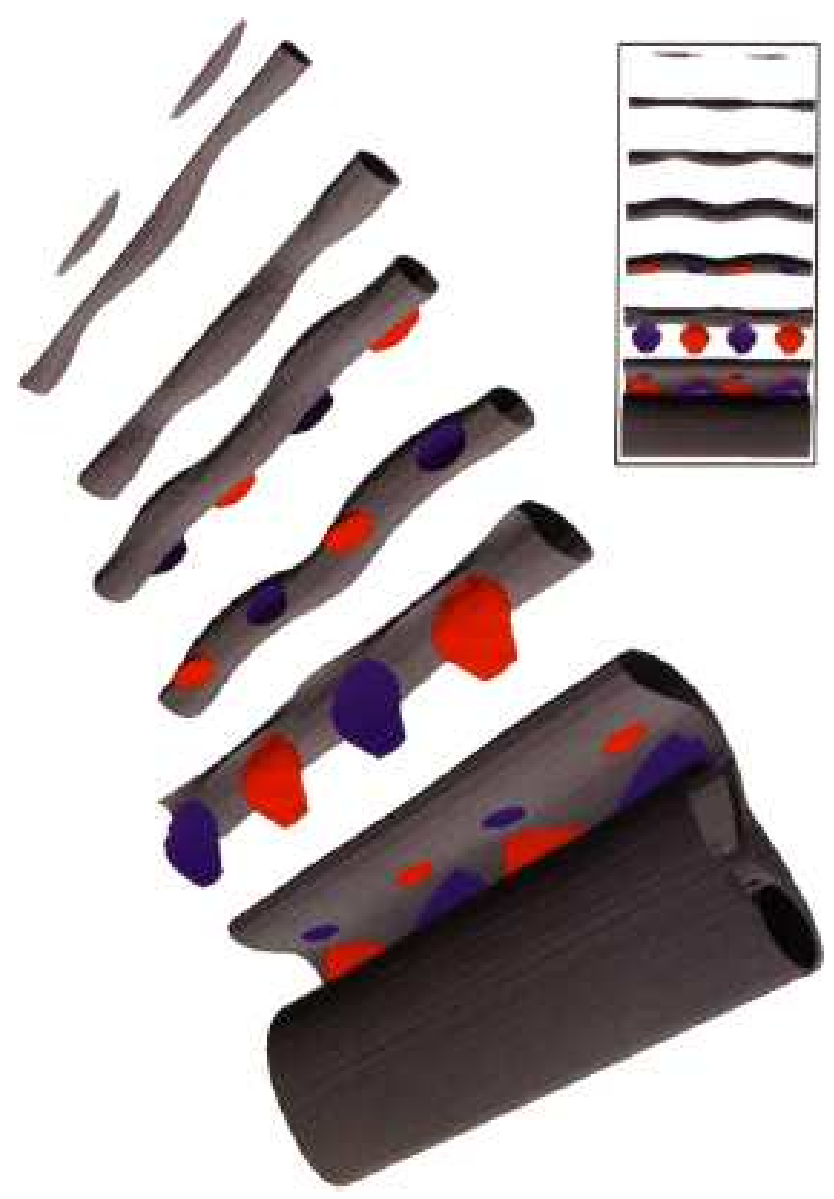

Figura 3.12: Superposição do modo crítico de Floquet na esteira de Von Kármán. Os tubos cinza são contornos de $z$-vorticidade $\left|\omega_{z}+\tilde{\omega}_{z}\right|$. Conectando os vórtices de Von Kármán, se tem regiões de $x$-vorticidade $\left(\tilde{\omega_{x}}\right)$ positiva (vermelha) e negativa (azul). O modo de Floquet deforma os vórtices de Von Kármán na direção de envergadura. Extraído de Barkley e Henderson ${ }^{7}$

de vorticidade na direção do escoamento ( $x$-vorticidade) e os contornos de vorticidade ao longo da envergadura ( $z$-vorticidade). A $z$-vorticidade é dominada pelos vórtices primários de Von Kármán, enquanto o efeito dos modos de Floquet é provocar uma perturbação periódica ao longo da envergadura, cujo comprimento de onda é aproximadamente de quatro diâmetros. Este escoamento tridimensional se assemelha muito ao modo A de desprendimento 


\subsection{Geração e desprendimento de vórtices em corpos cilíndricosl 9}

de vórtices definido por Williamson ${ }^{18}$.

Além do Reynolds e os comprimentos de onda, os modos A e B apresentam características espaço temporais completamente diferentes. Estas diferenças podem ser observadas visualizando a estrutura tridimensional dos modos usando contornos de $x$-vorticidade, tal como apresentado em Figura 3.13(a), Figura 3.13(b).

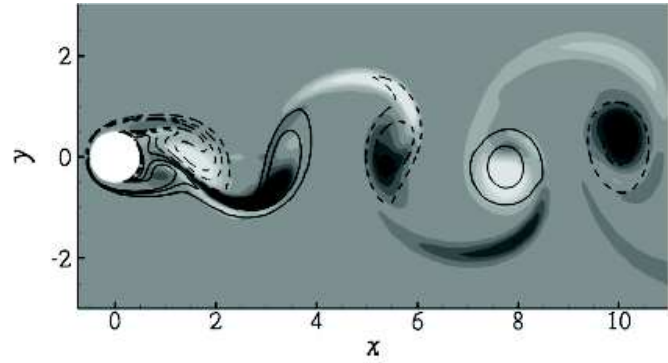

(a) Mode $\mathrm{A}-\mathrm{Re}=200, \beta D=1.571$

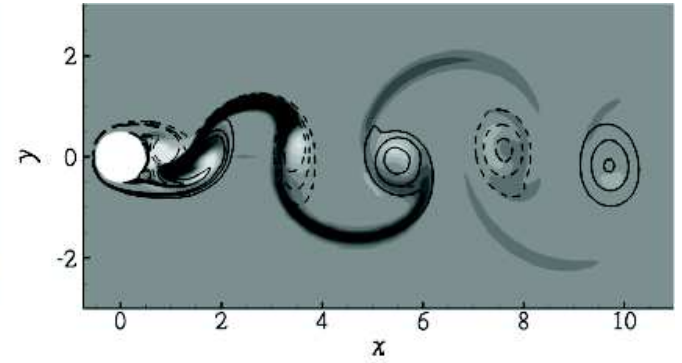

(b) Mode $\mathrm{B}-R e=300, \beta D=7.570$

Figura 3.13: Contornos do Modo de Floquet de $x$-vorticidade e, linhas de $z$-vorticidade do campo base para o escoamento ao redor de um cilindro isolado. Contornos claros e linhas pontilhadas representam vorticidade negativa. Contornos escuros e linhas continuas representam vorticidade positiva. Extraído de Carmo et al. ${ }^{6}$

A simetria observada para o modo A é

$$
\tilde{\omega}_{x}(x, y, z, t)=-\tilde{\omega}_{x}(x,-y, z, t+T / 2)
$$

Enquanto para o modo B se tem que

$$
\tilde{\omega}_{x}(x, y, z, t)=\tilde{\omega}_{x}(x,-y, z, t+T / 2)
$$

Para o modo A a $x$-vorticidade do modo de Floquet tem sinal diferente a cada lado da linha central da esteira, enquanto para o modo B a $x$-vorticidade 
tem o mesmo sinal num ciclo. Pode-se observar também que o modo A tem vorticidade maior nos núcleos dos vórtices, e modo B tem vorticidade maior nas camadas cisalhantes que os unem.

Finalmente Barkley e Henderson ${ }^{7}$ concluiram que o número Reynolds crítico para o início das instabilidades secundarias é $R e=188.5$. Por definição este é o valor mínimo para o qual o espectro de Floquet inclui um modo neutralmente estável $(\mu=1)$. Teoricamente este modo nem cresce nem decresce ante perturbações infinitesimais. Este resultado concorda com os resultados experimentais encontrados por Williamson ${ }^{19}$ que determinou que o início da instabilidade na esteira se dá ao redor de $R e=180$, e com os resultados de Leweke e Provensal ${ }^{20}$ que encontraram uma queda na freqüência de desprendimento de vórtices (sinal do início da instabilidade) ao redor de $\operatorname{Re}=185$ para o caso de escoamento sobre anéis, os quais para certas condições geométricas se comportam como cilindros de envergadura infinita. Já para Reynolds maiores aos Reynolds nos quais aparecem as instabilidades secundárias, se entra no denominado regime subcrítico de geração de vórtices $\left(\right.$ Meneghini $\left.^{2}\right)\left(350<\operatorname{Re}<2^{5}\right)$. Ondas de instabilidade começam a aparecer nas camadas cisalhantes formadas a partir dos pontos de separação, que oscila ao redor de $80^{\circ}$ no caso de um cilindro tal como apresentado na Figura 3.14. Uma das características mais interessantes do escoamento neste regime é o deslocamento a montante do ponto de transição à turbulência. Dado que esta transição acontece próxima ao corpo a maior parte da camada cisalhante se torna turbulenta.

$\mathrm{Na}$ faixa $2^{5}<\mathrm{Re}<7^{5}$ o escoamento se encontra no denominado regime crítico, neste regime o ponto de transição se encontra muito próximo ao ponto 


\subsection{Geração e desprendimento de vórtices em corpos cilíndricos 21}

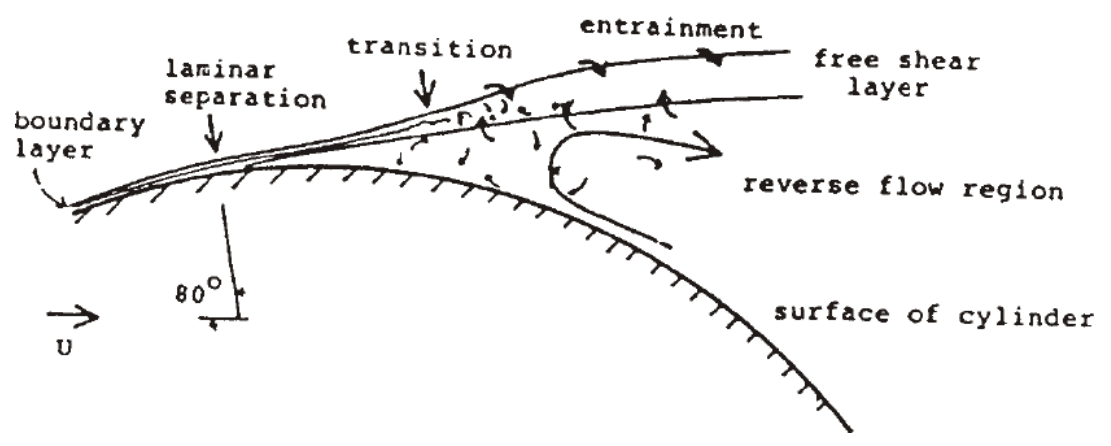

Figura 3.14: Separação da camada limite e camada cisalhante próxima à superficie, regime subcrítico $\left(350<\operatorname{Re}<2^{5}\right)$. Extraído de $\mathrm{Basu}^{8}$ apud Meneghini ${ }^{2}$

de separação (ver Figura 3.15). Adicionalmente se apresenta um interessante fenômeno no qual a camada cisalhante separada tende a se colar de novo à parede do cilindro, conforme pode ser visto na mesma Figura 3.15. A região formada entre o ponto de separação e o ponto de recolamento foi definida por Roschko ${ }^{21}$ como bolha de separação de recolamento. Neste regime crítico a estabilidade da bolha é muito baixa e pode aparecer em ambos os lados do cilindro ou em um dos seus lados somente, esta quebra de simetria pode gerar uma sustentação diferente de zero $\left(\right.$ Meneghini² $\left.{ }^{2}\right)$.

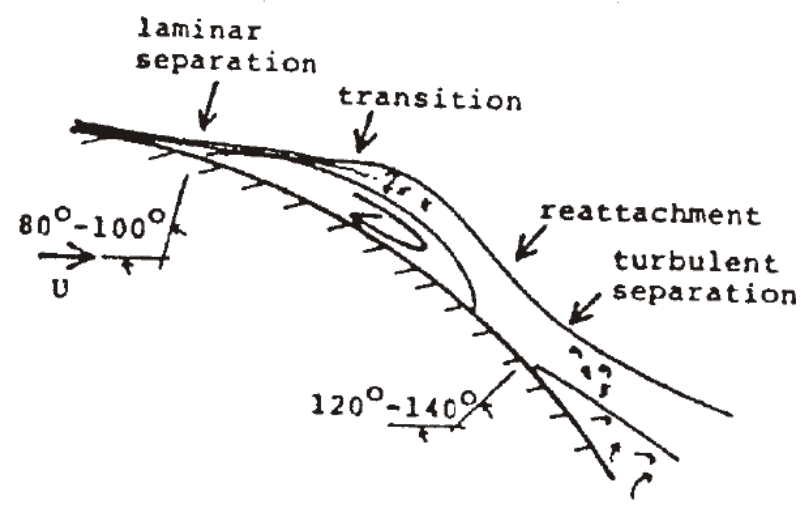

Figura 3.15: Separação da camada limite e camada cisalhante próxima à superficie, regime crítico $\left(2^{5}<\operatorname{Re}<7^{5}\right)$. Extraído de Basu ${ }^{8}$ apud Meneghini ${ }^{2}$ 


\subsection{Separação da camada limite}

A pequena região próxima à parede na qual os efeitos viscosos são muito consideráveis foi denominada de camada limite por Prandtl. Observações experimentais posteriores mostraram que o efeito da viscosidade era fazer com que não houvesse deslizamento do fluido junto à parede, tal como fora proposto por Prandtl na teoria da camada limite. Nesta camada as forças viscosas são da mesma ordem de grandeza das forças de inércia, sendo, portanto, a causa principal de arrasto num corpo imerso num fluido. No caso especifico de um fólio, uma parcela significativa da força de arrasto surge devido ao atrito provocado pelas camadas de fluido contíguas à parede, tudo isso devido aos efeitos viscosos presentes em fluidos reais. Esta análise vem ser mais complexa no caso de fólios em estol, devido ao fenômeno de desprendimento de vórtices que formam a região de esteira. Estes vórtices são formados e desprendidos devido à iteração das camadas cisalhantes, as quais se formaram devido à separação da camada limite. Dado que os efeitos viscosos são importantes somente na camada limite, pode-se desprezar numa primeira aproximação os efeitos viscosos fora de tal camada, prevalecendo o modelo de fluido ideal no qual é aplicável a teoria de escoamento potencial.

Quando uma região com um gradiente adverso de pressão $(d p / d x>0)$ existe ao longo da parede do corpo, as partículas do fluido não podem em geral penetrar muito nesta região devido à perda de energia cinética, então a camada limite se descola da superfície do corpo movendo-se dentro do escoamento principal, tal como mostrado em Figura 3.16.

O ponto de separação é definido como o limite entre o fluxo na direção 


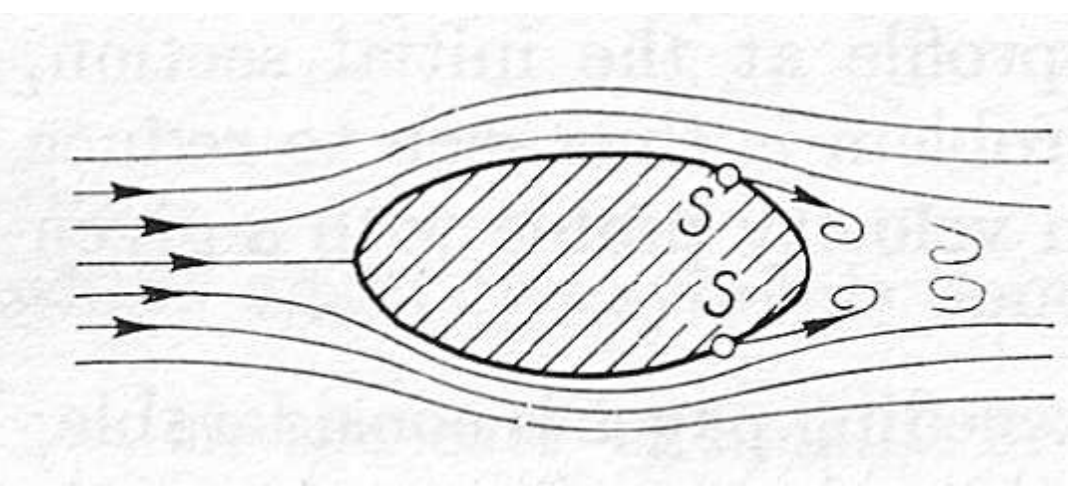

Figura 3.16: Escoamento ao redor de um cilindro com separação $\left(\right.$ Schlichting $\left.^{9}\right)$. Extraído de Meneghini ${ }^{2}$

do escoamento e o fluxo na direção oposta a ele na vizinhança da superfície, matematicamente esta condição se expressa como

$$
\left(\frac{\partial u}{\partial y}\right)_{y=0}=0
$$

O fato de acontecer desprendimento da camada limite somente em escoamentos desacelerados $(d p / d x>0)$ pode ser deduzido a partir das equações da camada limite de Prandtl (Schlichting ${ }^{9}$ ), que surgem das equações de Navierstokes em regime permanente. Destas equações com a condição de contorno $u=v=0$ na parede $(y=0)$ temos

$$
\mu\left(\frac{\partial^{2} u}{\partial y^{2}}\right)_{y=0}=\frac{d p}{d x}
$$

Então nas imediações da superfície do corpo a curvatura do perfil de velocidades depende completamente do sinal do gradiente de pressões. Para escoamentos acelerados $(d p / d x<0)$ vemos que $\partial^{2} u / \partial y^{2}<0$, partindo de um valor negativo e tendendo monotonicamente para zero ao longo da camada 
limite tal como ilustrado na Figura 3.17. Esta última condição é necessária devido ao fato que a solução na região externa à camada limite deve ter uma curvatura negativa no perfil de velocidades, e tender assintoticamente para zero quando $y \rightarrow \infty$.
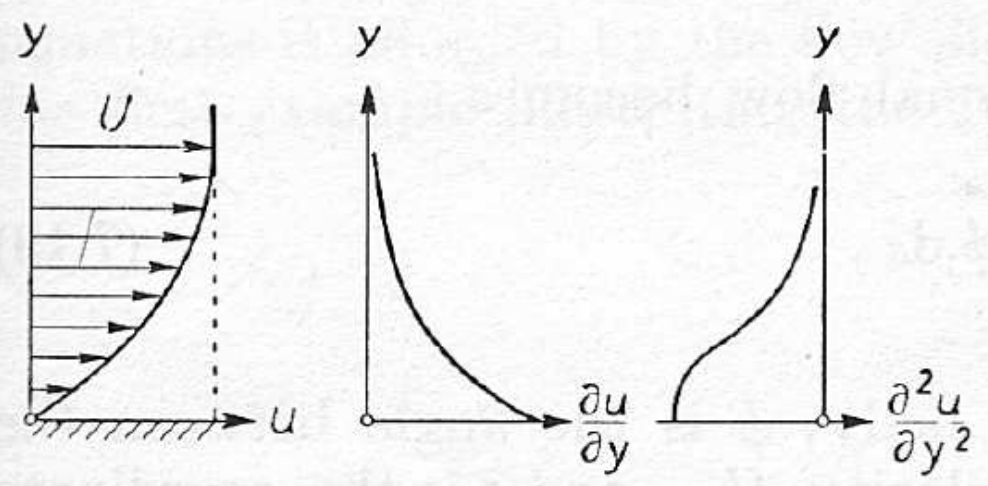

Figura 3.17: Perfil de velocidade, de sua primeira e segunda derivada em relação a $y$. Caso gradiente favorável de pressão $\left(\right.$ Schlichting $\left.^{9}\right)$. Extraído de Meneghini ${ }^{2}$

No caso de gradiente adverso de pressão (escoamento desacelerado $d p / d x>$ 0 ) encontramos que $\partial^{2} u / \partial y^{2}>0$, mas como deve-se cumprir a condição de contorno $\partial^{2} u / \partial y^{2}<0$ quando nos encontramos afastados da superfície do corpo, deve existir um ponto onde $\partial^{2} u / \partial y^{2}=0$ tal como ilustrado em Figura 3.18. Este será um ponto de inflexão do perfil de velocidades. Como o perfil de velocidades no ponto de separação com tangente nula deve ter um ponto de inflexão, então se conclui que a separação deve acontecer somente quando o escoamento está retardado, ou seja, quando sofre um gradiente adverso de pressão.

Finalmente cabe ressaltar que a presença de um gradiente adverso de pressão é uma condição necessária, mas não suficiente na hora de ter descolamento 
da camada limite $\left(\right.$ Meneghini $\left.^{2}\right)$. O porquê desta condição pode ser entendido

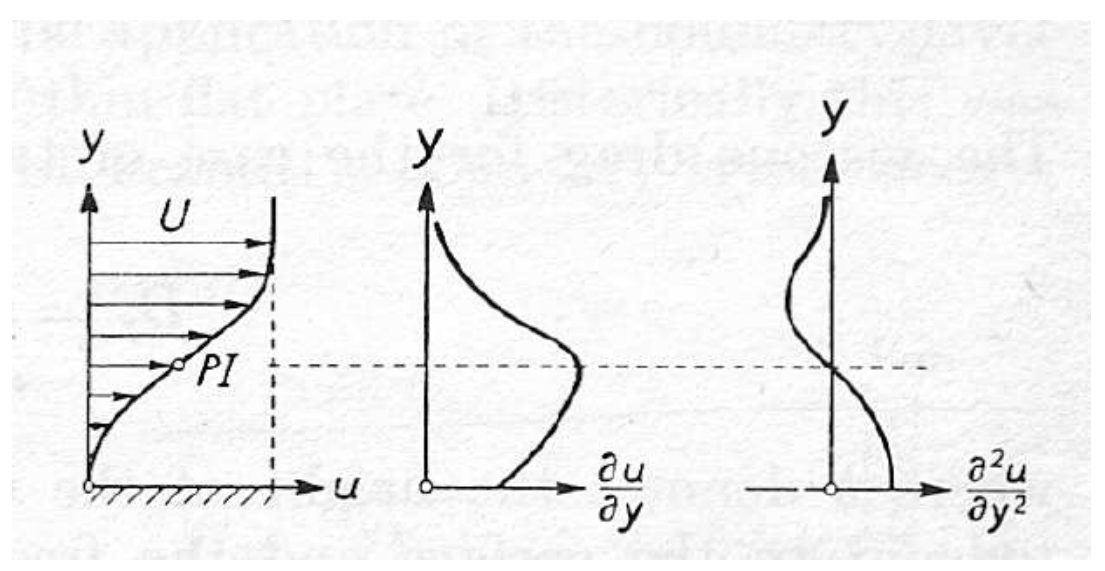

Figura 3.18: Perfil de velocidade, de sua primeira e segunda derivada em relação a $y$. Caso gradiente adverso de pressão (Schlichting ${ }^{9}$ ). Extraído de Meneghini ${ }^{2}$

através do escoamento sobre uma placa plana a $90^{\circ}$, sem e com outra placa alinhada com o escoamento e posicionada na linha de simetria perpendicular à placa principal, tal como ilustrado em Figura 3.19. Quando temos escoamento sobre a placa principal sozinha, apesar do escoamento ao longo da linha de simetria em direção ao ponto de estagnação frontal apresentar um elevado gradiente adverso de pressão, o fenômeno de separação não acontece ao longo de tal linha. No entanto quando posicionamos outra placa nesta linha de simetria, se apresenta separação devido ao gradiente adverso de pressão junto com o atrito, tal como pode ser visto na Figura 3.19(b). Esta análise permite concluir que, além do gradiente adverso de pressão é necessária a presença do atrito para que a separação aconteça. 


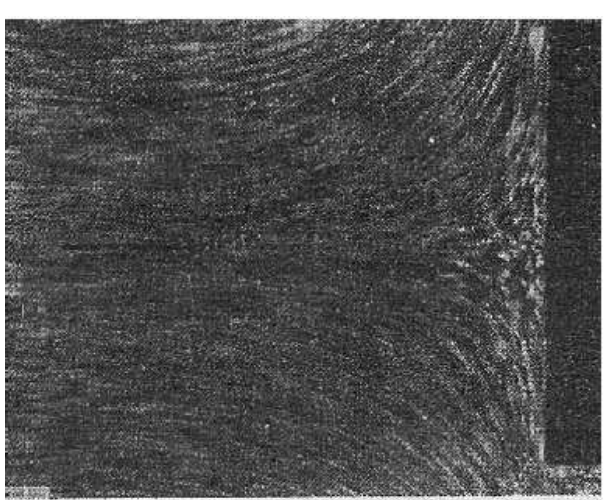

(a)

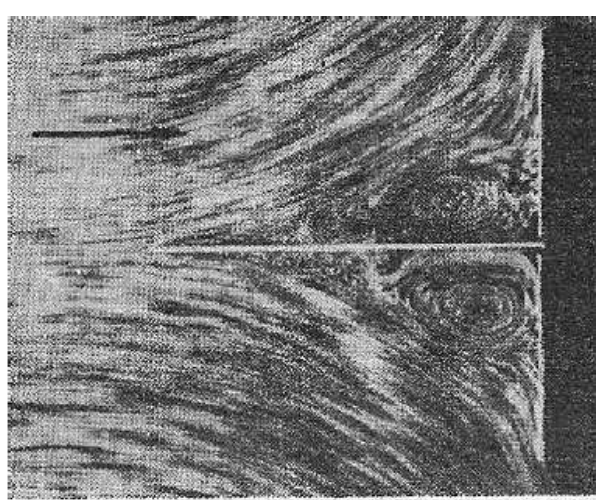

(b)

Figura 3.19: Escoamento incidente sobre uma placa plana a $90^{\circ}$, a) sem e b) com outra placa plana posicionada na frente da principal. Extraído de Schlichting ${ }^{9}$ apud Meneghini $^{2} \operatorname{Re}=600$

\subsection{Geração e desprendimento de vórtices em arranjos de corpos cilíndricos}

Quando dois ou mais corpos estão próximos e imersos num fluido, as forças experimentadas pelos corpos e o escoamento ao redor deles muda completamente em relação ao escoamento sobre os mesmos corpos, quando estão isolados e localizados no mesmo fluido. A presença de outros corpos no fluido é denominada interferência, a qual é crucial em muitos fenômenos apresentados em aerodinâmica e hidrodinâmica. Um dos tipos de interferência mais interessantes é a interferência de esteira, que acontece quando um corpo está localizado a montante de outro corpo modificando o padrão de esteira que atinge o corpo a jusante. Por exemplo, no caso de dois cilindros alinhados a interferência causa inversão de arrasto no cilindro à jusante, além de atrasar a transição para turbulência quando a separação entre eles é menor que a 


\subsection{Geração e desprendimento de vórtices em arranjos de corpos cilíndricos

distância crítica. (Carmo et al. ${ }^{6}$ ) Mizushima e Suehiro ${ }^{22}$ estudaram a estabilidade e transição do fluido estacionário ao redor também de dois cilindros alinhados. Os resultados desse trabalho mostram que a presença do cilindro a jusante estabiliza o fluido, fazendo com que a transição de fluido estacionário para fluido periódico no tempo aconteça a Reynolds mais elevados comparado com a transição para fluido periódico no caso de um cilindro isolado. Adicionalmente os cálculos de estabilidade mostram que a instabilidade primária do sistema de cilindros alinhados é do tipo subcrítico, enquanto a instabilidade primária apresentada num cilindro isolado é de Hopf ou supercrítica.

Carmo e Meneghini ${ }^{23}$ estudaram o efeito das tridimensionalidades na interferência no sistema de dois cilindros alinhados no regime $160<\operatorname{Re}<320$. Encontraram que para separações pequenas entre os cilindros, da ordem de $L_{x} / D=1.5$, não há diferença entre as simulações bidimensionais e tridimensionais na hora de estudar a distribuição de forças ao redor dos corpos. No entanto os resultados foram completamente diferentes quando os corpos se localizavam próximos à separação crítica ou de inversão de arrasto.

Carmo et al. ${ }^{6}$ apresentaram o estudo de estabilidade para um sistema composto por dois cilindros alinhados, encontrando três regimes de desprendimento de vórtices de acordo com a separação entre os corpos na faixa de Reynolds de instabilidade secundária. Para uma separação de $L_{x} / D=1.5$ se formam dois vórtices simétricos na região intersticial entre os corpos, e as camadas cisalhantes que se desprendem do cilindro a montante e atingem o cilindro a jusante são praticamente estacionárias. Carmo et al. ${ }^{6}$ definem este regime como SG (symmetric in the gap). Neste regime o cilindro a 
jusante apresenta um arrasto negativo em relação à direção do escoamento livre. Para $L_{x} / D=1.8, L_{x} / D=2.3$ não há desprendimento de vórtices na região intersticial, mas as camadas cisalhantes nessa região oscilam de acordo com a freqüência de desprendimento de vórtices. As forças nesse regime definido como AG (alternating in the gap) não mudam muito respeito ao caso anterior, ainda que o arrasto sobre o cilindro a jusante aumenta consideravelmente. Finalmente para $L_{x} / D=5$ os vórtices são desprendidos na região intersticial, este regime é referido como WG (wake in the gap), todas as forças sobre os corpos se incrementam e o arrasto sobre o cilindro a jusante se torna positivo, mostrando uma descontinuidade aerodinâmica no sistema.

Por outro lado, Carmo et al. ${ }^{24}$ estudaram o escoamento ao redor de cilindros escalonados (staggered arrangements) variando a distância transversal entre os cilindros $L_{y} / D$ na faixa $L_{y} / D=0$ até $L_{y} / D=2$. A distância entre os centros dos corpos na direção do escoamento (direção $x$ ) permaneceu constante para todos os casos estudados. Para $L_{y} / D=0$ os vórtices desprendidos do cilindro a montante atingem completamente o cilindro a jusante concordando completamente com os padrões encontrados por Carmo et al. ${ }^{6}$ No caso $0.5 \leq L_{y} / D \leq 1$, os vórtices que provêm do cilindro a montante não atingem diretamente o cilindro a jusante, mas interatuam com o vórtice desprendido da superfície inferior do cilindro a jusante. Observa-se também que a interação entre vórtices na região de esteira próxima ao cilindro a jusante é completamente diferente às interações entre vórtices acontecidas na região de esteira próxima ao cilindro a montante. Para este último o padrão de interação cumpre com o modelo de Gerrard ${ }^{1}$ descrito anteriormente, enquanto o desprendimento de vórtices na região de esteira próxima do cilindro a ju- 


\subsection{Geração e desprendimento de vórtices em arranjos de corpos cilíndricos

sante parece estar forçada pela influência da esteira a montante. A esteira no cilindro a jusante não mostra uma região de formação, pois não se apresenta uma interação significativa entre os vórtices e as camadas cisalhantes. Dos resultados para o sistema composto por dois cilindros escalonados, Carmo et al. ${ }^{24}$ encontraram que para as configurações $L_{y} / D=0, L_{y} / D=0.5$, as curvas de $|\mu|$ em função de $\beta D$ apresentaram dois picos de instabilidade muito semelhantes como os modos A e B reportados por Williamson ${ }^{18}$ no caso de cilindros isolados, mas com algumas diferenças remarcáveis. As diferenças mais notórias estão ligadas como os Reynolds nos quais os modos ficam instáveis e nos comprimentos de onda na bifurcação. Por exemplo, o Reynolds no qual o modo A fica instável e o comprimento de onda do modo instável são menores em relação ao caso do cilindro isolado. Por outro lado, o modo B fica instável depois em termos do número Reynolds, e o comprimento de onda na bifurcação é praticamente igual ao caso do cilindro isolado. Já para $L_{y} / D=1,2 \leq L_{y} / D \leq 3$ o sistema oferece um cenário bastante diferente, pois se observa um pico de número de onda intermediário entre os modos A e B que corresponde a um novo modo referido como C. Para $2 \leq L_{y} / D \leq 3$, os números de Reynolds crítico e os correspondentes comprimentos de onda dos modos A e B foram muito próximos aos valores encontrados para o caso do cilindro isolado. O novo modo $\mathrm{C}$ encontrado por Carmo et al. ${ }^{24}$ apresenta uma diferença significativa em relação com os modos A e B, já que o modo C se origina na esteira próxima do cilindro a jusante enquanto os modos A e B se originam na esteira próxima do cilindro a montante. Um segundo aspecto a mencionar é que o modo $\mathrm{C}$ tem período $2 \mathrm{~T}$, onde $\mathrm{T}$ é o período de desprendimento de vórtices, em contraste os modos A e B tem período T. A 
simetria do modo $\mathrm{C}$ tem portanto a forma

$$
\tilde{\omega}_{x}(x, y, z, t)=-\tilde{\omega}_{x}(x, y, z, t+T)
$$

Além das diferenças de comprimento de onda e período, o modo $\mathrm{C}$ apresenta uma estrutura similar com o modo B no sentido que este é intenso nas camadas cisalhantes que unem os núcleos.

Os trabalhos apresentados mostram que existem diversos estudos que caracterizam os modos, e determinam o início de instabilidades tridimensionais secundárias no escoamento periódico ao redor de certos corpos rombudos. No entanto não se encontraram na literatura estudos em relação ao interessante fenômeno de transição de esteira entre um cilindro e um fólio.

\subsection{Geração e desprendimento de vórtices em corpos aerodinâmicos}

O escoamento ao redor de cilindros e aerofólios é tema de pesquisa atual devido a suas múltiplas aplicações na indústria. Do lado científico estudar estes sistemas é muito interessante, pois tais escoamentos apresentam fenômenos tais como separação, transição e formação de esteira. No movimento de um fluido sobre a superfície de corpos rombudos e aerodinâmicos, os efeitos viscosos e inércias se comportam de forma diferenciada, por exemplo, os efeitos viscosos são menos representativos a números Reynolds altos e vice-

versa. Este fato somado com a ocorrência de fenômenos de transição pode gerar padrões diferentes no escoamento inclusive numa mesma geometria. Tal 
fenômeno pode ser visualizado na Figura 3.20 e Figura 3.21. Nelas podem-se observar o escoamento ao redor de um perfil a diferentes ângulos de ataque.

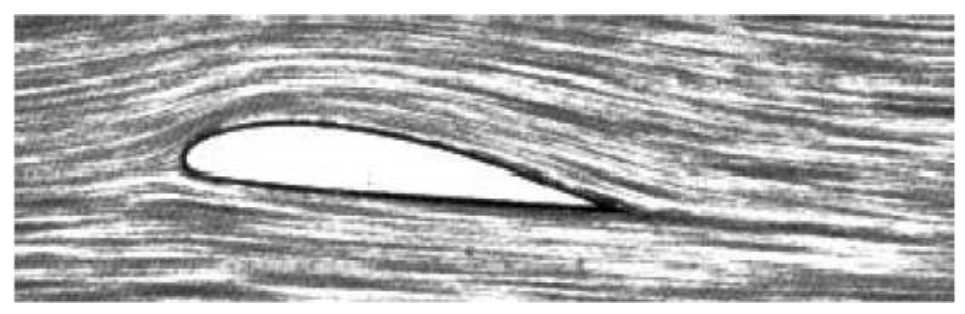

Figura 3.20: Escoamento ao redor de um aerofólio a baixo ângulo de ataque. Extraído de Schlichting ${ }^{9}$

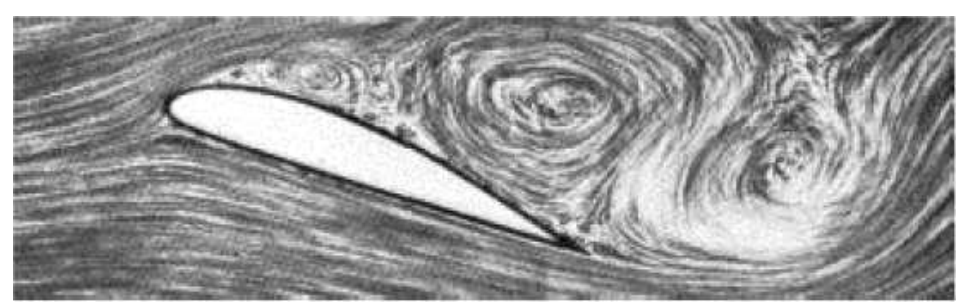

Figura 3.21: Escoamento ao redor de um aerofólio a alto ângulo de ataque. Extraído de Schlichting ${ }^{9}$

Quando o ângulo é nulo os efeitos viscosos são pouco representativos no escoamento, no entanto quando o ângulo de ataque supera certo valor crítico se apresenta descolamento da camada limite na superfície do perfil, fenômeno conhecido como estol. Na medida em que o número de Reynolds é aumentado, as camadas cisalhantes se tornam instáveis e tendem a se enrolar pelo efeito da tensão cisalhante viscosa. Este enrolamento é conhecido com instabilidade de Kelvin-Helmholtz. As instabilidades formadas a partir das camadas cisalhantes dão origem a uma esteira de escoamento turbilhonar alternado e contra-rotativo denominada esteira de Von Karman. De forma que quando acontece o estol, o aerofólio passa a se comportar como um corpo 
rombudo apresentando desprendimento de vórtices na esteira do corpo.

Muitos trabalhos foram focados em estudar intensivamente o escoamento ao redor de fólios, no entanto não há muitos trabalhos que estudem a transição tridimensional que acontece na esteira de Von Kármán ao redor destes corpos, pois historicamente os cientistas tiveram maior interesse em estudar os fenômenos de instabilidade apresentados em certos corpos rombudos, especialmente em sistemas compostos por cilindros isolados e em interferência. Tentando encher este vácuo Meneghini et al. ${ }^{10}$ apresentam o estudo das características dos modos tridimensionais na esteira formada a partir de um corpo aerodinâmico em estol. Para tal estudo foi usado o perfil NACA 0012 em ângulo de ataque de vinte graus, dado que o aerofólio nessa disposição geométrica apresenta separação massiva da camada limite e formação de esteira. O modelo empregado por Meneghini et al. ${ }^{10}$ permite estudar a transição na esteira de corpos com sustentação que apresentam separação massiva da camada limite, dado que o corpo estudado tem circulação não nula e a esteira resultante é não simétrica. A Figura 3.22 mostra o comportamento dos multiplicadores de Floquet $|\mu|$ em função do número de onda da perturbação para cada um dos Reynolds estudados. Analisando a curva de estabilidade neutra (Figura 3.23) pode-se observar que o sistema é estável para $\operatorname{Re}<450$, ficando neutralmente estável para um $\operatorname{Re}=456$ com número de onda $\beta c=11$. Este modo é subharmônico com período $2 \mathrm{~T}$ onde $\mathrm{T}$ é o período do campo base. A Figura 3.24 apresenta os contornos de vorticidade do campo base combinados com o modo instável de Floquet com $\beta c=11$. Pode-se perceber que o modo tridimensional observado se origina na esteira próxima, sendo intenso nas camadas cisalhantes que unem os núcleos. Ao 
3.4. Geração e desprendimento de vórtices em corpos aerodinâmicos

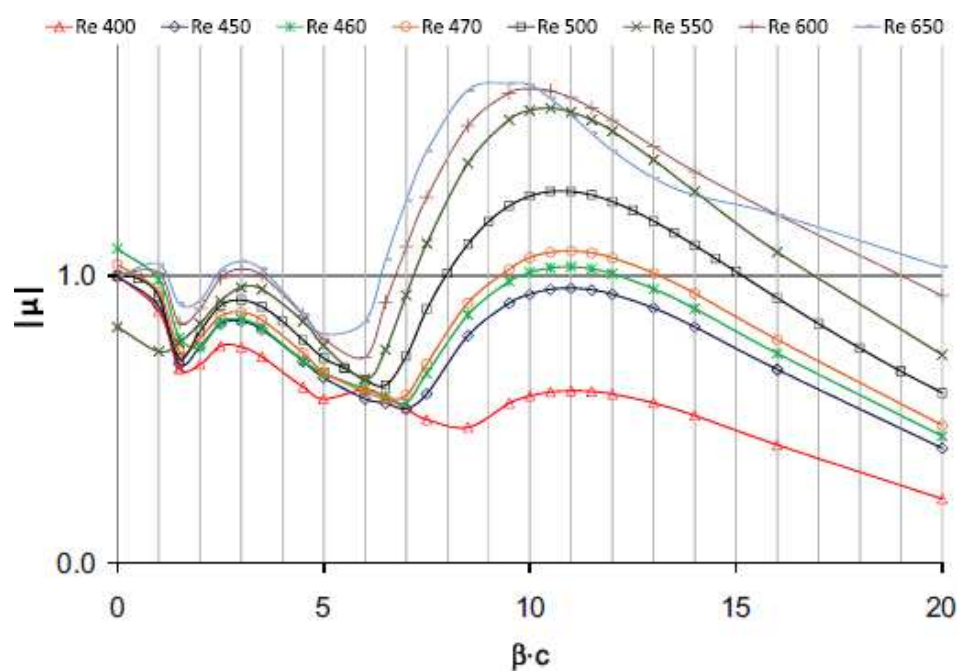

Figura 3.22: Multiplicadores de Floquet, caso NACA 0012 ângulo de ataque $20^{\circ}$. Extraído de Meneghini et al. ${ }^{10}$

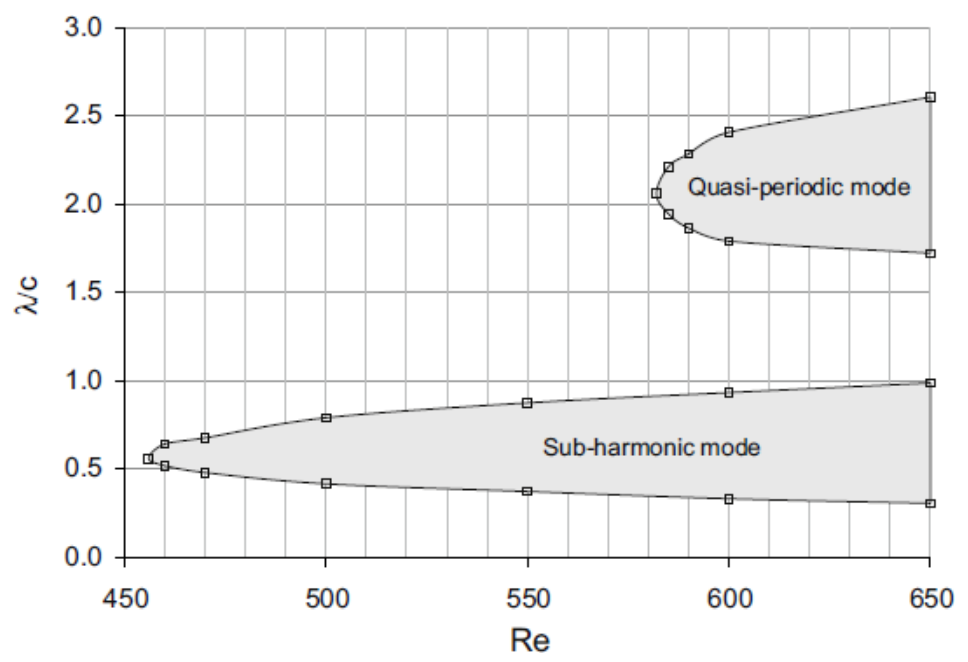

Figura 3.23: Curva de estabilidade neutra, caso NACA 0012 ângulo de ataque $20^{\circ}$. Extraído de Meneghini et al. ${ }^{10}$

redor de $\operatorname{Re}=580$, se apresenta outro modo instável com número de onda de $\beta c=3$ correspondente a um comprimento de onda de $\lambda / c=2.1$. Este comportamento é oposto a aquele apresentado no caso de um cilindro isolado. Nesse sistema o modo de maior comprimento de onda (modo A) fica instável 
primeiro (respeito ao Reynolds) que o modo de curto comprimento de onda (modo B).

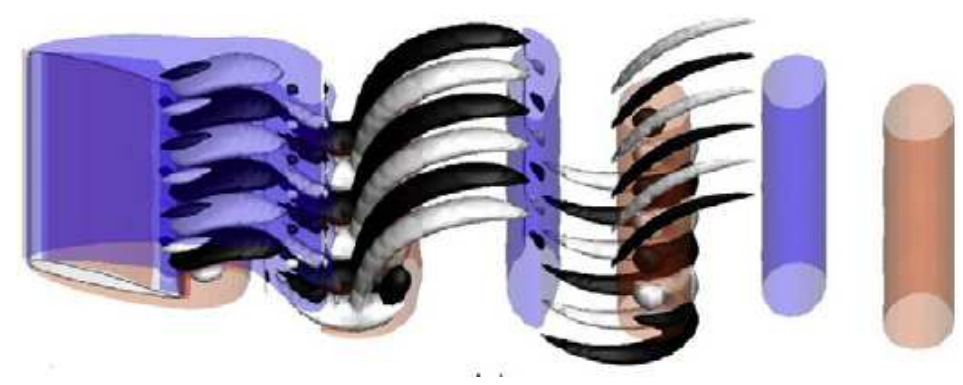

Figura 3.24: Escoamento base combinado com o modo instável de Floquet, $\beta c=11$. Superficies translúcidas correspondem a iso-superficies de $\omega_{z}$ enquanto as superficies escuras e claras correspondem a iso-superficies de $\omega_{x} . \operatorname{Re}=500$ $\alpha=20^{\circ}$. Extraído de Meneghini et al. ${ }^{10}$

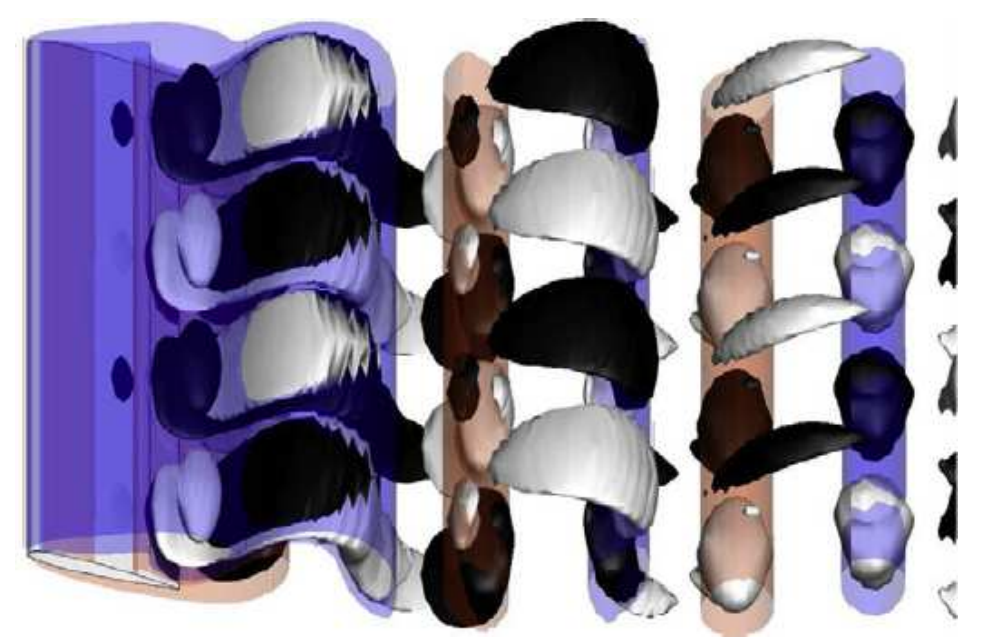

Figura 3.25: Escoamento base combinado com o modo instável de Floquet, $\beta c=3$. Superficies translúcidas correspondem a iso-superficies de $\omega_{z}$ enquanto as superficies escuras e claras correspondem a iso-superficies de $\omega_{x} . \operatorname{Re}=590$ $\alpha=20^{\circ}$. Extraído de Meneghini et al. ${ }^{10}$

Na Figura 3.25, se observa o campo base combinado com o modo instável de Floquet com $\beta c=3$. Este modo instável tem multiplicadores complexos de Floquet sendo, portanto, um modo quase-periódico. Em tais instabilida- 
des, as perturbações tridimensionais apresentam um período característico diferente do período de desprendimento de vórtices T.

\subsection{Estabilidade hidrodinâmica}

Os esforços por clarificar e explicar teoricamente o processo de transição iníciou faz muito anos. Tais investigações teóricas estão baseadas na hipótese de que escoamentos laminares podem ser afetados por pequenas perturbações, que no caso de corpos imersos num fluido podem provir de irregularidades na parede do corpo ou irregularidades no escoamento externo. Um dos focos principais das teorias de estabilidade, consiste em tentar descrever o comportamento temporal das perturbações quando são superpostas ao escoamento principal. Uma das perguntas mais importantes por responder é se a perturbação incrementa ou decai no tempo. Se a perturbação decai se diz que o fluxo é estável, por outro lado, se as perturbações crescem no tempo o fluxo é instável e existe a possibilidade de transição para turbulência. Neste contexto o objeto da teoria de estabilidade é predizer o valor do Reynolds crítico em um fluido. A teoria de estabilidade de fluidos laminares, descompõe o escoamento em uma parcela devida ao escoamento principal cuja estabilidade é o objeto de estudo, e uma parcela devida às perturbações que se assumem pequenas em comparação ao escoamento principal. O escoamento principal tomado neste caso como estacionário, pode ser descrito pelas componentes cartesianas de velocidade $U, V, W$ e pressão $P$. As correspondentes quantidades para a perturbação não estacionária podem ser denotadas por $u^{\prime}, v^{\prime}, w^{\prime}$ e $p^{\prime}$ respectivamente. Então no movimento 
resultante as componentes da velocidade são

$$
\begin{gathered}
u=U+u^{\prime}, v=V+v^{\prime}, w=W+w^{\prime} \\
p=P+p^{\prime}
\end{gathered}
$$

O estudo de estabilidade de um fluido pode ser desenvolvido a partir de dois caminhos diferentes. O primeiro se enfoca em analisar a variação no tempo das perturbações na energia. O segundo caminho só aceita fluidos que cumprem com as equações de movimento e é denominado teoria de pequenas perturbações. Este método mostrou muito sucesso e será usado neste trabalho.

Vamos considerar fluidos bidimensionais incompressíveis, da mesma maneira serão consideradas perturbações bidimensionais. As equações de movimento descritas por (3.6) e (3.7) devem satisfazer as equações de Navier-Stokes. Além das simplificações mencionadas vamos assumir fluidos paralelos, ou seja, vamos admitir que a velocidade $U$ depende somente da coordenada $y$, então $U=U(y)$, enquanto as outras duas componentes vão se supor nulas. Estes fluidos paralelos são interessantes neste trabalho, pois na camada limite a dependência com a coordenada $x$ da velocidade $U$ no escoamento principal é muito menor que em $y$. No entanto na pressão é necessário assumir dependência com $x$, porque o gradiente de pressão $d p / d x$ se mantém no fluido. Em conclusão vamos assumir fluidos do tipo

$$
U(y) ; V=W=0 ; P(x, y)
$$


Por outro lado a perturbação bidimensional é uma função do tempo e o espaço, cujas componentes serão

$$
u^{\prime}(x, y, t), v^{\prime}(x, y, t), p^{\prime}(x, y, t)
$$

Então o movimento resultante, de acordo com as equações (3.6) e (3.7), é descrito por

$$
u=U+u^{\prime} ; v=v^{\prime} ; w=0 ; p=P+p^{\prime}
$$

Assume-se que tanto o escoamento principal (3.8), como o escoamento resultante (3.10), devem cumprir com as equações de Navier-Stokes. As flutuações na velocidade da perturbação são tomadas pequenas no sentido que todos os termos quadráticos são depreciáveis em relação aos termos lineares. Substituindo as equações (3.10) nas equações de Navier-Stokes para fluidos bidimensionais estacionários e incompressíveis, e desprezando termos quadráticos obtemos

$$
\begin{gathered}
\frac{\partial u^{\prime}}{\partial t}+U \frac{\partial u^{\prime}}{\partial x}+v^{\prime} \frac{d U}{d y}+\frac{1}{\rho} \frac{\partial P}{\partial x}+\frac{1}{\rho} \frac{\partial p^{\prime}}{\partial x}=\nu\left(\frac{d^{2} U}{d y^{2}}+\nabla^{2} u^{\prime}\right) \\
\frac{\partial v^{\prime}}{\partial t}+U \frac{\partial v^{\prime}}{\partial x}+\frac{1}{\rho} \frac{\partial P}{\partial y}+\frac{1}{\rho} \frac{\partial p^{\prime}}{\partial y}=\nu \nabla^{2} v^{\prime} \\
\frac{\partial u^{\prime}}{\partial x}+\frac{\partial v^{\prime}}{\partial y}=0
\end{gathered}
$$

Dado que o escoamento principal satisfaz as equações de Navier-Stokes, as equações anteriores se reduzem ao conjunto

$$
\frac{\partial u^{\prime}}{\partial t}+U \frac{\partial u^{\prime}}{\partial x}+v^{\prime} \frac{d U}{d y}+\frac{1}{\rho} \frac{\partial p^{\prime}}{\partial x}=\nu \nabla^{2} u^{\prime}
$$




$$
\begin{gathered}
\frac{\partial v^{\prime}}{\partial t}+U \frac{\partial v^{\prime}}{\partial x}+\frac{1}{\rho} \frac{\partial p^{\prime}}{\partial y}=\nu \nabla^{2} v^{\prime} \\
\frac{\partial u^{\prime}}{\partial x}+\frac{\partial v^{\prime}}{\partial y}=0
\end{gathered}
$$

Desta maneira se obtém um conjunto de equações para as componentes, $u^{\prime}$, $v^{\prime}, p^{\prime}$. As condições de contorno obrigam a $u^{\prime}$ e $v^{\prime}$ ser nulas na superfície do corpo (condição de não deslizamento).

O escoamento principal que se move na direção $x$ com velocidade $U(y)$, se assume influênciado por uma perturbação composta por um número discreto de flutuações parciais, cada uma de elas consiste de uma onda que se propaga na direção $x$. A função de corrente (stream function) que representa uma oscilação simples da perturbação se assume como

$$
\varphi(x, y, t)=\phi(y) e^{i(\alpha x-\beta t)}
$$

Qualquer perturbação bidimensional pode ser expandida numa série de Fourier, onde cada um dos termos representa uma oscilação parcial. Na equação (3.17) $\alpha$ é real, e a quantidade $\lambda=2 \pi / \alpha$ e o comprimento de onda da perturbação, a quantidade $\beta$ é complexa e tem a forma.

$$
\beta=\beta_{r}+i \beta i
$$

Onde $\beta_{r}$ é a freqüência da oscilação parcial, enquanto $\beta_{i}$ (fator de amplificação) determina o grau de amplificação ou amortecimento. Neste contexto a perturbação amortece se $\beta_{i}<0$ e o escoamento laminar é estável, enquanto 
que se $\beta_{i}>0$ o escoamento é instável. Adicionalmente se define a quantidade

$$
c=\frac{\beta}{\alpha}=c_{r}+i c_{l}
$$

$c_{r}$ representa a velocidade de fase (velocidade de propagação na direção $x$ ), enquanto $c_{l}$ determina o grau de amortecimento ou amplificação dependendo do sinal que ele tem. Da equação (3.17) é possível obter as componentes da velocidade na perturbação

$$
\begin{gathered}
u^{\prime}=\frac{\partial \varphi}{\partial y}=\phi^{\prime}(y) e^{i(\alpha x-\beta t)} \\
v^{\prime}=-\frac{\partial \varphi}{\partial x}=-i \alpha \phi(y) e^{i(\alpha x-\beta t)}
\end{gathered}
$$

Introduzindo estes valores nas equações (3.14) e (3.15) se obtém a seguinte equação diferencial de quarta ordem para a amplitude $\phi(y)$

$$
(U-c)\left(\phi^{\prime \prime}-\alpha^{2} \phi\right)-U^{\prime \prime} \phi=-\frac{i}{\alpha R}\left(\phi^{\prime \prime \prime \prime}-2 \alpha^{2} \phi^{\prime \prime}+\alpha^{4} \phi\right)
$$

Esta é a equação de estabilidade mais conhecida como equação de OrrSommerfeld. Os termos da esquerda são derivados dos termos de inércia das equações de movimento, enquanto os termos da direita dos termos viscosos. Para definir completamente o problema é necessário fixar as condições de contorno do escoamento, usualmente se utiliza a condição de não desliza- 
mento, que pode-se expressar como

$$
\begin{gathered}
y=0: u^{\prime}=v^{\prime}=0 ; \phi=0, \phi^{\prime}=0 ; \\
y \rightarrow \infty: u^{\prime}=v^{\prime}=0 ; \phi=0, \phi^{\prime}=0
\end{gathered}
$$

Neste ponto é possível fazer a objeção que perturbações superpostas a padrões de fluido bidimensionais não precisam ser bidimensionais. Schlichting ${ }^{9}$ assumiu perturbações periódicas na direção $z$, e provou que os escoamentos tridimensionais ficaram instáveis a números de Reynolds maiores em relação aos fluidos bidimensionais. Inferindo-se que os fluidos 2D são mais suscetíveis às perturbações que os fluidos 3D.

Quando a quantidade $U(y)$ é especificada, a equação (3.22) contém quatro parâmetros $\left(\alpha, \operatorname{Re}, c_{r}\right.$ e $\left.c_{l}\right)$, no entanto o número de Reynolds e o comprimento de onda $\lambda=2 \pi / \beta$ são conhecidos. Desta maneira a equação de OrrSommerfeld junto com as condições de contorno (equações (3.23) e (3.24)) fornece uma eigenfunção $\phi(y)$ e um autovalor complexo $c=c_{r}+i c_{l}$ para cada par de valores $R$ e $\alpha$. O valor $c_{r}$ corresponde à velocidade de fase da perturbação e o sinal de $c_{l}$ define se a onda se amplifica $\left(c_{l}>0\right)$ ou se amortece $\left(c_{l}<0\right)$. O caso $c_{l}=0$ corresponde a perturbações neutrais. Na Figura 3.26 se representa graficamente o diagrama $\alpha, R$ resultante da análise de estabilidade de certo fluido $U(y)$. Em particular o local $c_{l}=0$ separa a região de estabilidade da região de instabilidade. Este local é denominado curva de estabilidade neutra. O ponto sobre esta curva onde o Reynolds toma o mínimo valor é denominado número de Reynolds crítico, sendo de especial interesse, pois indica o Reynolds limite debaixo do qual todas as oscilações 


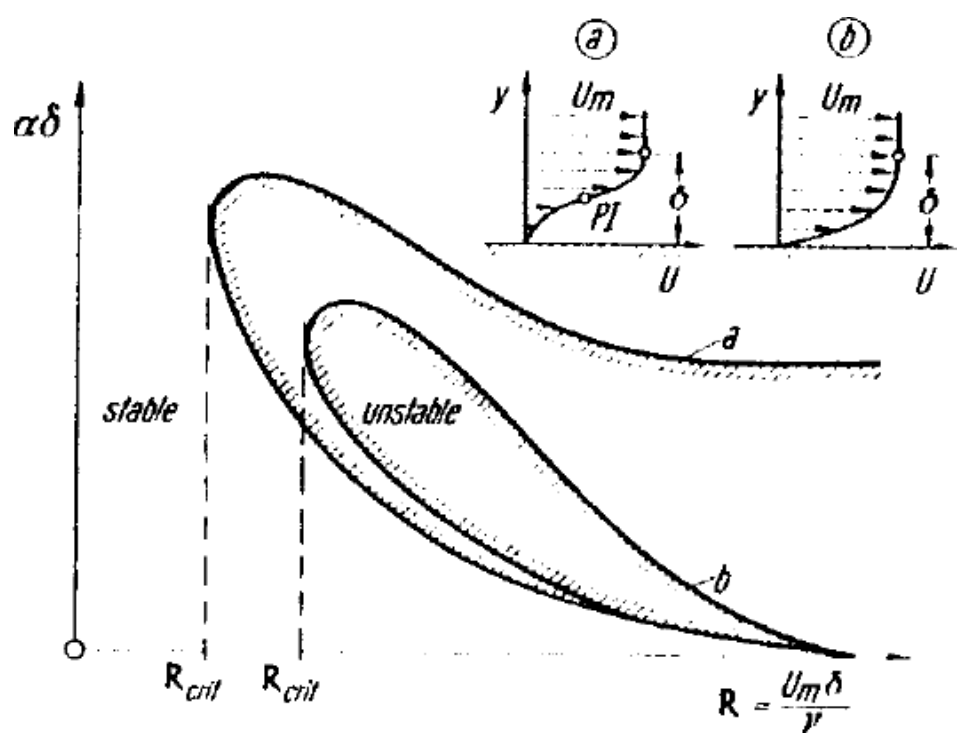

Figura 3.26: Curva de estabilidade neutra para camada limite bidimensional com perturbações bidimensionais. Extraído de Schlichting ${ }^{9}$

decaem, enquanto acima dele se amplificam. Cabe destacar que o Reynolds crítico calculado a partir de considerações de estabilidade não tem que ser igual ao Reynolds observado no ponto de transição. Se prestarmos atenção à camada limite, o Reynolds crítico indica o ponto onde as perturbações começam a crescer. A transformação de tais perturbações em turbulência toma um tempo finito, então as perturbações instáveis têm a chance de viajar a jusante no escoamento. É de se esperar então, que a posição do ponto de transição deve estar a jusante do calculado teoricamente, ou seja, o valor de Reynolds crítico experimental excede o valor teórico. Para distinguir entre estas duas quantidades, se denomina Reynolds crítico como o número obtido da teoria de estabilidade e o Reynolds experimental como o ponto de transição.

A teoria de estabilidade exposta anteriormente de forma breve, mostra uma 
dificuldade matematicamente muito grande que implica também uma implementação muito sofisticada, por tal motivo a seguir será exposta a teoria de Floquet, que finalmente define o marco de referência no qual os cálculos de estabilidade são feitos neste trabalho.

A utilização de propriedades locais (instabilidades desenvolvidas no perfil de velocidades) e a restrição imposta no uso de escoamentos paralelos de velocidade são sujeitas a muitas críticas. Respeito às propriedades locais, o problema radica em que ainda não está muito bem compreendida a relação entre os modos de instabilidade local com os modos de instabilidade global no escoamento (instabilidades do escoamento como um todo), enquanto o problema no uso de escoamentos paralelos, o escoamento médio se desenvolve espacialmente e, então, um modo diferente cresce temporalmente em uma posição a jusante $\left(\right.$ Meneghini $\left.^{2}\right)$, de maneira que não se sabe qual destes modos corresponde à resposta global observada.

Levando em conta o conceito de estabilidade global, Monkewitz ${ }^{25}$ estudou as características físicas da esteira no escoamento ao redor de diversos corpos rombudos, na vizinhança do número de Reynolds crítico no qual se dá início o fenômeno de geração de vórtices. Contrastando com os dados experimentais, Monkewitz ${ }^{25}$ (1988) encontrou que existem modos globais de instabilidade inclusive a Reynolds menores que o crítico, ou seja, para um

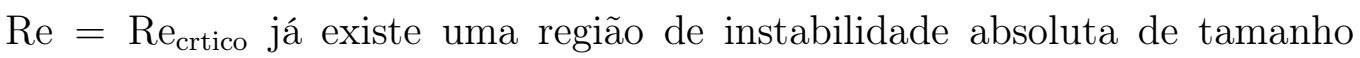
considerável na esteira, deduzindo-se que a existência de uma instabilidade absoluta é uma condição necessária, mas não suficiente para o início de geração de vórtices. Em relação ao problema de escoamentos paralelos, Chomaz et $\mathrm{al}^{26}$ usaram um modelo onde levaram em conta os efeitos de não parale- 
lismo no escoamento. Neste trabalho se concluiu que uma instabilidade local é uma condição necessária, mas não suficiente para que um modo global se torne auto-excitado coincidindo com os resultados de Monkewitz.

\subsection{Teoria de estabilidade de Floquet}

O método numérico empregado para os cálculos de estabilidade, consiste em avaliar a estabilidade de escoamentos bidimensionais $(2 \mathrm{D}) \mathbf{U}(x, y, t)$ ante uma perturbação infinitesimal 3D $\mathbf{u}^{\prime}(x, y, z, t)$, cuja evolução é governada pela equação

$$
\begin{gathered}
\frac{\partial \mathbf{u}^{\prime}}{\partial t}=-(\mathbf{U} \cdot \nabla) \mathbf{u}^{\prime}-\left(\mathbf{u}^{\prime} \cdot \nabla\right) \mathbf{U}-\nabla p^{\prime}+\frac{1}{R e} \nabla^{2} \mathbf{u}^{\prime}, \\
\nabla \cdot \mathbf{u}^{\prime}=0 .
\end{gathered}
$$

Que em forma compacta pode ser escrita como

$$
\frac{\partial \mathbf{u}^{\prime}}{\partial t}=\mathbf{L}\left(\mathbf{u}^{\prime}\right)
$$

O operador $\mathbf{L}\left(\mathbf{u}^{\prime}\right)$ é periódico com período $T$, dado que ele depende linearmente do escoamento base $\mathbf{U}(x, y, z)$ que também tem período $T . p^{\prime}$ é uma perturbação na pressão. A estabilidade desse sistema de equações é investigada usando a teoria de Floquet. Para isso se propõe uma solução para as equações (3.25) e (3.26) como uma soma de funções $\hat{u}(x, y, z, t) e^{\sigma t}$, onde $\hat{u}(x, y, z, t)$ são os modos de Floquet. A estabilidade do sistema é dada pelo sinal da parte real do expoente $\sigma$. Em análises de Floquet é habitual se 
definir $\mu=e^{\sigma t}$, dessa maneira o sistema é estável se $\mu<1$, instável se $\mu>1$ e neutralmente estável se $|\mu|=1$.

Como a direção $z$ é homogênea, o campo de velocidades perturbado pode ser escrito como uma integral de Fourier

$$
\mathbf{u}^{\prime}(x, y, z, t)=\int_{-\infty}^{\infty} \hat{u}(x, y, z, \beta) e^{i \beta z} d \beta
$$

sendo $\beta$ o número de onda na direção da envergadura $(\beta=2 \pi / \lambda$, sendo $\lambda$ o comprimento de onda na envergadura). De maneira similar pode-se operar com $p^{\prime}$. Como as equações (3.25) e (3.26) são lineares, perturbações com números de onda distintos não interagem entre si. Isso implica que dada uma configuração geométrica, análises de estabilidade 3D podem ser executadas realizando uma série de cálculos de estabilidade para cada um dos diferentes números de onda. Avaliam-se, então, as perturbações da forma

$$
\begin{gathered}
\mathbf{u}^{\prime}(x, y, z, t)=(\hat{u} \cos (\beta z), \hat{v} \cos (\beta z), \hat{w} \sin (\beta z)), \\
p^{\prime}(x, y, z, t)=\hat{p} \cos (\beta z) .
\end{gathered}
$$

Estas perturbações conservam sua forma sobre a ação do operador $\mathbf{L}$, de maneira que os modos de Floquet $\hat{u}(x, y, z, t)$ devem ter a mesma estrutura. Para calcular os modos de Floquet se constrói um operador A que representa a evolução do sistema durante um período como em Carmo et al. ${ }^{24}$. Esta evolução é dada pela equação

$$
\mathbf{u}_{n+1}^{\prime}=\mathbf{A}(\mathbf{U}) \mathbf{u}_{n}^{\prime}
$$


onde $\mathbf{u}_{n}^{\prime}=\mathbf{u}^{\prime}\left(x, y, z, t_{0}+n T\right)$ é o vetor de perturbações depois de $n$ períodos. Os autovalores de $\mathbf{A}$ são os multiplicadores de Floquet de $\mathbf{L}$ e os autovetores de $\mathbf{A}$ são os modos de Floquet em relação ao instante $t_{0}$. O método de Arnoldi é usado para calcular os multiplicadores de Floquet de maior magnitude. Uma decrição completa do método de Arnoldi é dada em Saad ${ }^{27}$.

\subsection{Método de elementos finitos espectrais}

Esta seção faz uma breve introdução teórica dos métodos numéricos empregados neste trabalho. Os comentários apresentados estão baseados no trabalho de Carmo ${ }^{12}$. Uma descrição teórica profunda do método de elementos espectrais é dada em Karniadakis e Sherwin ${ }^{11}$.

Patera $^{28}$ apresenta um método numérico que combina a generalidade do método de elementos finitos com a precisão das técnicas espectrais, e o utiliza na solução das equações de Navier-Stokes para escoamento incompressível. Esta publicação serve como base do trabalho de Karniadakis e Sherwin ${ }^{11}$, o qual constitui a base das ferramentas computacionais usadas no presente trabalho. Patera ${ }^{28}$ denomina o método como SEM (spectral element method). Este método toma do método espectral a alta ordem das funções de aproximação, o qual garante alta resolução e convergência exponencial, enquanto do método de elementos finitos toma a divisão do domínio em pequenos subdomínios, o qual permite o estudo de geometrias complexas e o refinamento das áreas de interesse. No método SEM se define uma função base em cada elemento do domínio. A convergência do método depende da refinação da malha (refinamento $h$ ) e do grau do polinômio usado como base da expansão 
(refinamento $p$ ), por tal motivo o método é denominado $h p$. Para fazer o refinamento tipo $h$, se divide o domínio computacional em pequenos subdomínios cujo tamanho é convenientemente diminuído, deixando a malha mais fina em regiões onde se apresentam altos gradientes, como nas proximidades da superfície do corpo e na região de descolamento. O refinamento tipo $p$ consiste em aumentar o grau da função base interpoladora usada em cada subdomínio, visando uma convergência exponencial, para fazer isso o tamanho da malha e o número de elementos obtidos no refinamento $h$ são mantidos constantes.

Karniadakis ${ }^{29}$ propõe um método misto entre elementos espectrais e Fourier, para simular escoamentos turbulentos em sistemas tridimensionais que possuem uma direção que não tem um comprimento característico. Assumindo a direção homogênea como $z$, a idéia de Karniadakis consistiu em usar o método de elementos finitos espectrais em diversos planos $x-y$ e depois utilizar uma expansão de Fourier ao longo de $z$. Um avance muito interessante neste trabalho, foi a definição de bases utilizadas na discretização de elementos espectrais em termos de polinômios de Legendre, além do uso de eficientes quadraturas Gaussianas associadas com operações de integração.

Karniadakis e Orszag $^{30}$ descrevem uma formulação para a pressão em métodos de avanço no tempo. Nesse trabalho condições de contorno para a pressão de alta ordem no tempo são introduzidas, conseguindo-se alta resolução temporal e estabilidade. Esta metodologia foi também empregada no presente trabalho.

Warburton et al. ${ }^{31}$ descrevem novas bases adequadas para a discretizações do tipo espectral em malhas bidimensionais. As bases apresentadas nesse tra- 
balho são $C^{\circ}$ continuas o qual permite fazer em ensamble global da solução em cada subdomínio. Adicionalmente o conceito de decomposição contornointerior é introduzida além de polinômios gerais de Jacobi os quais permitem acomodar quadraturas numéricas exatas. Finalmente na monografia apresentada por Karniadakis e Sherwin ${ }^{11}$, se apresentam detalhadamente todos os conceitos matemáticos e físicos do método de elementos finitos espectrais, tal como foi utilizado nas simulações deste trabalho.

\subsection{Simulações quase tridimensionais}

Consideremos o movimento de um fluido ao longo de um corpo de forma arbitrária com envergadura infinita. O escoamento se assume com densidade $(\rho)$ e viscosidade $(\mu)$ constantes. Uma descrição completa do sistema depende de três parâmetros: um comprimento característico $(c)$, a velocidade de escoamento livre $\left(u_{\infty}\right)$ e o radio entre a viscosidade do fluido e a densidade $(\mu / \rho)$. A única combinação entre estes parâmetros é definido como o número de Reynolds $\operatorname{Re}=u_{\infty} c / \mu$, e serve como parâmetro de controle do sistema. O estado do sistema em qualquer instante de tempo está definido pelos campos $\mathbf{u}(x, y, z, t), p(x, y, z, t)$. Neste caso se assumirá que o escoamento livre esta alinhado com a direção $x$ do eixo de coordenadas, enquanto $y$ é perpendicular ao escoamento e $z$ está ao longo da envergadura do corpo.

A evolução do fluido está dada pela equação incompressível de NavierStokes

$$
\frac{\partial \mathbf{u}}{\partial t}=-(\mathbf{u} \cdot \nabla) \mathbf{u}-\frac{1}{\rho} \nabla p+\frac{1}{R e} \nabla^{2} \mathbf{u}
$$




$$
\nabla \cdot \mathbf{u}=0
$$

Apesar desta descrição matemática do problema estar completa, é possível reduzir o problema usando uma série de Fourier na discretização da direção de envergadura, segundo foi proposto por Karniadakis ${ }^{29}$. O primeiro passo da discretização é reduzir o problema do corpo de envergadura infinita para um problema de dimensão finita $L$, ou seja, se impõe sobre o campo $\mathbf{u}(x, y, z, t)$ a condição de periodicidade

$$
\mathbf{u}(x, y, z, t)=\mathbf{u}(x, y, z+L, t)
$$

O campo de velocidades $\mathbf{u}(x, y, z, t)$ pode ser projetado dentro de um conjunto bidimensional de modos de Fourier $\tilde{\mathbf{u}}_{q}$ como

$$
\tilde{\mathbf{u}}_{q}(x, y, t)=L^{-1} \int_{0}^{L} \mathbf{u}(x, y, z, t) e^{-i(2 \pi / L) q z} d z
$$

Da mesma forma os modos de Fourier permitem fazer a expansão

$$
\mathbf{u}(x, y, z, t)=\sum_{q=-\infty}^{\infty} \tilde{\mathbf{u}}_{q}(x, y, t) e^{i(2 \pi / L) q z}
$$

Substituindo esta última expansão de Fourier na equação de Navier Stokes se obtem um conjunto de equações diferenciais para os modos bidimensionais $\tilde{\mathbf{u}}_{q}$ como

$$
\begin{gathered}
\frac{\partial \tilde{\mathbf{u}}_{q}}{\partial t}=-\mathbf{N}_{q}(u)-\frac{1}{\rho} \tilde{\nabla} \tilde{p}_{q}+\frac{1}{R e} \tilde{\nabla}^{2} \tilde{\mathbf{u}}_{q} \\
\tilde{\nabla} \cdot \tilde{\mathbf{u}}_{q}=0
\end{gathered}
$$


onde

$$
\mathbf{N}_{q}(u)=L^{-1} \int_{o}^{L} \mathbf{N}(\mathbf{u}) e^{-i(2 \pi / L) q z} d z
$$

Para levar a cabo estas operações é necessário definir os operadores

$$
\tilde{\nabla} \equiv\left(\partial_{x}, \partial_{y}, i \beta_{q}\right), \tilde{\nabla}^{2} \equiv\left(\partial_{x}^{2}, \partial_{y}^{2},-\beta_{q}^{2}\right)
$$

$\operatorname{com} \beta_{q} \equiv(2 \pi / L) q$. Uma descrição completa da dinâmica do sistema pode ser feita usando um conjunto finito de modos $M$ de Fourier, onde $M$ é da ordem $M=O\left(L \operatorname{Re}^{1 / 2}\right)$ (Henderson $\left.{ }^{32}\right)$, então a representação da velocidade pode ser feita pela série truncada

$$
\mathbf{u}(x, y, z, t)=\sum_{q=-M}^{M} \tilde{\mathbf{u}}_{q}(x, y, t) e^{i(2 \pi / L) q z}
$$

Computacionalmente é mais fácil simular o comportamento dos modos bidimensionais de Fourier $\tilde{\mathbf{u}}_{q}$ que o campo de velocidades tridimensional completo $\mathbf{u}(x, y, z, t)$. Dado que $\mathbf{u}(x, y, z, t)$ é real é possível fazer mais uma simplificação, pois o sistema satisfaz a condição de simetria $\tilde{\mathbf{u}}_{-q}=-\tilde{\mathbf{u}}_{q}^{*}$, então somente a metade do espectro $(q \geq 0)$ é necessário. Além das simplificações computacionais expostas, expressar o sistema em modos de Fourier traz consigo propriedades muito interessantes, dado que provê uma maneira natural de relacionar modos particulares do sistema com padrões tridimensionais específicos do escoamento. Adicionalmente a teoria de Floquet pode predizer quais desses modos tem uma forte interação com o escoamento 2D para produzir esses padrões tridimensionais. 



\section{Capítulo 4}

\section{Metodologia}

A precisão do método de elementos finitos espectrais, como qualquer outro método computacional depende completamente da discretização do domínio computacional. Por tal motivo testes de convergência devem ser feitos com o fim de obter uma malha ótima, definida como aquela que tendo o menor grau de refinamento possível, permite obter resultados acertados dentro de uma faixa de tolerância. No presente trabalho se utilizaram elementos quadriláteros estruturados, pois o método empregado apresenta uma melhor eficiência quando vem a utilizar este tipo de malhas ao invés de malhas desenhadas a partir de elementos triangulares (Tsiloufas ${ }^{33}$ ).

Dado que se utilizou o método de elementos finitos espectrais $h p$, devem fazer-se dois tipos de testes de convergência. Primeiro deve-se gerar uma malha com uma ótima distribuição de elementos (refinamento $h$ ), e em segundo lugar, devem ser feitos testes de convergência variando-se o grau do polinômio usado como função base (refinamento $p$ ). Para conseguir uma ótima distribuição de elementos na malha, precisam-se localizar uma maior 
quantidade de elementos em regiões onde se apresentem altos gradientes, tais como a camada limite e a esteira.

Para os testes de convergência foi escolhido o caso de um perfil NACA 0012 inclinado a vinte graus num regime de $R e=500$. Esta escolha se vê justificada pelo fato de que com estas condições o sistema apresenta desprendimento da camada limite, permitindo monitorar a variação no número de Strouhal.

Os procedimentos utilizados na hora de fazer os testes de convergência estão baseados nos trabalhos de Barkley e Henderson ${ }^{7}$, Carmo et al. ${ }^{24}$, Carmo ${ }^{12}$ e Tsiloufas ${ }^{33}$.

Todos os comprimentos usados nesta seção estão definidos em unidades de corda (c) em relação à origem do domínio computacional, que foi escolhido arbitrariamente como o ponto onde fica o bordo de ataque do aerofólio inclinado a zero grau.

Não foram feitos testes de convergência a montante do aerofólio dado que em Carmo et al. ${ }^{24}$ se mostra que tal parâmetro não tem grande influência nas grandezas do escoamento.

\subsection{Ordem da função base}

Dado que as funções base utilizadas no método de elementos finitos espectrais são polinômios, devem ser feitos testes de convergência variando-se o grau do polinômio utilizado como base, com o objetivo de analisar a sensibilidade dos resultados em relação a tais variações. Para tal fim analisou-se o comportamento do coeficiente médio e RMS de sustentação $\left(\overline{C_{L}}, C_{L}{ }^{\prime}\right)$, além 
de comportamento do coeficiente médio e RMS de arrasto $\left(\overline{C_{D}}, C_{D}{ }^{\prime}\right)$, finalizando com a análise da variação da freqüência de desprendimento de vórtices (número de Strouhal). Os resultados obtidos estão resumidos na Tabela 4.1. A distribuição de elementos e o grau de refinamento da malha usada nestes testes estão baseados no trabalho de Tsiloufas $^{33}$, tal como mostrado em Figura 4.1.

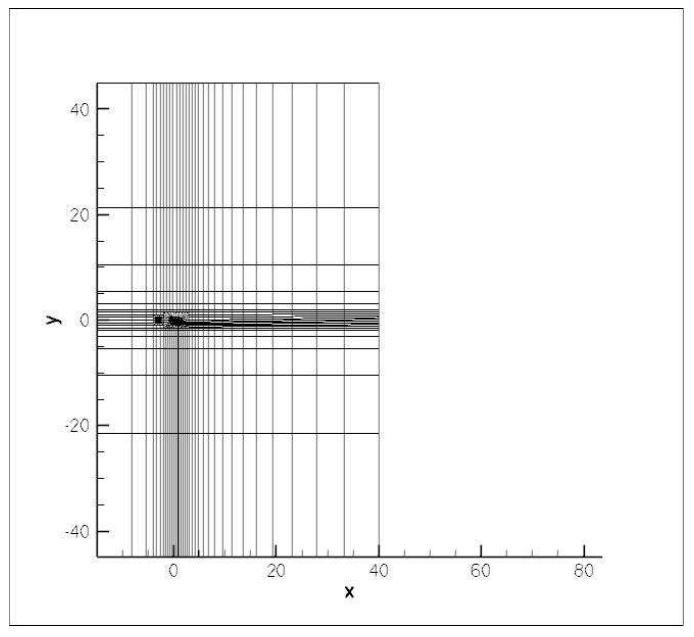

Figura 4.1: Malha usada no cálculo do campo base

Note-se que a região próxima à parede do aerofólio e a região onde a camada limite é formada apresentam um maior refinamento. A malha computacional mostrada na Figura 4.1 apresenta cinco fronteiras (as quatro fronteiras que conformam o domínio retangular e a fronteira do aerofólio). Na fronteira vertical esquerda e horizontal superior e inferior do domínio se impôs a condição de contorno de velocidade unitária. A fronteira vertical direita representa a região de saída, portanto se impôs a condição de contorno na qual as derivadas normais a ela são nulas. Finalmente na fronteira do aerofólio se impôs uma condição de contorno do tipo parede sem escorregamento. 


\begin{tabular}{|c||c||c||c||c||c|}
\hline \hline Ordem do polinômio & $\overline{C_{l}}$ & $C_{l}^{\prime}$ & $\overline{C_{d}}$ & $C_{d}{ }^{\prime}$ & $S_{t}$ \\
\hline \hline $8^{a}$ ordem & 0.7485 & 0.7543 & 0.4010 & 0.4012 & 0.5336 \\
\hline $9^{a}$ ordem & 0.7486 & 0.7543 & 0.4010 & 0.4012 & 0.5339 \\
\hline $10^{a}$ ordem & 0.7486 & 0.7543 & 0.4010 & 0.4012 & 0.5341 \\
\hline
\end{tabular}

Tabela 4.1: Influência da ordem da função base

Como critério de convergência tomou-se uma variação menor que 1\% dos seguintes parâmetros: valores médios e RMS do coeficiente de sustentação, valores médios e RMS do coeficiente de arrasto e número de Strouhal baseado na corda do aerofólio $\left(\overline{C_{L}}, C_{L}{ }^{\prime}, \overline{C_{D}}, C_{D}{ }^{\prime}\right.$ e $S t=f c / U$, respectivamente). Pode-se observar que um polinômio de grau 8 já atende com os requisitos de convergência estabelecidos, no entanto foi escolhido o polinômio de grau 9, já que o método de elementos finitos espectrais utiliza bases de expansão que são $\mathrm{C}^{\circ}$ continuas o qual não garante continuidade nas derivadas. Este fato gera alguns saltos nos valores de vorticidade afetando a definição dos contornos.

\subsection{Tamanho lateral da malha}

Uma vez definido o grau ótimo para os polinômios de Jacobi empregados no método, procede-se a definir o tamanho ótimo do domínio computacional. A primeira dimensão analisada foi o tamanho lateral da malha. Uma correta definição desta dimensão é indispensável na hora de fazer simulações computacionais, já que em domínios muito estreitos se apresenta o denominado efeito de blocagem. Tal fenômeno acontece quando se impõe uma velocidade de contorno (unitária nosso caso) numa região onde os efeitos da esteira não podem ser desprezados. O efeito final deste fenômeno é uma mudança signi- 
ficativa na freqüência de desprendimento de vórtices.

Para examinar os efeitos de blocagem mudamos a distância lateral do domínio no intervalo de $10 c$ até $50 c$ ( $c$ representa unidade de corda medidas a partir da origem do domínio computacional). Embora seja importante a distância dos contornos laterais, não há gradientes elevados no escoamento ao longe do fólio, então se decidiu adotar o procedimento de Tsiloufas et al. ${ }^{34}$, no qual se justifica o uso de grandes elementos nesta região. Sendo assim, as malhas foram geradas apenas esticando-se os elementos o que não acarreta maior custo computacional, visto que o número de elementos não se altera. Dado que os efeitos da distância lateral na blocagem foram pequenos, escolheu-se a malha com distância lateral de $45 c$ em uma abordagem mais conservativa. A Tabela 4.2 mostra os resultados para todas as larguras estudadas.

\begin{tabular}{|c||c||c||c||c||c|}
\hline \hline Distância lateral & $\overline{C_{l}}$ & $C_{l}{ }^{\prime}$ & $\overline{C_{d}}$ & $C_{d}{ }^{\prime}$ & $S_{t}$ \\
\hline \hline $10 c$ & 0.7612 & 0.7574 & 0.4047 & 0.4057 & 0.5338 \\
\hline $15 c$ & 0.7564 & 0.7625 & 0.4031 & 0.4041 & 0.5338 \\
\hline $20 c$ & 0.7529 & 0.7589 & 0.4025 & 0.4027 & 0.5338 \\
\hline $25 c$ & 0.7513 & 0.7575 & 0.4022 & 0.4024 & 0.5338 \\
\hline $30 c$ & 0.7497 & 0.7559 & 0.4015 & 0.4017 & 0.5338 \\
\hline $35 c$ & 0.7490 & 0.7552 & 0.4012 & 0.4015 & 0.5339 \\
\hline $40 c$ & 0.7489 & 0.7548 & 0.4011 & 0.4013 & 0.5341 \\
\hline $45 c$ & 0.7486 & 0.7543 & 0.4010 & 0.4012 & 0.5341 \\
\hline $50 c$ & 0.7484 & 0.7541 & 0.4009 & 0.4012 & 0.5341 \\
\hline
\end{tabular}

Tabela 4.2: Influência do contorno lateral da malha 


\subsection{Comprimento a jusante}

Diferente do caso anterior de testes de convergência para a largura da malha, o número de elementos para o presente caso foi variado de acordo com o tamanho do domínio, tudo isso com o fim de manter aproximadamente a mesma distribuição de densidade de elementos nas proximidades da região de saída, tal como sugerido por Carmo ${ }^{12}$.

Para testar os efeitos de fronteira na saída, prestou-se atenção na magnitude da vorticidade nos núcleos dos vórtices na esteira. Este procedimento foi sugerido por Barkley e Henderson ${ }^{7}$ e estendido por Carmo ${ }^{12}$. Para monitorar essa grandeza, utilizou-se o procedimento exposto em Carmo ${ }^{12}$. Para tal fim, se colocaram linhas paralelas regulares a jusante do aerofólio tal como mostrado na Figura 4.2. Tais linhas servem como estações onde é possível

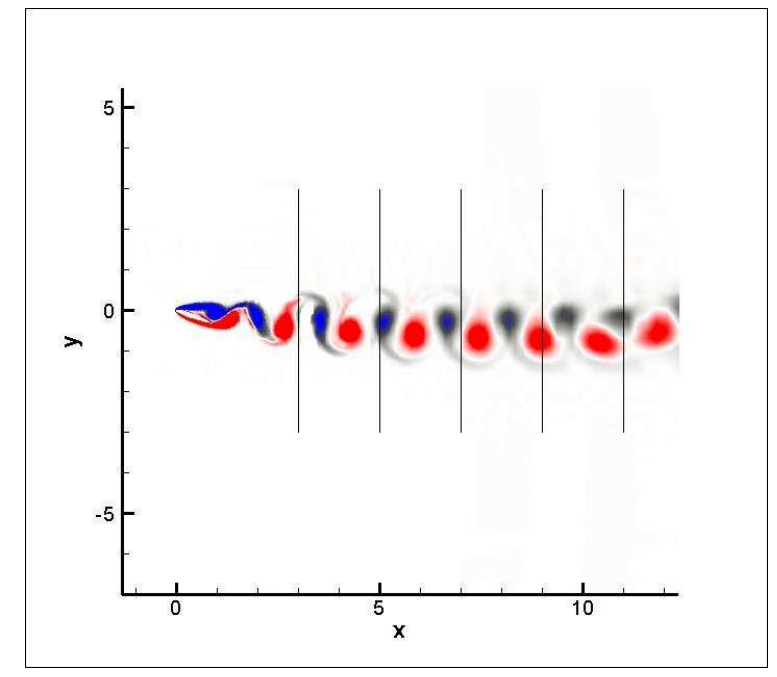

Figura 4.2: Linhas de medições do método usado no estudo de convergência da posição da fronteira a jusante.

avaliar o valor da vorticidade de forma regular. Para fazer esta análise foram 
gravados 16 quadros ao longo de um ciclo. De cada um destes 16 quadros foram extraídos os valores de vorticidade de 100 pontos ao longo de cada linha, de onde posteriormente se tira o valor máximo de vorticidade para cada linha. Então toma-se, finalmente, o valor de máxima vorticidade em cada estação num ciclo. Os resultados para malhas com distância da fronteira de $16 c, 23 c, 33 c$ e $40 c$ são apresentados em Figura 4.3. Pode-se inferir que há convergência inclusive nas malhas menores. Julgou-se que uma malha com distância de $40 c$ a jusante do aerofólio é suficiente para observar com detalhe as estruturas do escoamento.

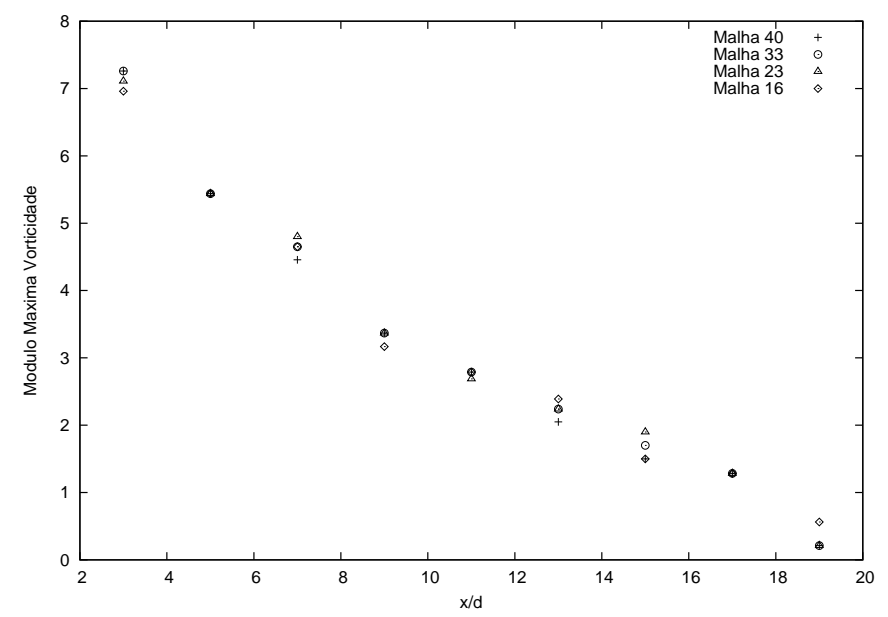

Figura 4.3: Valores de vorticidade ao longo da distância do teste de convergência da distância da fronteira a jusante.

\subsection{Malha resultante}

A malha final adotada se estende em unidades de corda do aerofólio (corda unitária), de -45 a +45 na direção y (vertical), e de -10 a +40 na direção $x$ (horizontal). A malha consiste de aproximadamente 700 elementos quadrilá- 
teros estruturados (ver Figura 4.1).

Na Figura 4.4 se mostra uma vista detalhada da região de interferência entre o cilindro e fólio. Para as malhas usadas nos casos de interferência não foram feitos testes de convergência já que o escoamento ao longe não sofre muitas perturbações, tudo isso devido a o cilindro possuir um diâmetro muito pequeno (do tamanho da espessura do aerofólio).

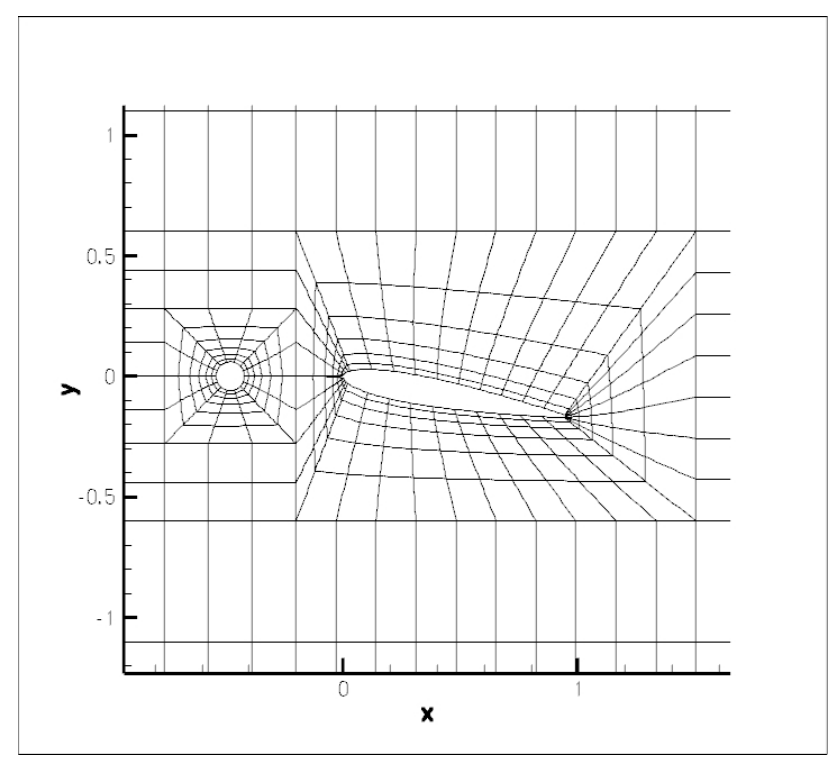

Figura 4.4: Vista detalhada da região de interferência.

\subsection{Malhas usadas na análise de Floquet}

Para os cálculos de estabilidade, não foi efetuado um estudo da convergência nas malhas de Floquet, pois se seguiu o padrão dado por Carmo et al. ${ }^{24}$ e Gioria et al. ${ }^{35}$. Nestes trabalhos, a malha de Floquet é uma versão reduzida da malha usada para calcular o campo base (ver Figura 4.5). Para a análise de Floquet, o parâmetro mais importante é o número de quadros do 
escoamento base usado em sua representação. O número de quadros usado foi 32 seguindo a recomendação de Carmo et al. ${ }^{24}$. Outro fator determinante na análise de Floquet é o tamanho do subespaço de Krilov no qual se resolve iterativamente o problema de autovalores. Foi usado um subespaço de dimensão 20, tal como sugerido por Gioria et al. ${ }^{35}$. No presente trabalho, o valor do resíduo das iterações para convergência foi mantido abaixo de $10^{-5}$.

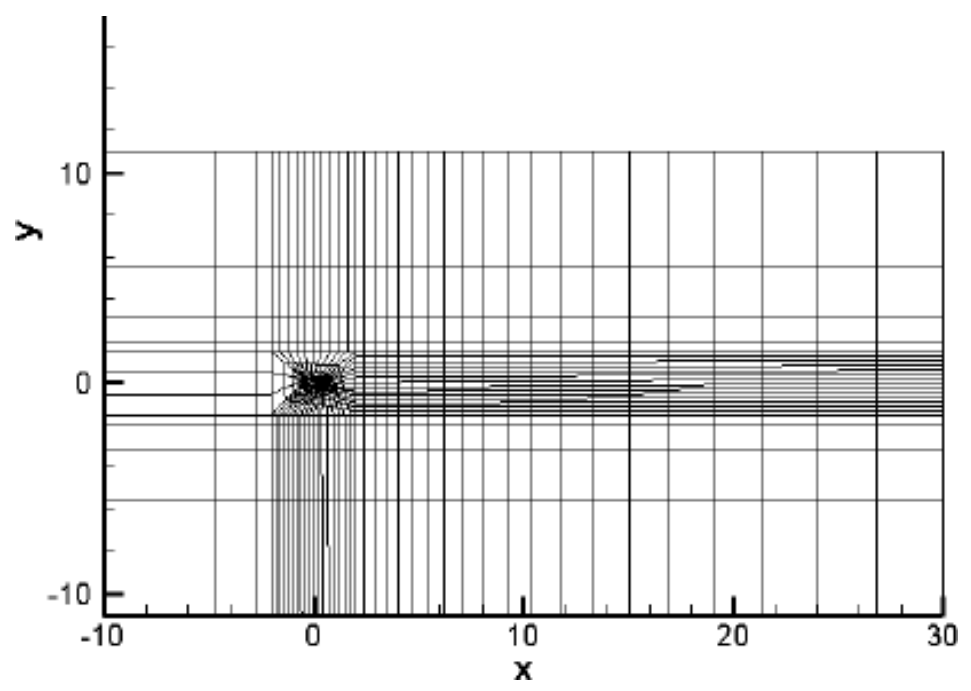

Figura 4.5: Malha utilizada para estudo de estabilidade. NACA 0012, $\alpha=20^{\circ}$ 



\section{Capítulo 5}

\section{Resultados}

\subsection{Campos base e análise de estabilidade de um fólio isolado}

\subsubsection{Simulações NACA 0012 ângulo de ataque zero grau}

Para um ângulo de ataque de zero grau o escoamento permanece colado sobre toda a superfície do aerofólio, deixando suavemente a superfície superior e inferior do bordo de fuga segundo a condição de Kutta, tal como apresentado na Figura 5.1, a qual representa o campo base do sistema quando $\mathrm{Re}=600$. A partir dos resultados das forças aerodinâmicas, percebe-se que a sustentação do sistema é nula em qualquer instante de tempo. Este mesmo comportamento se apresenta nos casos nos quais $R e=400, R e=500$ e concorda com os resultados da teoria de aerofólios, que prediz uma sustentação nula para corpos esbeltos simétricos tais como o NACA 0012. Dado que não 
há desprendimento de vórtices a jusante do aerofólio, não será aplicada a teoria de Floquet.

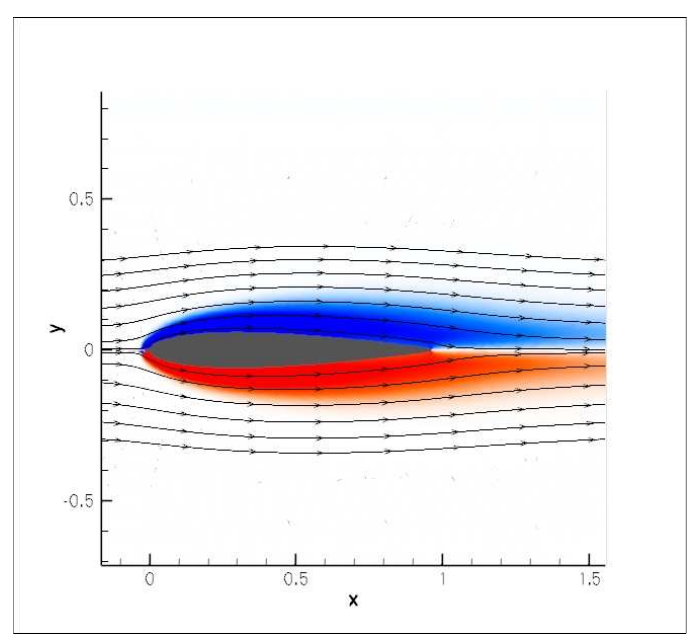

Figura 5.1: Contornos de vorticidade NACA sem ângulo de ataque, $R e=600$. Vorticidade -2 em azul a +2 em vermelho.

\subsubsection{Simulações NACA 0012 ângulo de ataque dez graus}

Para um ângulo de ataque de dez graus, simulações foram efetuadas com valores de Reynolds (Re) de 400, 500, 600. Apenas foi necessário expor o campo base para $\mathrm{Re}=600$, já que as outras duas simulações apresentam um comportamento muito similar com esta. Tal campo base é mostrado na Figura 5.2

Na Figura 5.3, podem ser vistos os comportamentos das forças aerodinâmicas do aerofólio para $R e=600$. Contrário ao caso do aerofólio inclinado a zero grau, já não há simetria entre o escoamento que circula ao redor da parte superior e inferior do corpo, produzindo-se uma sustentação total não nula. Os valores médios e RMS de sustentação e arrasto dos três regimes estuda- 


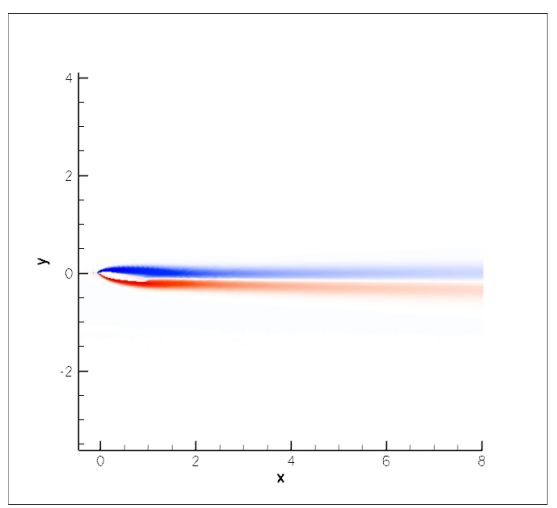

Figura 5.2: Contornos de vorticidade NACA 0012 ângulo de ataque dez graus, $\operatorname{Re}=600$. Vorticidade -2 em azul a +2 em vermelho

dos são apresentados na Tabela 5.1. Para $R e=400,500,600$ o escoamento se comporta como regime permanente, não havendo, portanto, valores RMS dos coeficientes de arrasto e sustentação, nem freqüência de desprendimento de vórtices. Apesar da teoria linear de Floquet ser aplicável em escoamentos estacionários, neste trabalho só será usada na hora de analisar escoamentos periódicos no tempo, portanto este tipo de análise não será empregada neste sistema.

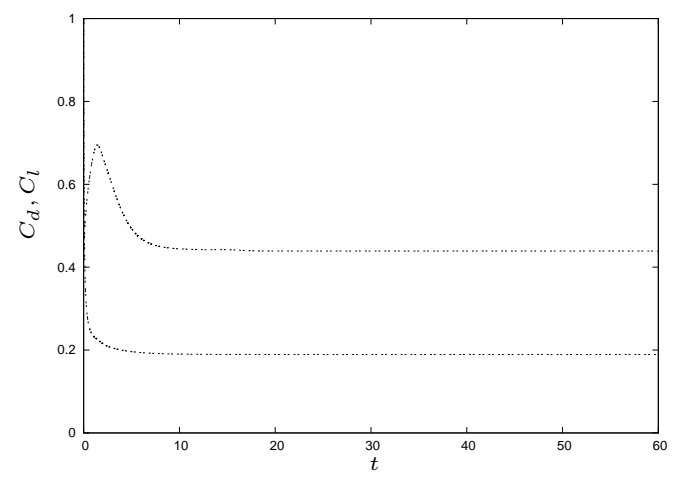

Figura 5.3: Comportamento do coeficiente de arrasto e sustentação $\left(C_{d}, C_{l}\right)$ em função do tempo, $\operatorname{Re}=600, \alpha=10^{\circ} . C_{d}$ curva inferior. 


\begin{tabular}{|c||c||c||c||c|}
\hline \hline $\operatorname{Re}$ & $\overline{C_{l}}$ & $C_{l}{ }^{\prime}$ & $\overline{C_{d}}$ & $C_{d}{ }^{\prime}$ \\
\hline \hline 400 & 0.4680 & - & 0.2283 & - \\
\hline 500 & 0.4534 & - & 0.2057 & - \\
\hline 600 & 0.4390 & - & 0.1899 & - \\
\hline
\end{tabular}

Tabela 5.1: Resultados aerodinâmicos NACA 0012 isolado, ângulo de ataque dez graus.

\subsubsection{Variação do Coeficiente de Arrasto}

Na Figura 5.4, se mostra também o comportamento do coeficiente de arrasto médio total $\left(\overline{C_{d}}\right)$. Pode-se observar que há uma tendência a decrescer com o aumento do Reynolds. Para entender melhor este fenômeno, separa-se o $C_{d}$ nas suas duas componentes, uma devida a efeitos viscosos e a outra devida aos efeitos de pressão. Uma visualização destas quantidades em relação ao Re é apresentada na Figura 5.5. Nota-se que estas grandezas diminuem quando o Reynolds aumenta, combinando-se para gerar uma queda no valor do coeficiente de arrasto total. A diminuição no arrasto total na medida em que o Reynolds aumenta é razoável nas condições estudadas, dado que os efeitos viscosos são menos representativos a Reynolds mais elevados. Esta diminuição no arrasto pode estar relacionada com a mudança da bolha de separação mostrada em Figura 5.6, Figura 5.7, Figura 5.8.

\subsubsection{Variação do Coeficiente de Sustentação}

Apesar do escoamento na Figura 5.2 parecer se comportar como em geometrias afiladas, uma análise mais detalhada das linhas de corrente sobre a superfície do corpo mostra um cenário bastante diferente. Tais linhas de corrente podem ser visualizadas nas Figura 5.6, Figura 5.7, Figura 5.8. A partir delas pode-se concluir que acontece descolamento da camada limite, tendo 


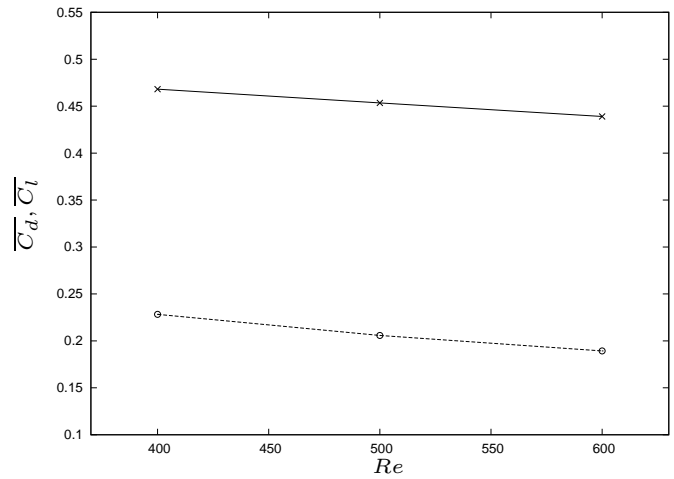

Figura 5.4: Comportamento dos coeficientes médios de arrasto e sustentação $\left(\overline{C_{d}}, \overline{C_{l}}\right)$ em função do Reynolds.

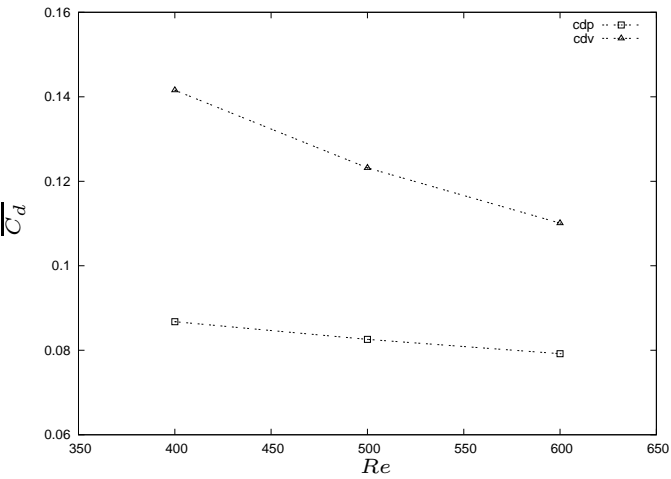

Figura 5.5: Coeficientes médios de arrasto de pressão e viscoso $\left(\overline{C_{d p}}, \overline{C_{d v}}\right)$ em função do Reynolds, $\alpha=10^{\circ}$

como conseqüência uma queda no valor da sustentação total em relação ao Reynolds, tal como apresentado na Figura 5.4.

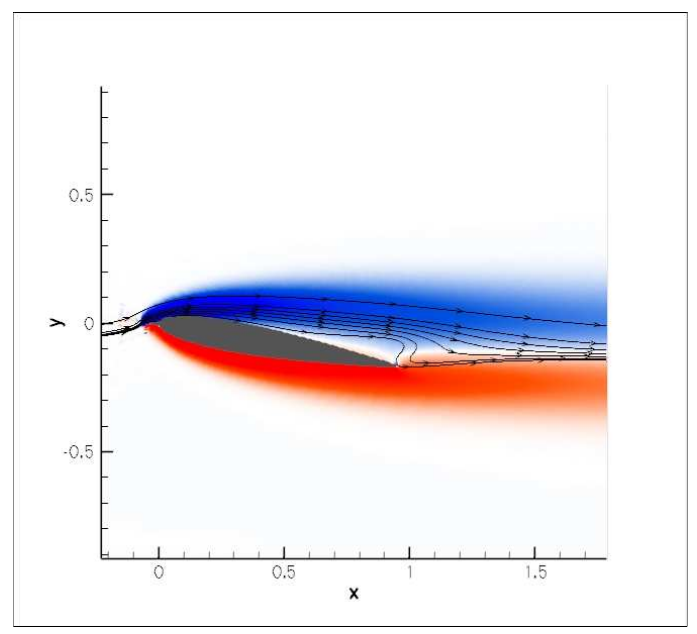

Figura 5.6: Linhas de corrente NACA 0012 a dez graus, $\operatorname{Re}=400$

Adicionalmente pode-se ressaltar que o tamanho da região de separação cresce com o aumento de Re, a qual segundo a Figura 5.9 gera uma zona cuja pressão cai enquanto o Reynolds é aumentado. O incremento da pressão no extradorso do aerofólio é finalmente responsável da queda na sustentação, 


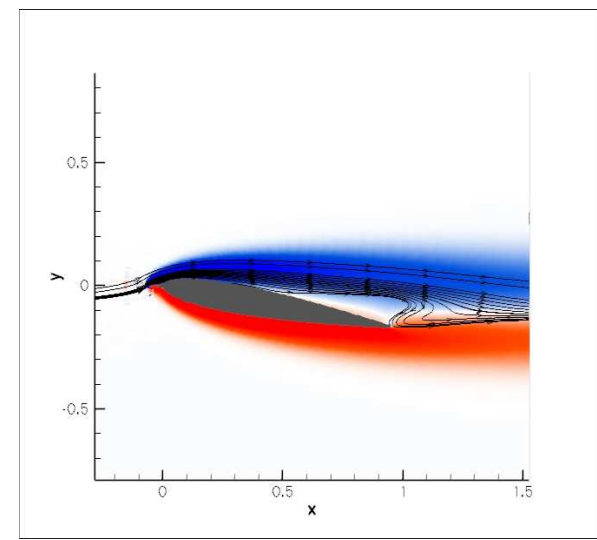

Figura 5.7: Linhas de corrente NACA 0012 a dez graus, $\operatorname{Re}=500$

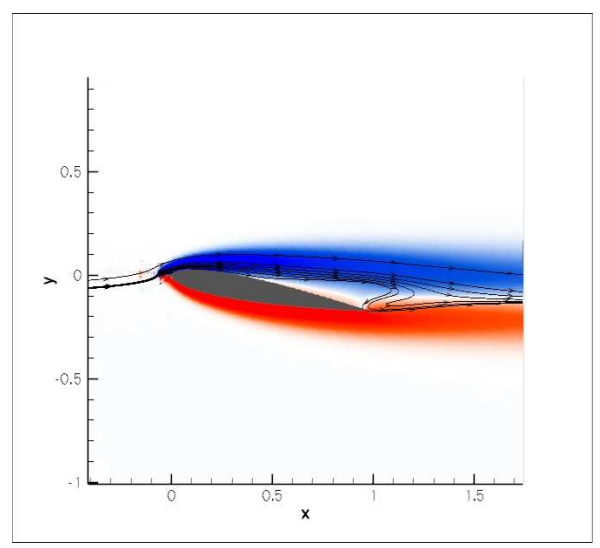

Figura 5.8: Linhas de corrente NACA 0012 a dez graus, $\operatorname{Re}=600$

já que a distribuição de pressão no intradorso do aerofólio é praticamente idêntica em todos os casos estudados.

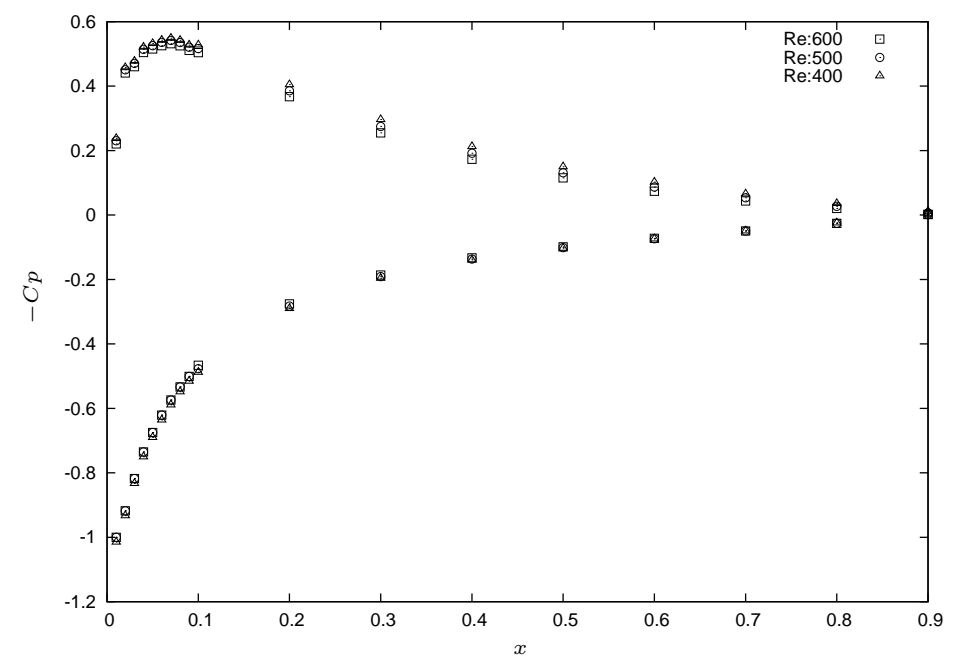

Figura 5.9: Distribuição do coeficiente de pressão $\left(C_{p}\right)$ na superficie do aerofólio em função do Reynolds. Curva inferior representa o intradorso, a superior o extradorso. $\alpha=10^{\circ}$. 


\subsubsection{Simulações NACA 0012 ângulo de ataque vinte graus}

Para um ângulo de ataque de vinte graus foram efetuadas simulações com número Reynolds de 400, 500, 600. Uma visualização dos contornos de vorticidade para o caso $R e=600$ é mostrada na Fig. 5.10. Este caso é ilustrativo, pois as simulações com $\operatorname{Re}=400, \operatorname{Re}=500$ apresentam praticamente o mesmo comportamento exceto por uma pequena variação na largura da esteira.

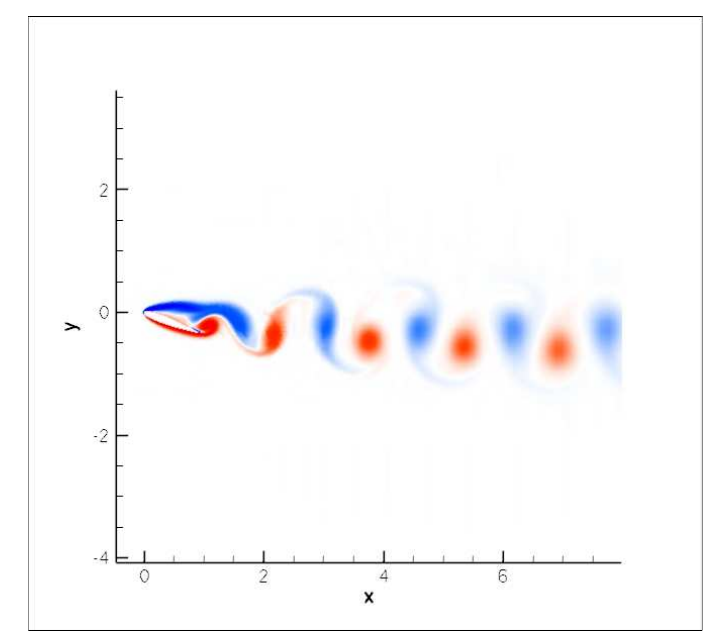

Figura 5.10: Contornos de vorticidade NACA 0012 ângulo de ataque vinte graus, $\operatorname{Re}=$ 600. Vorticidade -2 em azul a +2 em vermelho

Pode-se observar que nos regimes estudados há desprendimento massivo de vórtices e uma esteira periódica no tempo. Este último fato pode ser comprovado a partir do comportamento das forças aerodinâmicas sobre o perfil, tal como apresentado nas Figura 5.11 e Figura 5.12, para $\operatorname{Re}=400$, $\mathrm{Re}=600$ respectivamente.

Simulações adicionais foram feitas na faixa $\mathrm{Re}=400$ até $\mathrm{Re}=600$ dado que este é o intervalo de aparecimento das instabilidades secundárias do es- 

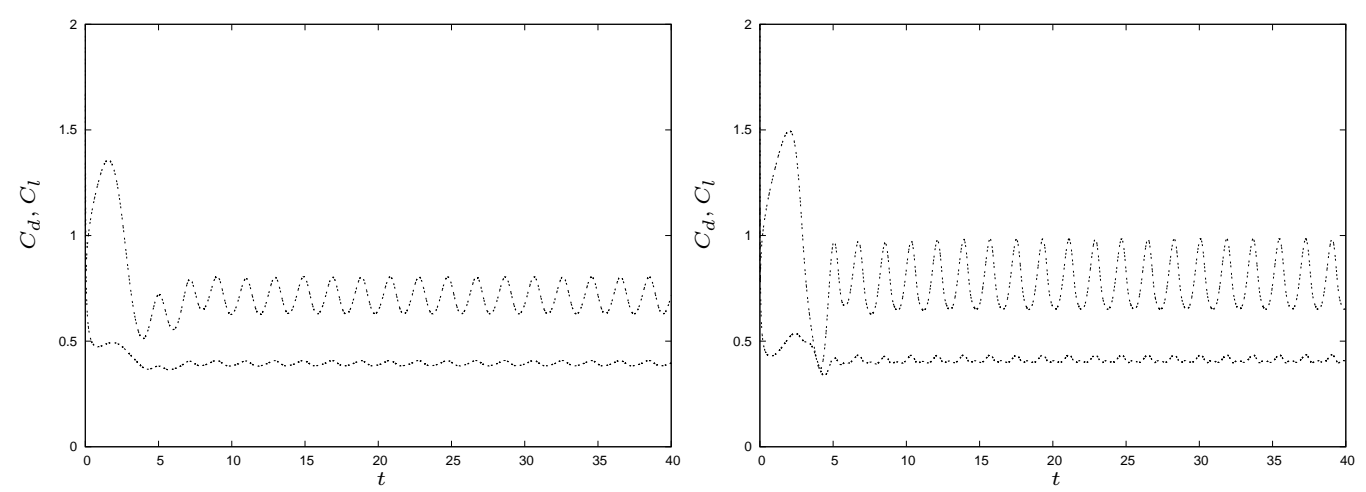

Figura 5.11: Comportamento dos coeficientes de arrasto e sus-

Figura 5.12: Comportamento dos coeficientes de arrasto e sustentação $\left(C_{d}, C_{l}\right)$ em função do tempo, $\operatorname{Re}=600$. tentação $\left(C_{d}, C_{l}\right)$ em função do tempo, $\operatorname{Re}=400$. $\alpha=20^{\circ}, C_{d}$ curva inferior. $\alpha=20^{\circ} . C_{d}$ curva inferior.

coamento. A Tabela 5.2, resume os resultados das simulações aerodinâmicas de todos os casos estudados.

\begin{tabular}{|c||c||c||c||c||c|}
\hline \hline Re & $\overline{C_{l}}$ & $C_{l}^{\prime}$ & $\overline{C_{d}}$ & $C_{d}{ }^{\prime}$ & $S_{t}$ \\
\hline \hline 400 & 0.7111 & 0.7137 & 0.3944 & 0.3945 & 0.5036 \\
\hline 500 & 0.7486 & 0.7543 & 0.4010 & 0.4012 & 0.5341 \\
\hline 600 & 0.7867 & 0.7956 & 0.4115 & 0.4113 & 0.5493 \\
\hline
\end{tabular}

Tabela 5.2: Resultados aerodinâmicos NACA 0012 isolado, ângulo de ataque vinte graus.

\subsubsection{Variação do Coeficiente de Sustentação}

A partir do comportamento do coeficiente de sustentação apresentado na Figura 5.13, pode-se observar que o máximo valor médio da sustentação se apresenta no caso em que o NACA 0012 esta em um escoamento cujo Reynolds é $\operatorname{Re}=600$. Este comportamento é comprovado pela distribuição de pressão na superfície do corpo, como pode-se observar na Figura 5.14. Comparando os três conjuntos de pontos mostrados nesta figura, nota-se que 
a maior área encerrada pelas curvas se apresenta quando $R e=600$ e a menor quando $\operatorname{Re}=400$, gerando-se um aumento na sustentação na medida em que o Reynolds aumenta.

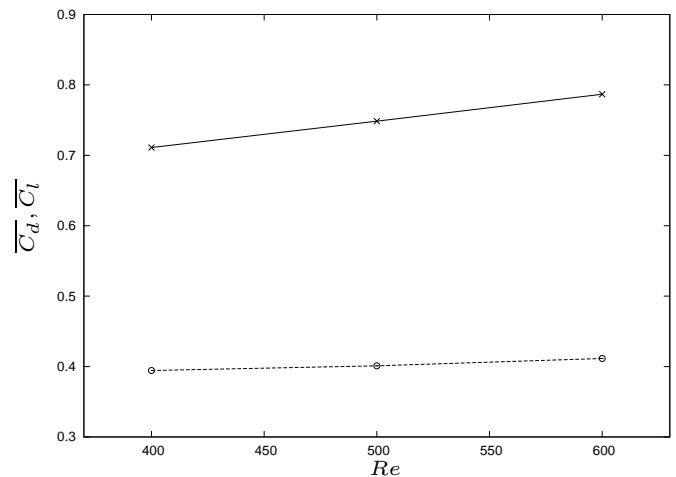

Figura 5.13: Comportamento dos coeficientes médios de arrasto e sustentação $\left(\overline{C_{d}}, \overline{C_{l}}\right)$ em função do Reynolds. NACA 0012, $\alpha=20^{\circ}$

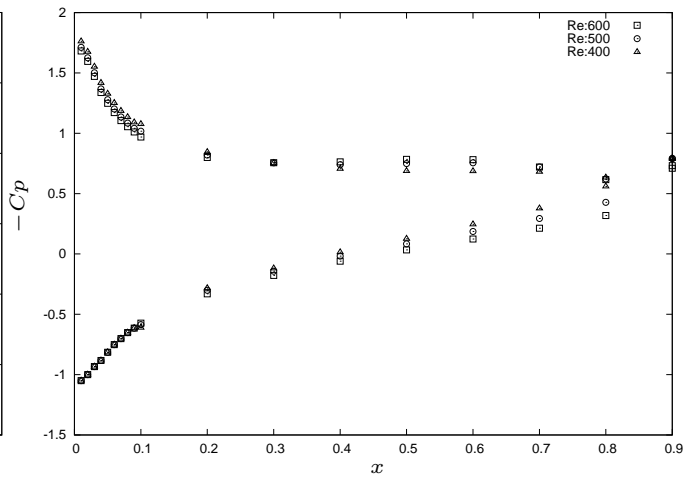

Figura 5.14: Distribuição do coeficiente de pressão $\left(C_{p}\right)$ na superficie do aerofólio em função do Reynolds. Curva inferior representa o intradorso, a superior o extradorso

Para justificar o fato da sustentação aumentar em relação ao Reynolds quando o sistema está em estol, deve-se analisar os contornos de vorticidade e linhas de corrente apresentados nas Figuras: 5.15, 5.16, 5.17. Percebe-se que a região de formação de esteira está cada vez mais a montante do bordo de fuga na medida em que o Re aumenta. Esta proximidade de esteira somada com o fato de ter desprendimento de vórtices faz com que a sustentação total no aerofólio aumente apesar da camada limite estar completamente descolada. Adicionalmente pode-se destacar que devido ao estol e ao aparecimento de uma bolha de recirculação quando o corpo esta inclinado a vinte graus (Figura 5.15), a distribuição de pressão na superfície do NACA 0012 não é homogênea, afastando-se daquele comportamento monotônico apresentado 
quando o ângulo é de dez graus, tal como ilustrado em Figura 5.9.

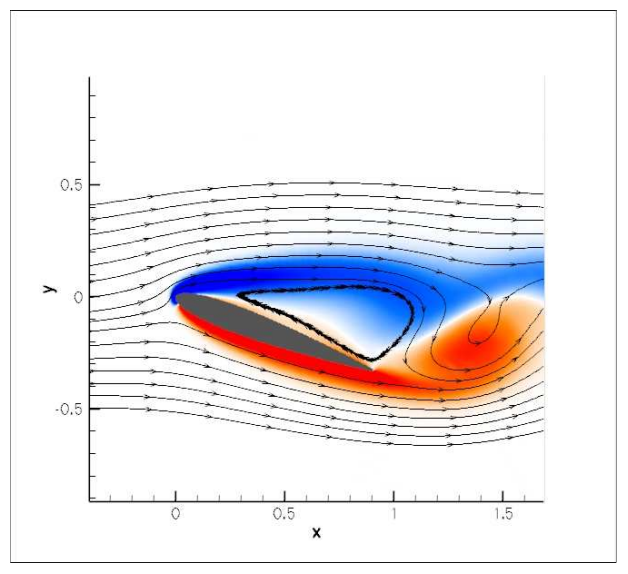

Figura 5.15: Linhas de corrente NACA 0012 a vinte graus, $\mathrm{Re}=400$

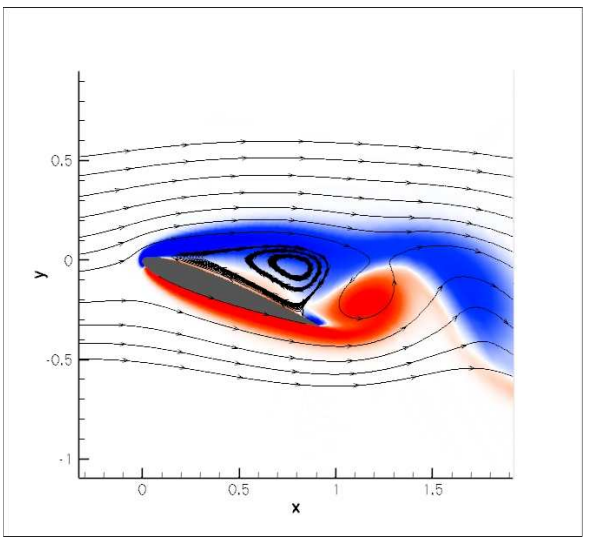

Figura 5.16: Linhas de corrente NACA 0012 a vinte graus, $\operatorname{Re}=500$

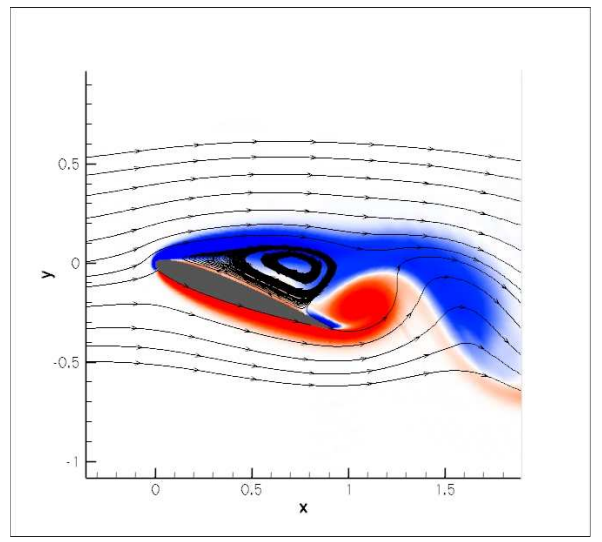

Figura 5.17: Linhas de corrente NACA 0012 a vinte graus, $\operatorname{Re}=600$

\subsubsection{Variação do Coeficiente de Arrasto}

Observando a Figura 5.13, podemos notar que o arrasto aumenta levemente quando o Reynolds é aumentado. Isto é devido à ocorrência de separação da camada limite com a consequente diminuição da pressão na região 
imediatamente a jusante do ponto de separação. Da Figura 5.18, vemos que o coeficiente de arrasto devido a efeitos de pressão aumenta com o Reynolds, enquanto o coeficiente de arrasto devido a efeitos viscosos diminui, devido a que existe uma bolha no extradorso do fólio (ver Figura 5.15, Figura 5.16, Figura 5.17) que faz uma força viscosa na direção oposta ao escoamento, cujo tamanho se torna cada vez menor a medida que o Re aumenta. Finalmente os efeitos devidos à pressão terminam dominando no escoamento, fazendo com que o arrasto médio total aumente.

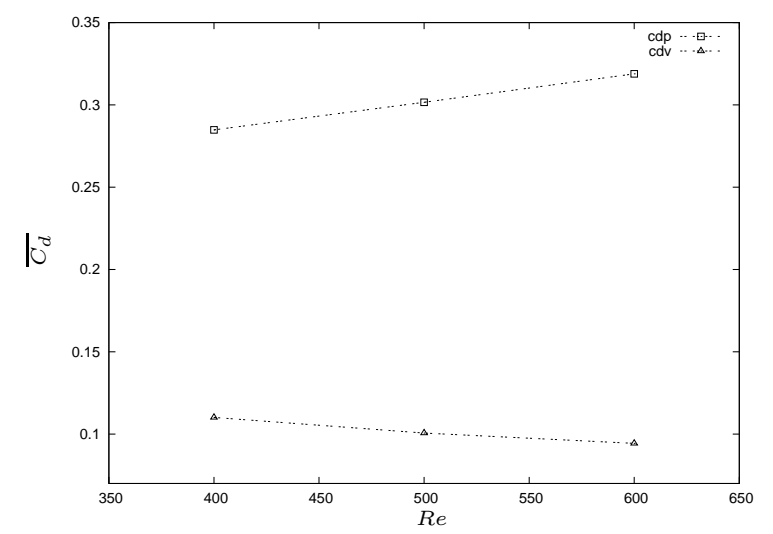

Figura 5.18: Coeficientes médios de arrasto de pressão e viscoso $\left(\overline{C_{d p}}, \overline{C_{d v}}\right)$ em função do Reynolds, $\alpha=20^{\circ}$

\subsubsection{Variação do número de Strouhal}

Uma visualização detalhada do escoamento mostrado nas Figura 5.15, Figura 5.16, Figura 5.17, mostra que quanto maior o valor de Re mais próximo do bordo de fuga o primeiro vórtice é formado, fazendo com que o Strouhal da esteira gerada pelo aerofólio aumente, tal como mostrado em Figura 5.19. Este tipo de comportamento foi encontrado também por Carmo ${ }^{12}$ no escoamento ao redor de um cilindro. 


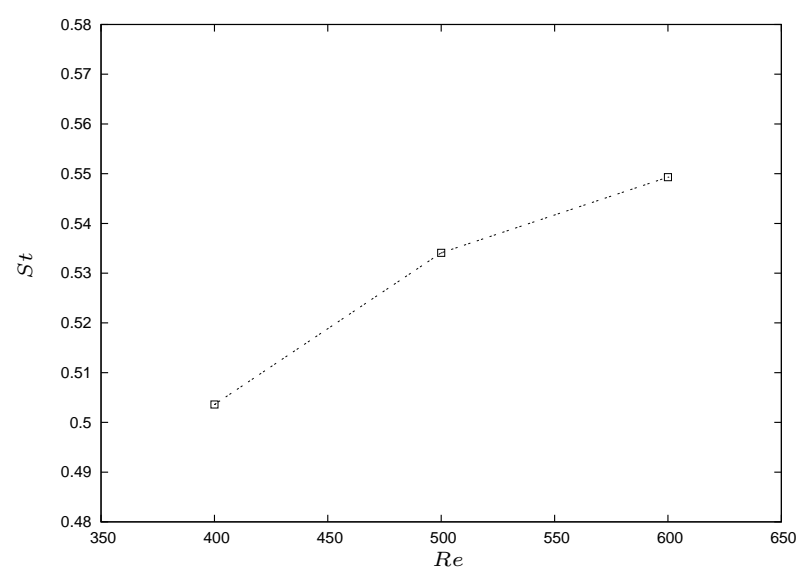

Figura 5.19: Gráfico do número de Strouhal em função do número Reynolds, $\alpha=20^{\circ}$.

\subsubsection{Análise de Floquet}

A Figura 5.20 mostra a variação do módulo do multiplicador de Floquet em relação ao número de onda em $z$ da perturbação, para diferentes números Reynolds. Da figura fica claro que o sistema é estável ante perturbações tridimensionais infinitesimais na faixa $450 \leq R e<460$ (o módulo do multiplicador é menor que 1 para todos os números de onda). Simulações adicionais foram levadas a cabo com o objetivo de obter a curva de estabilidade neutra, tal como ilustrado em Figura 5.21.

Dois diferentes modos instáveis se apresentam na faixa de Reynolds estudada. A bifurcação do primeiro modo instável (o modo de número de onda mais alto) ocorre a $\mathrm{Re}=454$. O comprimento de onda de máxima taxa de crescimento para este modo é ao redor de $\lambda / c=0.57$. Da Figura 5.22 e Figura 5.23, percebe-se que as tridimensionalidades são mais fortes nas regiões que interligam os vórtices que nos núcleos deles. 


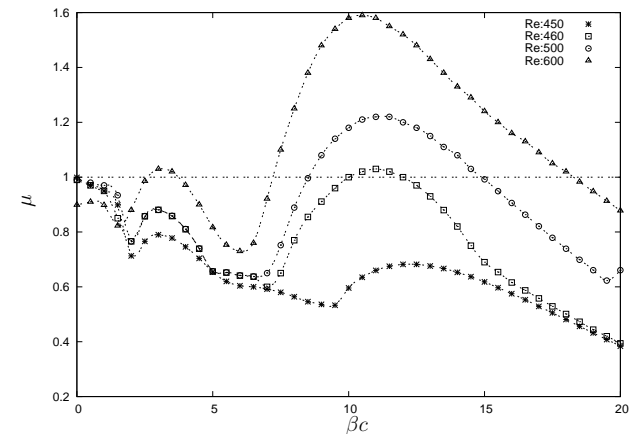

Figura 5.20: Curva do módulo dos multiplicadores de Floquet $|\mu|$ pelo número de onda $\beta$, sendo o comprimento de onda $\lambda=$ $2 \pi / \beta$. Casos aerofólio NACA0012 isolado com ângulo de ataque $20^{\circ}$.

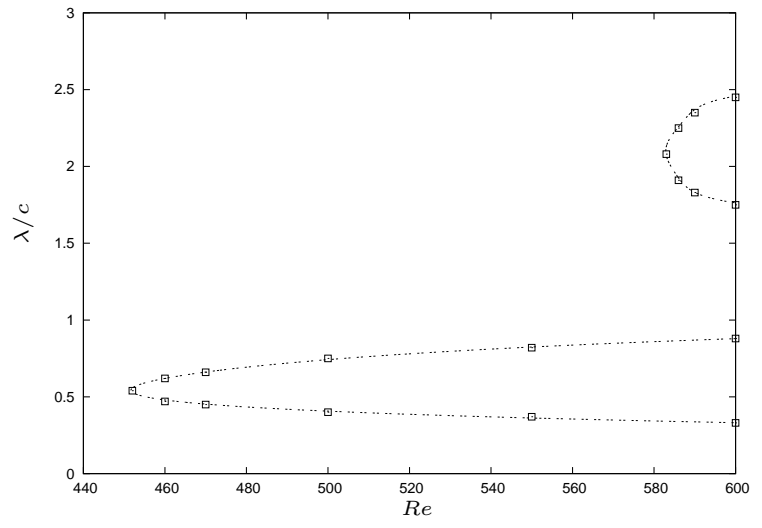

Figura 5.21: Curva de estabilidade neutra (instável é dentro da curva).

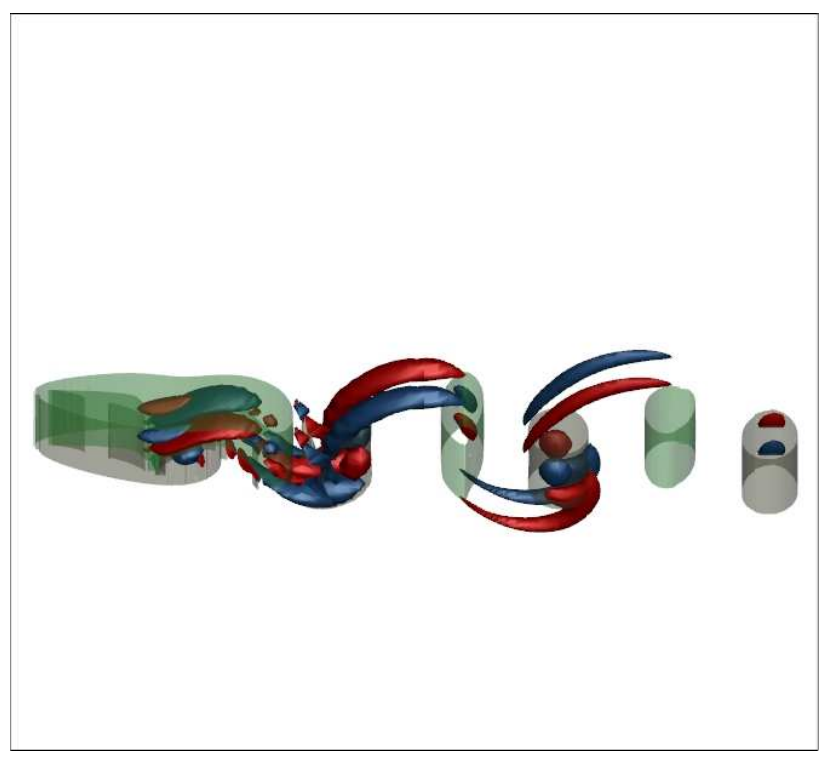

Figura 5.22: Escoamento remontado a partir do campo base bidimensional e das perturbações tridimensionais. As iso-superfícies translúcidas são de $\omega_{z}$ do campo base. As iso-superfícies sólidas azuis e vermelhas representam valores negativos e positivos do modo instável $\omega_{x} . \operatorname{Re}=500, \alpha=20^{\circ}, \beta=11$

Também se pode notar a partir da Figura 5.23 que o modo tridimensional tem período 2T, conseqüência do multiplicador de Floquet ser um real 


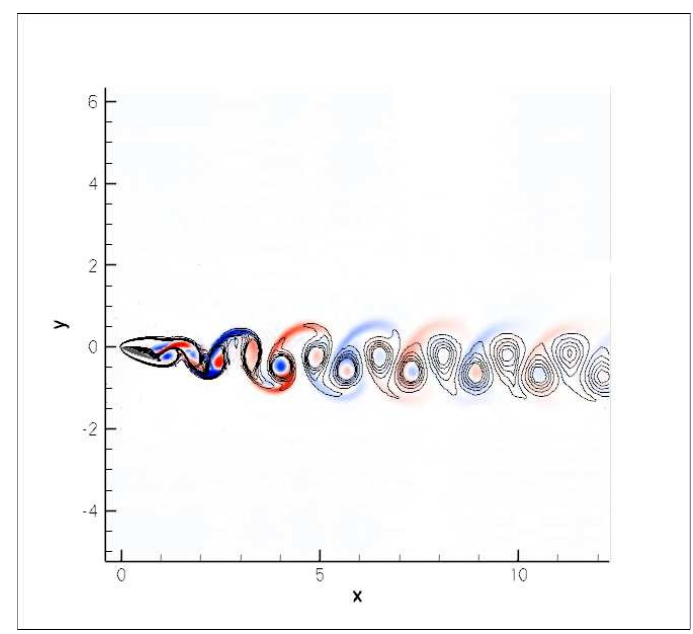

Figura 5.23: Contornos de $\mathrm{x}$-vorticidade em cores do modo de Floquet sobrepostos as linhas de vorticidade em $z$ constante do campo base

negativo. Este modo tem a seguinte característica

$$
\omega_{x}(x, y, z, t)=\omega_{x}(x, y, z, t+2 T)
$$

e recebe o nome do subharmônico. Tal modo se assemelha ao modo C (Zhang et al. ${ }^{36}$; Sheard et al. ${ }^{37}$ ), e foi encontrado por Carmo et al. ${ }^{24}$ no estudo de cilindros desalinhados. Este modo acontece geralmente em esteiras não simétricas (Gioria et al. ${ }^{35}$ ).

Um segundo modo instável surge para $\mathrm{Re}=582$, com comprimento de onda de máximo crescimento de $\lambda / c=2.1$. Este modo apresenta multiplicadores de Floquet complexos, sendo portanto um modo quase-periódico. Este fato faz com que as componentes tridimensionais do escoamento tenham um período de desprendimento diferente do período de desprendimento do campo base. Este tipo de modo, encontrado também em Blackburn et al. ${ }^{38}$, tem a 
característica

$$
\omega_{x}(x, y, z, t)=\omega_{x}\left(x, y, z+k_{z}, t+T\right)
$$

e podem ser visualizados no escoamento como uma onda estacionária ou propagante na direção de envergadura. As Figuras: 5.24, 5.25 mostram as iso-superfícies de vorticidade em $z$ combinadas com o modo instável de vorticidade em $x$ de Floquet. Cabe ressaltar que o aerofólio NACA 0012 inclinado a vinte graus se comporta como um corpo rombudo assimétrico, pois os modos que surgem ao redor deste corpo (modo subharmônico e quase-periódico) diferem das características espaço temporais apresentadas pelos modos A e B encontrados por Williamson ${ }^{18}$ e Barkley e Henderson ${ }^{7}$ ao redor de cilindros circulares, mas são parecidos aos modos que acontecem no escoamento ao redor de cilindros quadrados e outras geometrias não simétricas.

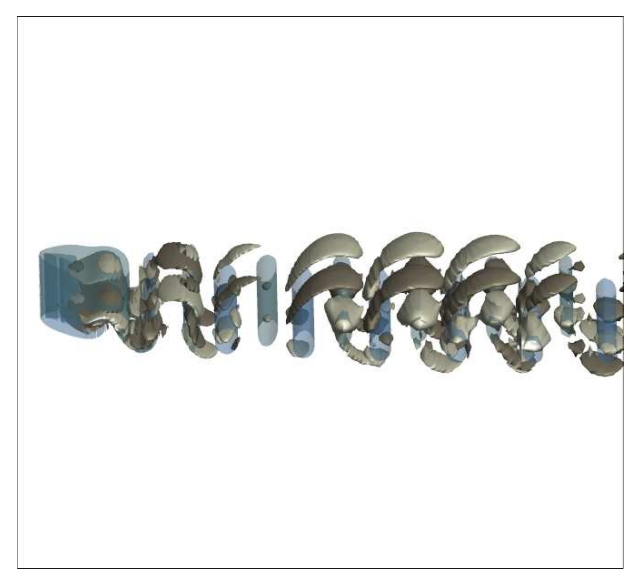

Figura 5.24: Escoamento remontado a partir do campo base bidimensional e das perturbações tridimensionais. As iso-superfícies translúcidas são de $\omega_{z}$ do campo base. As iso-superfícies sólidas cinza escuras e claras representam valores de $\omega_{x}$ do modo de Floquet negativos e positivos. $\operatorname{Re}=600, \alpha=20^{\circ}, \beta=3$ 


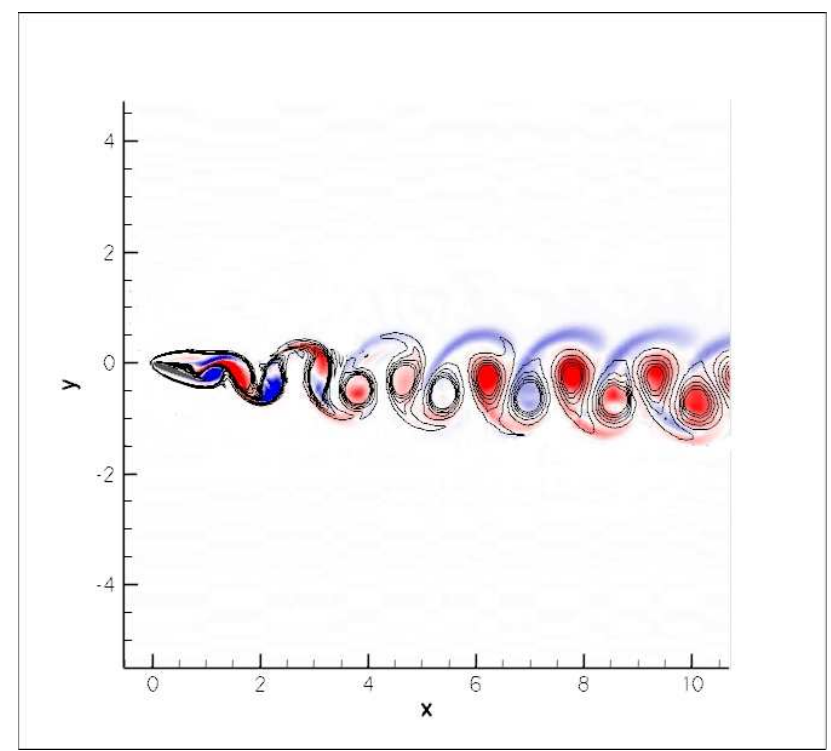

Figura 5.25: Contornos de $\mathrm{x}$-vorticidade em cores do modo de Floquet sobrepostos as linhas de vorticidade em $z$ constante do campo base

\subsection{Campos base e análise de estabilidade de um aerofólio alinhado com um cilindro}

\subsubsection{Simulações cilindro com NACA 0012 ângulo de ataque zero grau}

O resultado do campo base ao redor do aerofólio NACA 0012, sem ângulo de ataque em interferência com um cilindro no regime $\mathrm{Re}=600$ é mostrado na Figura 5.26. Os resultados das simulações nos casos $R e=500, R e=400$ não são apresentadas, pois o escoamento ao redor do sistema praticamente não muda em relação ao caso $R e=600$. Da Figura 5.26 pode-se inferir que o escoamento praticamente permanece colado à superfície do aerofólio, este fato pode ser confirmado a partir de uma visualização das linhas correntes ao redor do perfil, tal como apresentado em Figura 5.27. 
5.2. Campos base e análise de estabilidade de um aerofólio alinhado com um cilindro

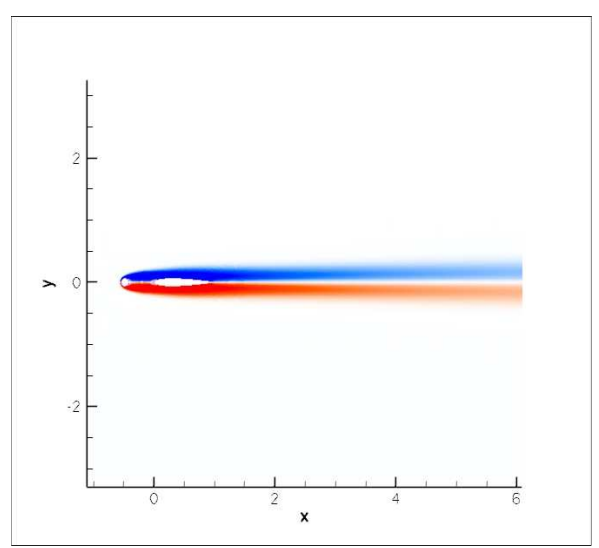

Figura 5.26: Contornos de vorticidade cilindro com NACA 0012 inclinado zero grau, $\operatorname{Re}=$ 600. Vorticidade -2 em azul a +2 em vermelho

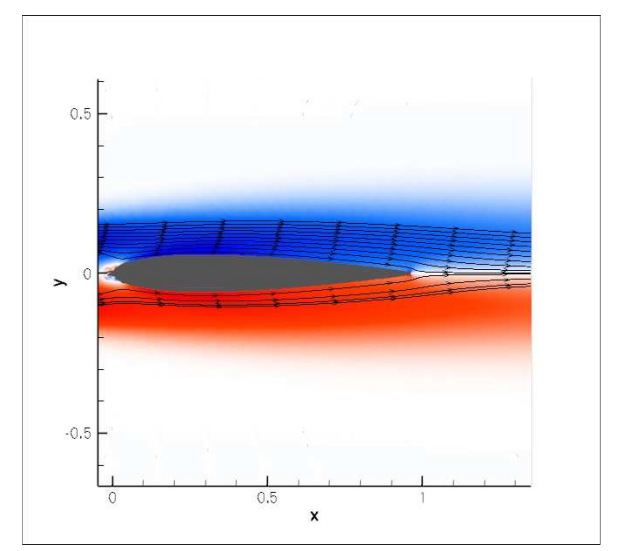

Figura 5.27: Vista detalhada linhas de corrente NACA 0012 a zero grau em interferência com cilindro, $\mathrm{Re}=600$

Assim como no caso do aerofólio isolado, as linhas de corrente deixam suavemente a superfície do NACA 0012 sem presença de desprendimento de vórtices. No entanto na região intersticial (Figura 5.28) pode-se observar um interessante fenômeno no qual dois vórtices simétricos são formados antes do bordo de ataque. Este regime de interferência se assemelha ao regime C definido por Igarashi ${ }^{39}$ no escoamento ao redor de pares de cilindros alinhados, o qual é interessante, pois o aerofólio se comporta como um corpo rombudo nesta disposição geométrica, onde o diâmetro do cilindro é da mesma ordem de magnitude da espessura do aerofólio.

Da Tabela 5.3, pode-se observar que a sustentação total sobre o aerofólio é praticamente nula. Isso acontece porque apesar do aerofólio estar em interferência, as linhas de corrente que circundam a superfície superior e inferior do NACA 0012 exibem uma simetria que faz com que o corpo não apresente sustentação. Essa simetria é só possível no caso em que o fólio tem ângulo de ataque nulo. 


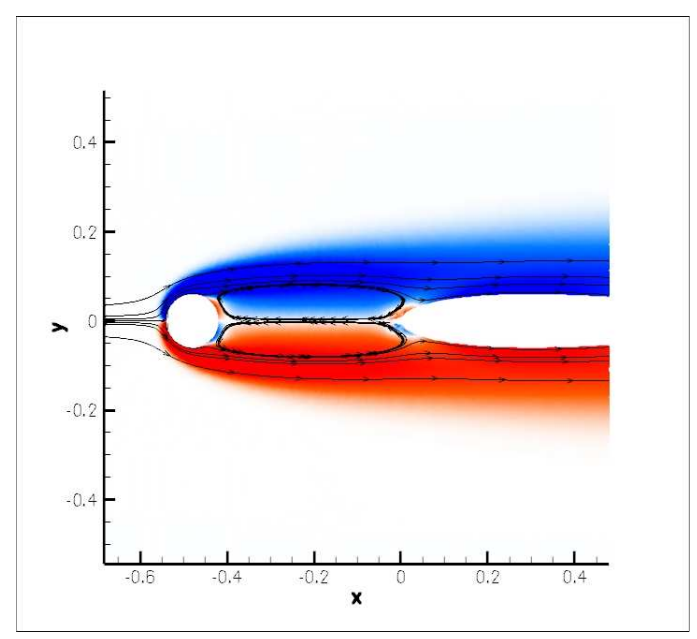

Figura 5.28: Linhas de corrente cilindro com NACA 0012 a zero grau, $\operatorname{Re}=600$

\begin{tabular}{||c||c|c|c|c||c|c||c|c||}
\hline \hline \multirow{2}{*}{ Re } & \multicolumn{3}{|c|}{$\overline{C_{l}}$} & \multicolumn{2}{|c|}{$C_{l}^{\prime}$} & \multicolumn{2}{c|}{$\overline{C_{d}}$} & \multicolumn{2}{|c|}{$C_{d}{ }^{\prime}$} \\
\cline { 2 - 9 } & Cil & NACA & Cil & NACA & Cil & NACA & Cil & NACA \\
\hline 400 & 0 & $1.75 \times 10^{-5}$ & - & - & 0.1538 & 0.0736 & - & - \\
\hline 500 & 0 & $2.01 \times 10^{-5}$ & - & - & 0.1427 & 0.0588 & - & - \\
\hline 600 & 0 & $2.43 \times 10^{-5}$ & - & - & 0.1349 & 0.0477 & - & - \\
\hline
\end{tabular}

Tabela 5.3: Resultados aerodinâmicos cilindro com NACA, sem ângulo de ataque.

\subsubsection{Variação do Coeficiente de Arrasto}

De acordo com a Figura 5.29, os valores do coeficiente de arrasto médio viscoso e de pressão para o cilindro e aerofólio decaem com o Reynolds, de maneira que o arrasto médio total nos dois corpos diminui com este parâmetro, dado que o valor do $C_{d}$ total é dado pela soma da componente de pressão na direção do escoamento $\left(C_{d p}\right)$ e pelo valor das tensões de cisalhamento $\left(C_{d v}\right)$. Este fato é consistente com o apresentado na Tabela 5.3. 
5.2. Campos base e análise de estabilidade de um aerofólio alinhado com um cilindro

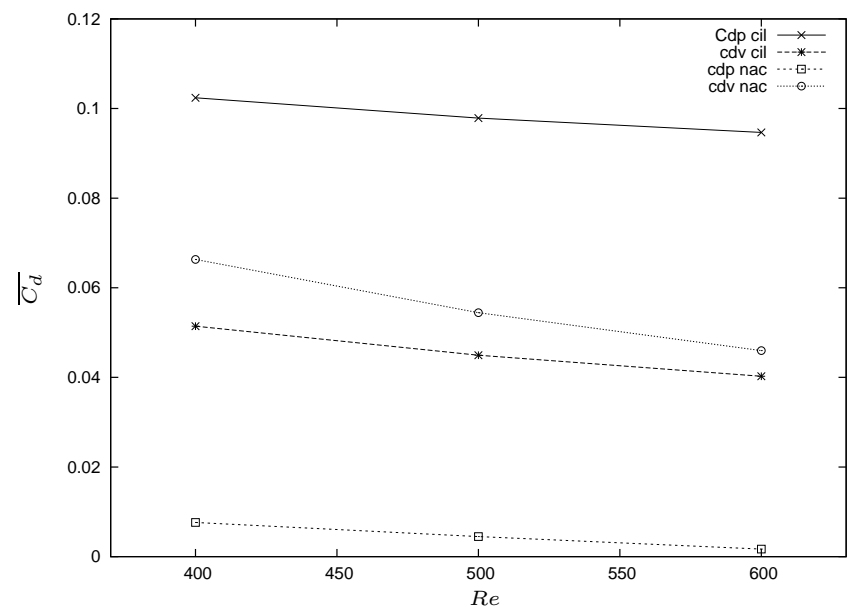

Figura 5.29: Coeficientes médios de arrasto de pressão e viscoso $\left(\overline{C_{d p}}, \overline{C_{d v}}\right)$ do cilindro (cil) e o fólio (nac) em função do Reynolds

\subsubsection{Simulações cilindro com NACA 0012 ângulo de ataque dez graus}

O regime de desprendimento de vórtices muda significativamente na faixa de Reynolds estudada. As mudanças no regime podem ser observadas nos campos base apresentados nas Figura 5.30, Figura 5.31, Figura 5.32. Para $\operatorname{Re}=400$, a esteira ainda não passou pela transição primária, dado que as duas camadas cisalhantes de vorticidade oposta não se misturaram nem variam no tempo. Para $\operatorname{Re}=500$ e $\operatorname{Re}=600$ há oscilação na esteira, mas no caso $\operatorname{Re}=500$ a desestabilização acontece mais afastada do aerofólio.

Na Tabela 5.4 mostram-se os resultados aerodinâmicos para os valores de Reynolds estudados. Um resultado interessante pode ser observado das simulações. Para uma distância de três diâmetros entre o cilindro e o aerofólio, não há desprendimento de vórtices na região entre os corpos, mas se apresenta uma região de concentrada vorticidade no bordo de ataque do aerofólio. 


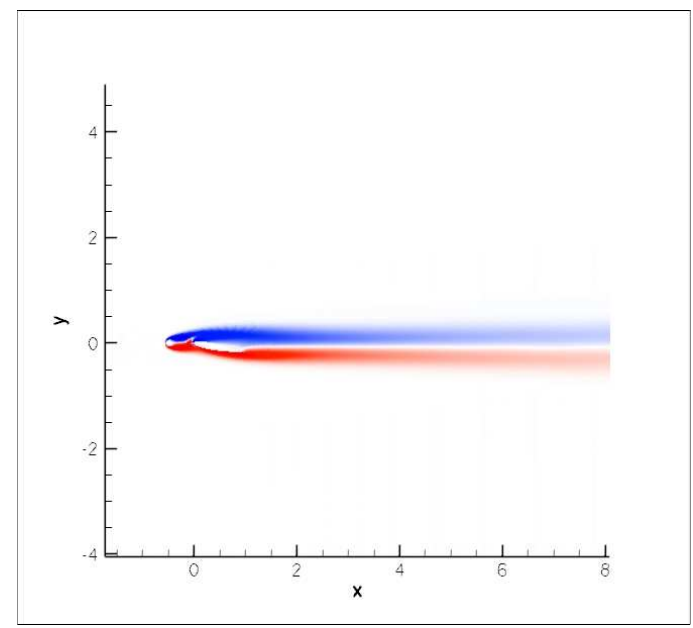

Figura 5.30: Contornos de vorticidade cilindro com NACA 0012 a dez graus, $\operatorname{Re}=400$

Este fenômeno faz com que a pressão dinâmica do escoamento que atinge o corpo seja menor em relação às condições de fluxo livre, gerando uma queda no valor da sustentação para todos os casos de interferência comparadas com as simulações feitas para o aerofólio isolado.

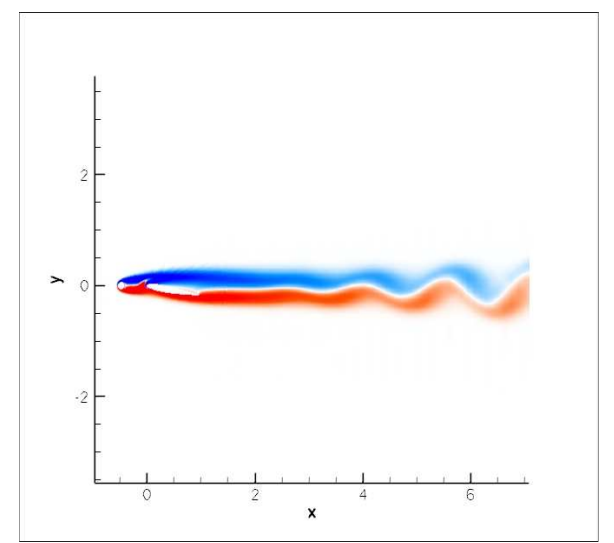

Figura 5.31: Contornos de vorticidade cilindro com NACA 0012 a dez graus, $\mathrm{Re}=500$

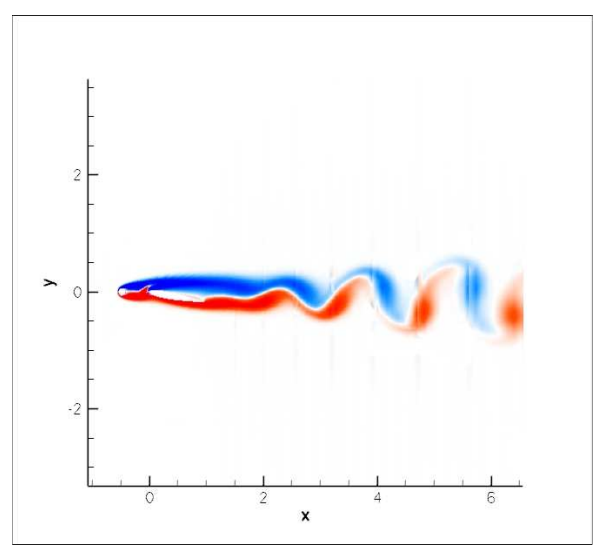

Figura 5.32: Contornos de vorticidade cilindro com NACA 0012 a dez graus, $\mathrm{Re}=600$ 
5.2. Campos base e análise de estabilidade de um aerofólio alinhado com um cilindro

\begin{tabular}{||c||c|c||c|c||c|c||c|c||}
\hline \hline \multirow{2}{*}{ Re } & \multicolumn{2}{|c|}{$\overline{C_{l}}$} & \multicolumn{2}{c|}{$C_{l}^{\prime}$} & \multicolumn{2}{c|}{$\overline{C_{d}}$} & \multicolumn{2}{c||}{$C_{d}^{\prime}$} \\
\cline { 2 - 9 } & Cil & NACA & Cil & NACA & Cil & NACA & Cil & NACA \\
\hline 400 & 0.0044 & 0.2908 & - & - & 0.1499 & 0.1414 & - & - \\
\hline 500 & 0.0038 & 0.2793 & 0.0038 & 0.2793 & 0.1388 & 0.1278 & 0.1388 & 0.1278 \\
\hline 600 & 0.0038 & 0.2933 & 0.0038 & 0.2933 & 0.1321 & 0.1247 & 0.1321 & 0.1247 \\
\hline
\end{tabular}

Tabela 5.4: Resultados aerodinâmicos cilindro com NACA, ângulo de ataque dez graus.

\subsubsection{Variação do Coeficiente de Arrasto}

A Figura 5.33 traz os resultados do coeficiente de arrasto médio total das simulações 2D para o cilindro e o aerofólio. Analisando esta figura pode-se ressaltar que o coeficiente de arrasto médio tem uma tendência decrescente com o aumento do Reynolds para ambas as geometrias. Para entender o significado físico deste comportamento divide-se de novo o coeficiente de arrasto em suas duas componentes, uma devida à pressão e outra devida às tensões de cisalhamento. Os resultados dos valores médios destas quantidades podem ser vistos explicitamente em forma de gráfico na Figura 5.34.

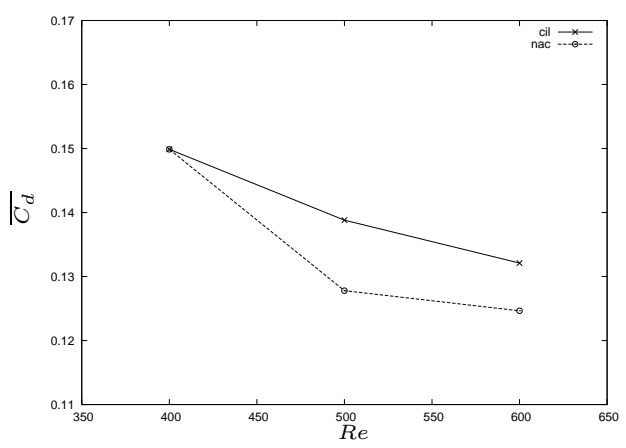

Figura 5.33: Comportamento do coeficiente médio de arrasto $\left(\overline{C_{d}}\right)$ em função do Reynolds para o cilindro (cil) e o fólio (nac), $\alpha=10^{\circ}$

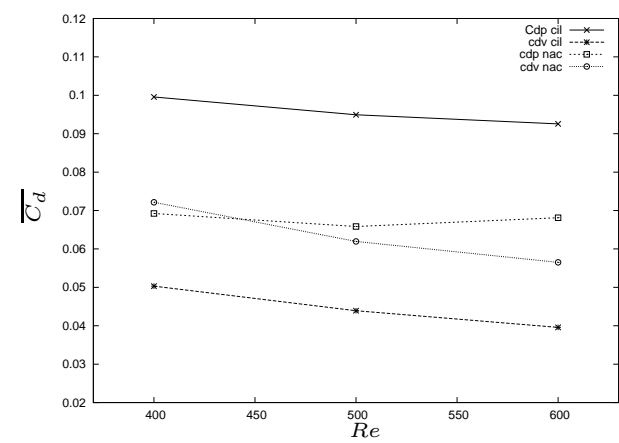

Figura 5.34: Coeficientes médios de arrasto de pressão e viscoso $\left(\overline{C_{d p}}, \overline{C_{d v}}\right)$ do cilindro e o fólio em função do Reynolds, $\alpha=10^{\circ}$

A partir dos resultados do cilindro, verifica-se que a componente de ten- 
sões viscosas tem uma tendência a diminuir com o aumento do Reynolds. Por outro lado a componente devida a pressão também diminui com Re, mas a diferença entre o máximo valor do coeficiente de arrasto médio de pressão $\left(C_{d p}\right)$ e o mínimo, é menor que a diferença entre estas mesmas duas quantidades no caso do coeficiente de arrasto viscoso. Finalmente os efeitos devidos a variação do arrasto viscoso e arrasto de pressão se combinam para gerar uma queda no coeficiente de arrasto total.

A Figura 5.36 mostra o comportamento da pressão na região entre o cilindro e o aerofólio. Pode-se perceber que há uma diminuição na pressão com o aumento do Re. Este efeito é causado porque aumenta-se a vorticidade das camadas cisalhantes, intensificando a recirculação do fluido mostrado na Figura 5.35.

A variação do arrasto médio total do NACA 0012 é determinada principalmente pela variação do coeficiente de arrasto viscoso, tal como pode se inferir das Figura 5.34 e Figura 5.33. Pois, enquanto que o $C_{d v}$ tem um comportamento decrescente com Re, $C_{d p}$ tem um salto em $\mathrm{Re}=600$.

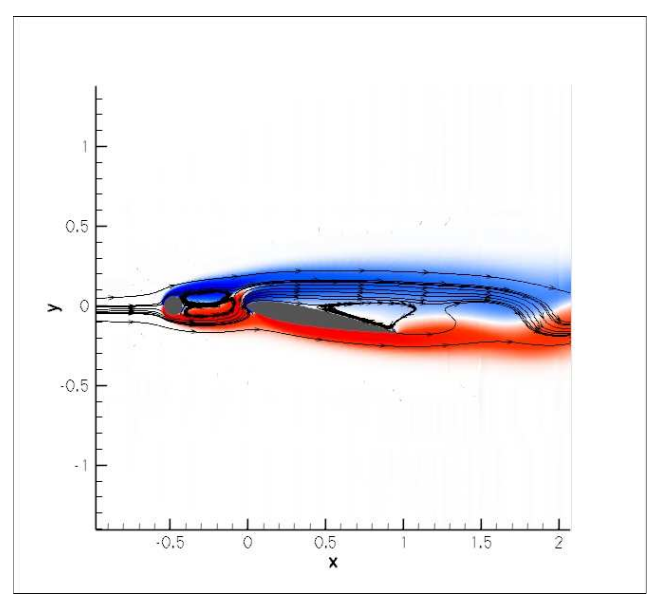

Figura 5.35: Linhas de corrente cilindro com NACA 0012 a dez graus, $\operatorname{Re}=600$ 
5.2. Campos base e análise de estabilidade de um aerofólio alinhado com um cilindro

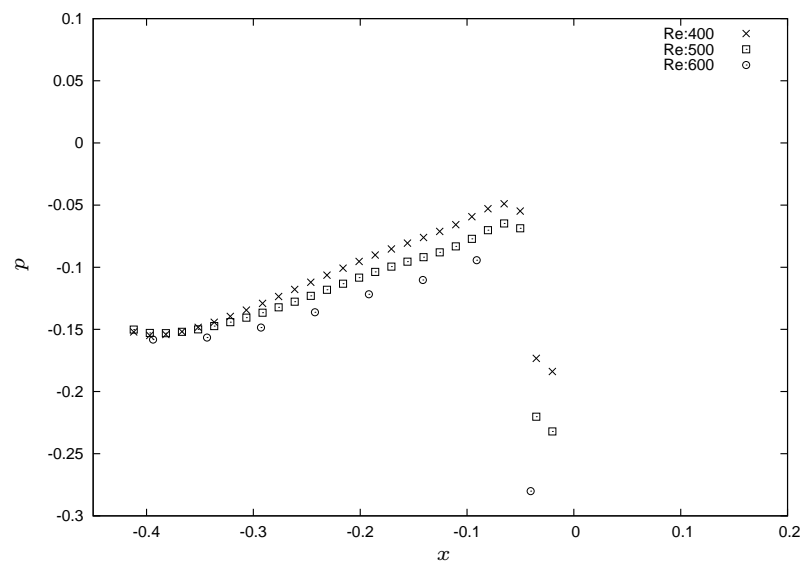

Figura 5.36: Pressão média na região intersticial, $\operatorname{Re}=400,500,600$

\subsubsection{Variação do Coeficiente de Sustentação}

A Figura 5.37 apresenta o comportamento do coeficiente de sustentação para o cilindro e o aerofólio. Pode-se observar uma queda na sustentação do aerofólio quando o regime muda de $\mathrm{Re}=400$ a $\mathrm{Re}=500$, enquanto apresenta um acréscimo quando $R e=600$. Este fato pode ser explicado a partir da distribuição de pressão ao longo da superfície do aerofólio dada na Figura 5.38. Nela pode-se observar que para $\operatorname{Re}=400$ e $R e=600$, a pressão debaixo e em cima do aerofólio são quase iguais, por tal motivo $\left.\mathrm{C}_{1}\right|_{\operatorname{Re}=400}$ e $\left.\mathrm{C}_{1}\right|_{\operatorname{Re}=600}$ estão quase no mesmo patamar na Figura 5.37. Por outro lado no regime $\mathrm{Re}=500$ pode-se perceber que a diferença de pressão entre o intradorso e o extradorso do aerofólio é menor que os respectivos $\Delta p$ de $\mathrm{Re}=400$ e $\mathrm{Re}=600$, por tal motivo a sustentação tem uma queda neste valor. Nos regimes $R e=$ 500 e Re $=600$ há oscilação na esteira, mas no caso $\operatorname{Re}=500$ a desestabilização acontece mais afastada do aerofólio gerando uma sustentação menor respeito do caso $R e=600$, já que a flutuação da esteira é menos sentida no aerofólio. 


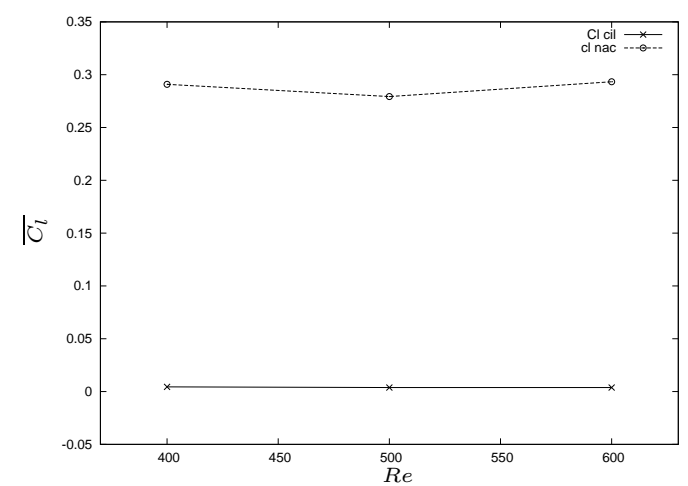

Figura 5.37: Comportamento do coeficiente médio de sustentação $\left(\overline{C_{l}}\right)$ para o cilindro e o fólio em função do Reynolds, $\alpha=10^{\circ}$

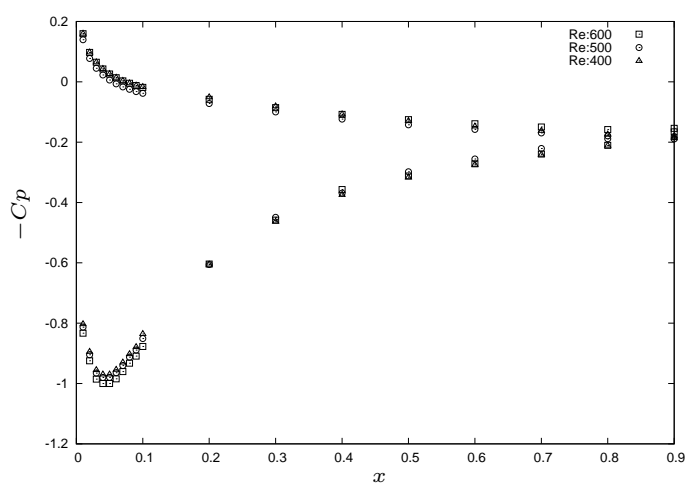

Figura 5.38: Distribuição do coeficiente de pressão $\left(C_{p}\right)$ na superficie do aerofólio em função do Reynolds. Curva inferior representa o intradorso, a superior o extradorso

\subsubsection{Número de Strouhal}

No regime $\mathrm{Re}=400$ não se apresenta desprendimento de vórtices, tal como pode-se verificar no campo base dado na Figura 5.30. No entanto nos regimes $\operatorname{Re}=500$ e $\operatorname{Re}=600$ há oscilação de esteira sendo possível calcular o número de Strouhal a partir do espectro do coeficiente de sustentação das geometrias. Nos dois regimes estudados o Strouhal do cilindro aumenta com o Reynolds, tal como no caso de dois corpos rombudos em interferência $\left(\mathrm{Carmo}^{12}\right)$. Como 
5.2. Campos base e análise de estabilidade de um aerofólio alinhado com um cilindro

o Strouhal do cilindro está acoplado com o Strouhal do aerofólio, a freqüência de desprendimento de vórtices da esteira do fólio termina apresentando um comportamento crescente com o Re.

\subsubsection{Análise de Floquet}

A Figura 5.39 mostra a variação do módulo do multiplicador de Floquet menos estável em relação ao número de onda da perturbação. Pode-se notar a partir da figura que não há modos instáveis na faixa de Reynolds estudada.

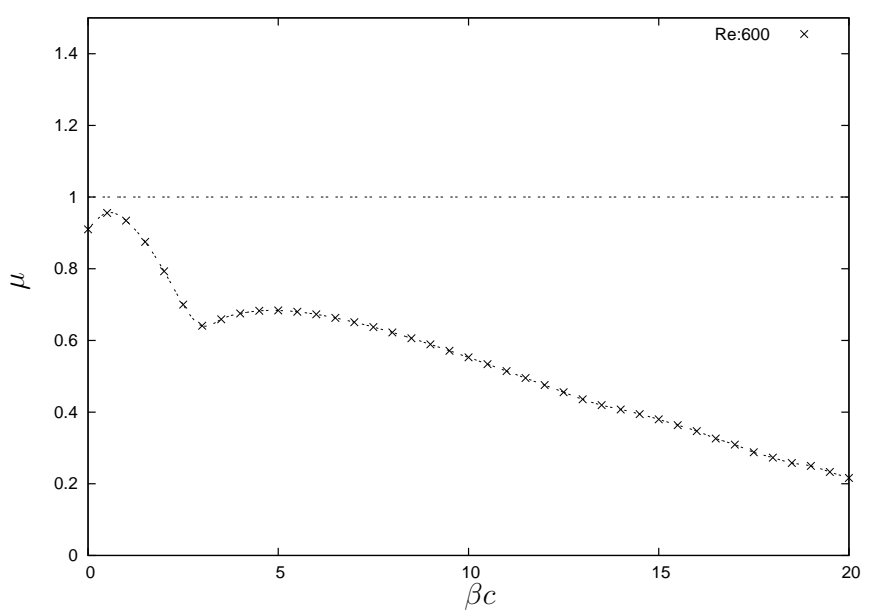

Figura 5.39: Curva do módulo dos multiplicadores de Floquet $|\mu|$ pelo número de onda $\beta$, sendo o comprimento de onda $\lambda=2 \pi / \beta$. Caso cilindro com aerofólio NACA0012 em ângulo de ataque $10^{\circ}$

\subsubsection{Simulações cilindro com NACA 0012 ângulo de ataque vinte graus}

Contornos de vorticidade no regime $\mathrm{Re}=600$ são apresentados na Figura 5.40. O escoamento que circula muito perto da superfície do aerofólio experimenta um gradiente de pressão que faz diminuir a velocidade ao longo 
do perfil. Neste caso o gradiente é suficientemente grande para mudar o movimento das partículas do fluido gerando desprendimento massivo da camada limite. Simulações com regimes $\mathrm{Re}=400$ e $\mathrm{Re}=500$ apresentam um comportamento muito similar ao campo base dado na Figura 5.40.

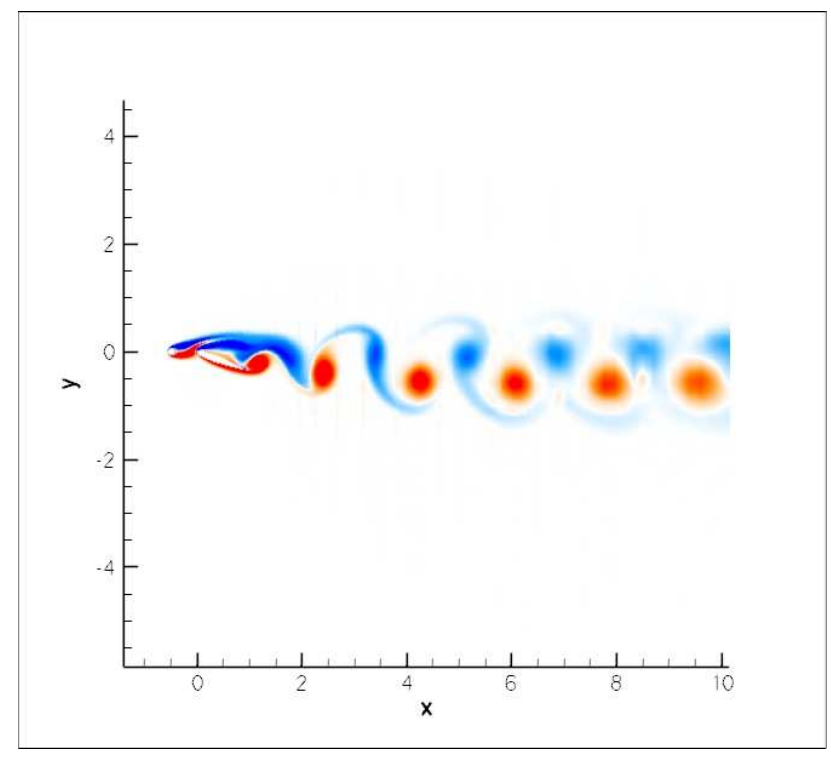

Figura 5.40: Contornos de vorticidade cilindro com NACA 0012 inclinado vinte graus, $\mathrm{Re}=600$. Vorticidade -2 em azul a +2 em vermelho.

\subsubsection{Variação do Coeficiente de Arrasto}

Na Figura 5.41 se mostra o comportamento do coeficiente de arrasto médio total para o cilindro e o perfil NACA 0012. Dos resultados obtidos e resumidos na Tabela 5.5, vê-se que o $C_{d}$ do aerofólio cresce com o número de Reynolds enquanto o $C_{d}$ do cilindro decresce. Para entender melhor estas tendências, usa-se a mesma filosofia de separar o arrasto total numa componente devida à pressão $\left(C_{d p}\right)$ e outra devida a efeitos viscosos $\left(C_{d v}\right)$. O comportamento destas quantidades é visualizado na Figura 5.42. 
5.2. Campos base e análise de estabilidade de um aerofólio alinhado com um cilindro

\begin{tabular}{||c||c|c||c|c||c|c||c|c||}
\hline \hline \multirow{2}{*}{ Re } & \multicolumn{2}{|c|}{$\overline{C_{l}}$} & \multicolumn{2}{c|}{$C_{l}^{\prime}$} & \multicolumn{2}{c|}{$\overline{C_{d}}$} & \multicolumn{2}{c||}{$C_{d}{ }^{\prime}$} \\
\cline { 2 - 9 } & Cil & NACA & Cil & NACA & Cil & NACA & Cil & NACA \\
\hline 400 & 0.0104 & 0.6563 & 0.0104 & 0.6577 & 0.1503 & 0.3409 & 0.1503 & 0.3410 \\
\hline 500 & 0.0101 & 0.6995 & 0.0101 & 0.7032 & 0.1403 & 0.3530 & 0.1403 & 0.3531 \\
\hline 600 & 0.0098 & 0.7322 & 0.0098 & 0.7386 & 0.1327 & 0.3657 & 0.1327 & 0.3657 \\
\hline
\end{tabular}

Tabela 5.5: Resultados aerodinâmicos cilindro com NACA, ângulo de ataque vinte graus.

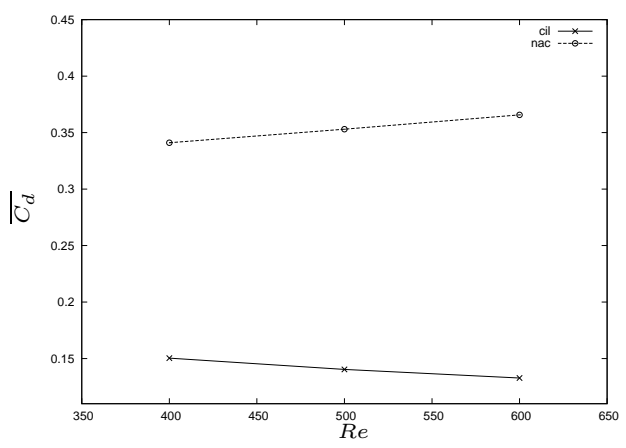

Figura 5.41: Comportamento dos coeficientes médio de arrasto $\left(\overline{C_{d}}\right)$ do cilindro e o fólio em função do Reynolds, $\alpha=20^{\circ}$

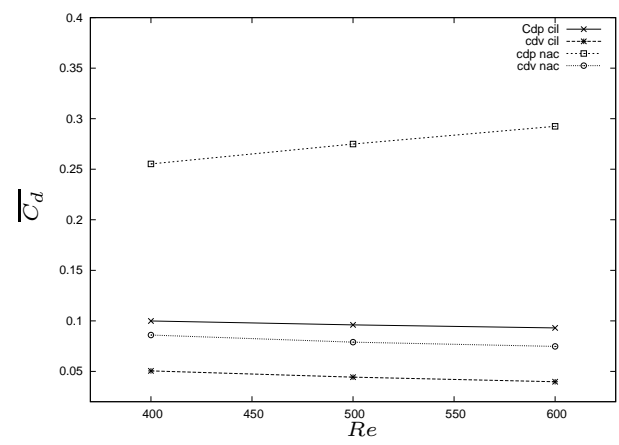

Figura 5.42: Coeficientes médios de arrasto de pressão e viscoso $\left(\overline{C_{d p}}, \overline{C_{d v}}\right)$ do cilindro e o fólio em função do Reynolds

No caso do cilindro, $C_{d v}$ e $C_{d p}$ decrescem com o aumento do número de Reynolds, portanto estas duas grandezas combinadas provocam uma queda no valor do arrasto total. Por outro lado o caso do aerofólio oferece um cenário diferente, pois enquanto o $C_{d v}$ decresce com o Reynolds o $C_{d p}$ cresce com este parâmetro, permitindo inferir que os efeitos de pressão dominam sobre os efeitos viscosos desencadeando um acréscimo no valor médio total de arrasto. Este acréscimo no arrasto é consistente com o fato de se apresentar separação da camada limite e escoamento reverso tal como ilustrado em Figura 5.43.

A separação da camada limite é a causa do fenômeno de estol apresentado nos regimes $\operatorname{Re}=400, \operatorname{Re}=500 \mathrm{Re}=600$, além do acréscimo no arrasto 
nas três simulações. Nestas condições o aerofólio se comporta praticamente como um corpo rombudo.

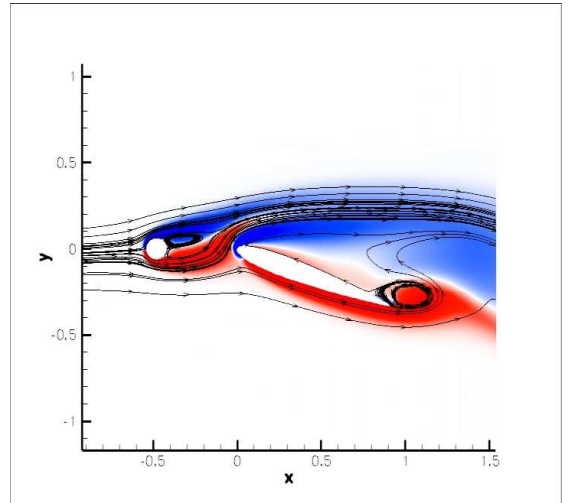

Figura 5.43: Linhas de corrente cilindro com NACA 0012 a vinte graus, $\operatorname{Re}=400$

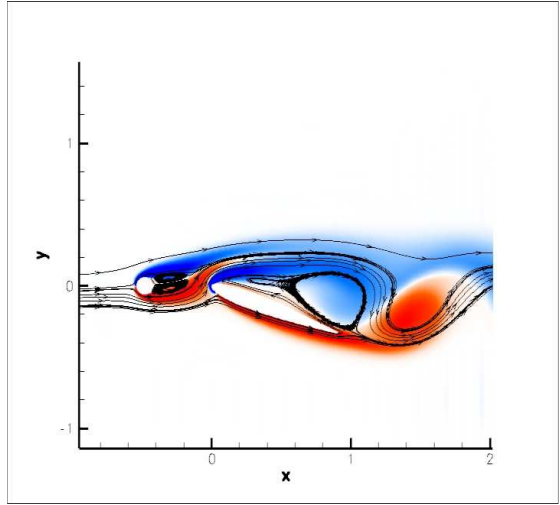

Figura 5.44: Linhas de corrente cilindro com NACA 0012 a vinte graus, $\operatorname{Re}=500$

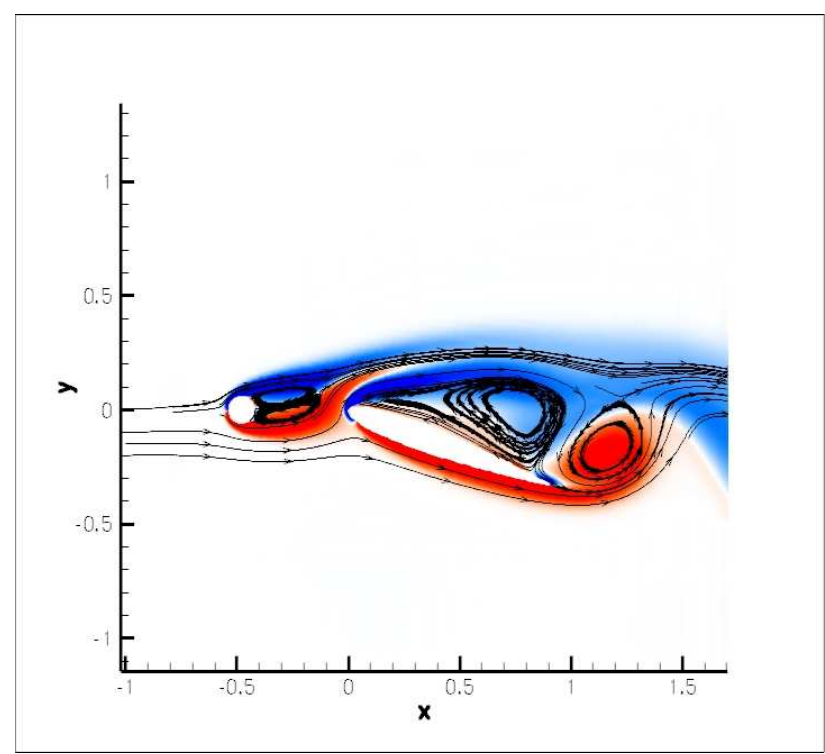

Figura 5.45: Linhas de corrente cilindro com NACA 0012 a vinte graus, $\operatorname{Re}=600$ 


\subsubsection{Variação da Sustentação}

Da Figura 5.46 pode-se ressaltar que a sustentação no aerofólio cresce na medida em que o número de Reynolds aumenta. Para justificar este comportamento é necessário observar de novo a distribuição de pressão na superfície do perfil, apresentado na Figura 5.47. Nela podemos observar que a diferença de pressão entre o lado superior e inferior do fólio aumenta com o Reynolds. Adicionalmente segundo as figuras: 5.43, 5.44, 5.45, nas três simulações estudadas $(\operatorname{Re}=400, R e=500, R e=600)$, a esteira fica mais próxima ao bordo de fuga quando o Reynolds é aumentado. Dado que o número de Strouhal aumenta com o Reynolds (Figura 5.48), as camadas cisalhantes se mexem de maneira mais vigorosa. Este fato afeta a maneira na qual a pressão se distribui na superfície do aerofólio gerando-se um aumento na sustentação em relação ao Reynolds.

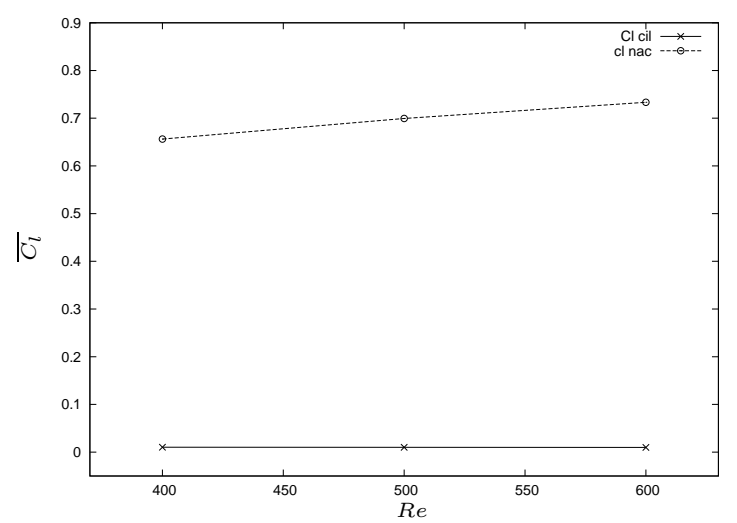

Figura 5.46: Comportamento do coeficiente médio de sustentação $\left(\overline{C_{l}}\right)$ do cilindro e o fólio em função do Reynolds. $\alpha=20^{\circ}$ 


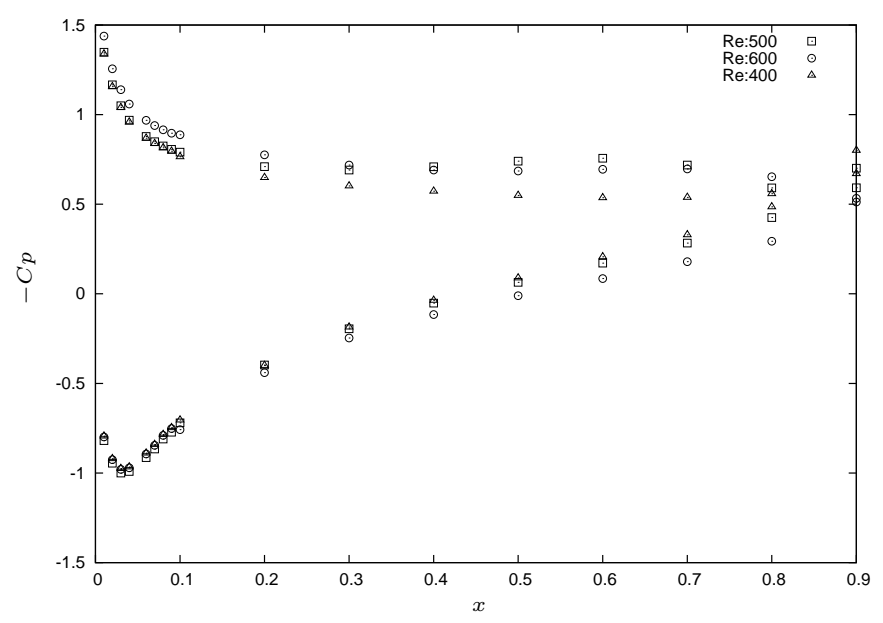

Figura 5.47: Distribuição do coeficiente de pressão $\left(C_{p}\right)$ na superficie do aerofólio em função do Reynolds. Curva inferior representa o intradorso, a superior o extradorso

\subsubsection{Número de Strouhal}

Na configuração de interferência entre um cilindro e um fólio inclinado a vinte graus, o número de Strouhal aumenta respeito ao número de Reynolds. Este comportamento está ilustrado na Figura 5.48. Semelhante ao caso do NACA 0012 com ângulo de ataque de dez graus, o desprendimento de vórtices nos dois corpos está acoplado, fazendo com que o Strouhal do sistema aumente dado que o Strouhal do cilindro cresce com o Reynolds, neste caso de interferência.

\subsubsection{Análise de Floquet}

Os resultados para o módulo do multiplicador de Floquet são mostrados na Figura 5.49. Para $R e=400$ o escoamento é estável, na faixa $400<R e<$ 450 se dá inicio às instabilidades secundárias e fica instável para Reynolds maiores a $R e \approx 418$. Só aparece um modo na faixa de Reynolds estudada, e 


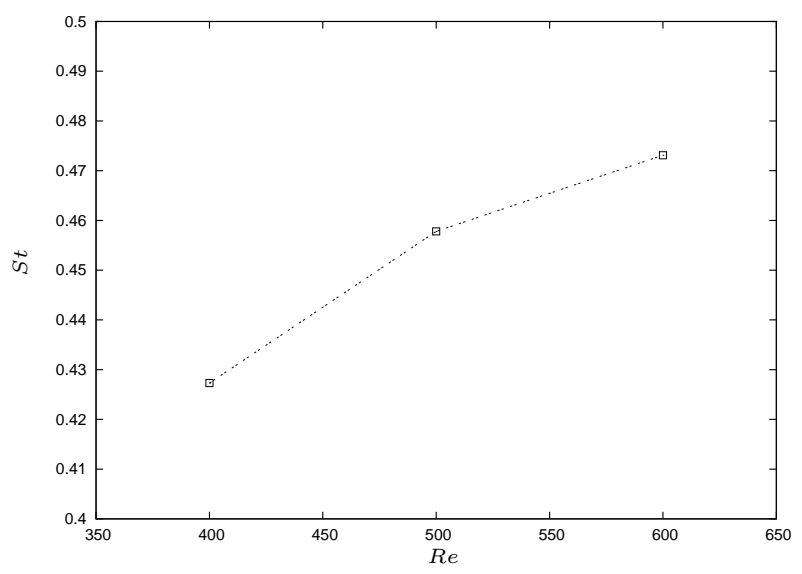

Figura 5.48: Gráfico do número de Strouhal cilindro com NACA 0012 em função do número Reynolds. $\alpha=20^{\circ}$

o número de onda adimensional de máximo crescimento para este modo tem multiplicador de Floquet real e negativo, exibindo as mesmas características de simetria temporal do modo subharmônico apresentado no caso do aerofólio isolado com ângulo de ataque de vinte graus, tal como ilustrado em Figura 5.51. De maneira similar ao modo subharmônico do aerofólio isolado, as estruturas tridimensionais não são mais fortes nos núcleos dos vórtices, mas sim nas regiões que os interligam, tal como pode se visualizar na Figura 5.52. Da análise de estabilidade neutra (Figura 5.50) pode-se notar que o início da instabilidade secundária deve acontecer para um regime $R e<450$ (pois o $\left.R e_{c} \approx 418\right)$ então o cilindro no caso de interferência adianta o início da instabilidade para o modo subharmônico do aerofólio, enquanto estabiliza o sistema em relação ao modo quase-periódico, pois as curvas de Floquet só mostraram um modo instável. 


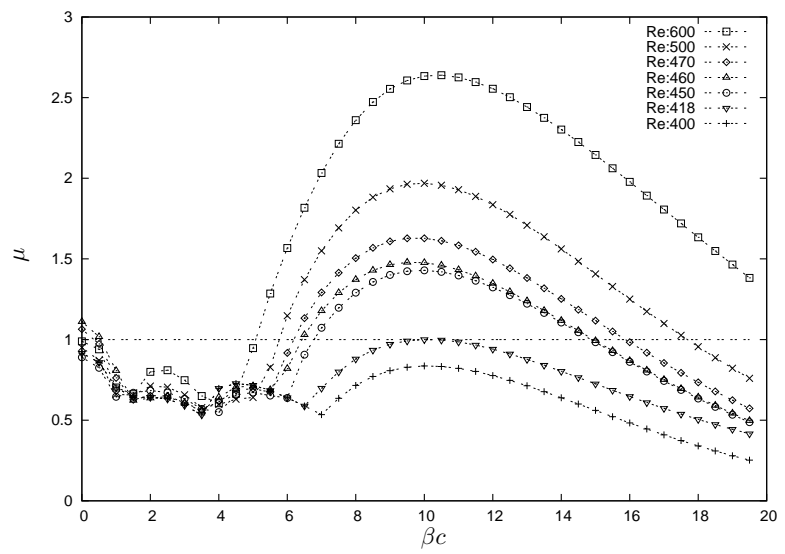

Figura 5.49: Curva do módulo dos multiplicadores de Floquet $|\mu|$ pelo número de onda $\beta$, sendo o comprimento de onda $\lambda=2 \pi / \beta$. Caso aerofólio NACA0012 em interferência com cilindro ângulo de ataque $20^{\circ}$.

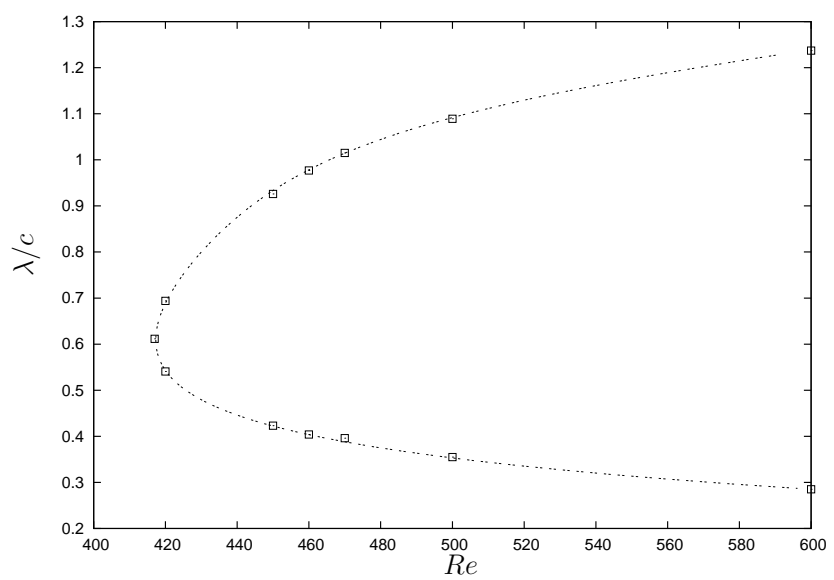

Figura 5.50: Curva de estabilidade neutra (instável é dentro da curva). 


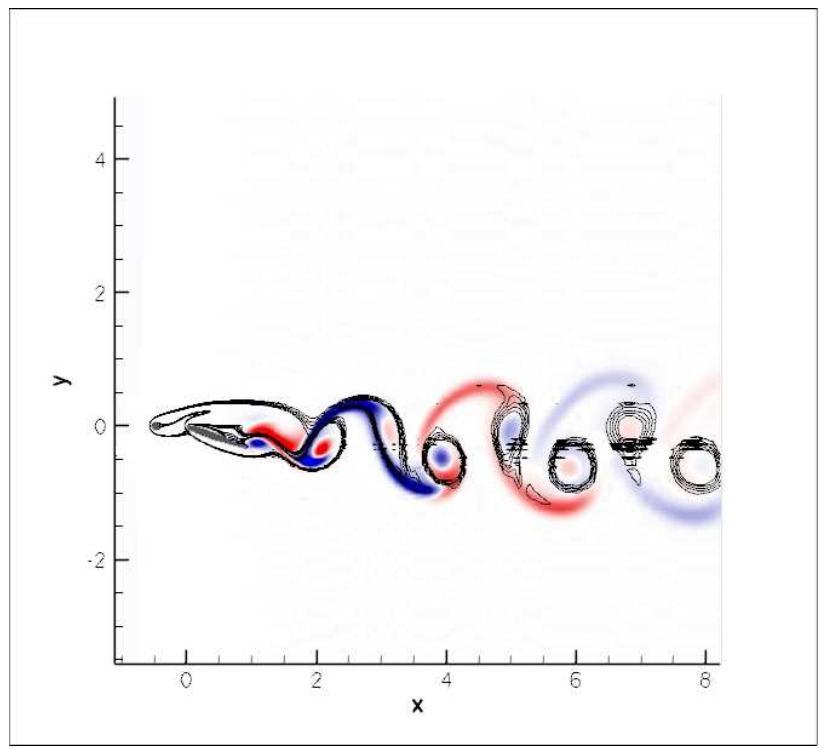

Figura 5.51: Contornos de x-vorticidade em cores do modo de Floquet sobrepostos as linhas de vorticidade em $z$ constante do campo base. NACA $0012 \mathrm{com}$ cilindro, $\alpha=20^{\circ}, \beta=3$

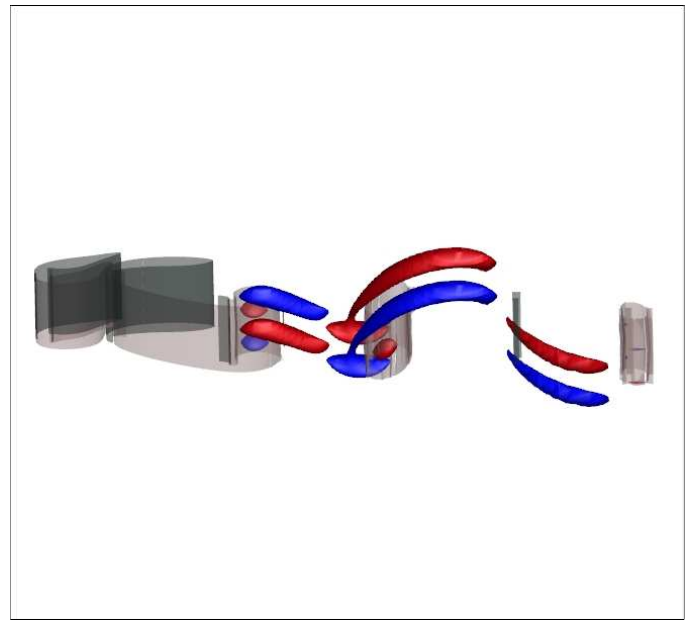

Figura 5.52: Escoamento remontado a partir do campo base bidimensional e das perturbações tridimensionais. As iso-superfícies translúcidas são de $\omega_{z}$ do campo base. As iso-superfícies sólidas azuis e vermelhas representam valores de $\omega_{x}$ negativos e positivos do modo de Floquet. $\operatorname{Re}=460, \alpha=20^{\circ}, \beta=11$ 



\section{Capítulo 6}

\section{Conclusões}

Em seções anteriores foram expostos os resultados do escoamento ao redor de um fólio isolado e um fólio em interferência com um cilindro. Tentouse entender as características físicas das forças aerodinâmicas apresentadas nos sistemas, além de uma análise de estabilidade usando a teoria linear de Floquet. A seguir serão expostos os resultados mais importantes encontrados para cada um dos regimes estudados.

\section{Caso aerofólio isolado}

Para um ângulo de ataque de zero grau o escoamento permanece colado sobre toda a superfície do aerofólio, deixando suavemente a superfície superior e inferior do bordo de fuga segundo a condição de Kutta. A partir dos resultados das forças aerodinâmicas, percebe-se que a sustentação do sistema é nula em qualquer instante de tempo, concordando com os resultados da teoria de aerofólios, que prediz uma sustentação nula para corpos esbeltos 
simétricos tais como o NACA 0012 sem ângulo de ataque.

Ao contrário do caso do aerofólio inclinado a zero grau, o fluxo ao redor de um fólio inclinado a dez graus apresenta uma assimetria entre o escoamento que circula ao redor da parte superior e inferior do corpo, produzindo-se uma sustentação total não nula. Para todos os regimes estudados o escoamento se comporta como regime permanente.

Em relação ao comportamento das forças aerodinâmicas apresentadas no fólio inclinado a dez graus, observa-se que o coeficiente de arrasto tem uma tendência a decrescer com o aumento do Reynolds. Para entender melhor este fenômeno, separou-se o $C_{d}$ nas suas duas componentes, uma devida a efeitos viscosos e a outra devida aos efeitos de pressão. Notou-se que estas grandezas diminuem quando o Reynolds aumenta, combinando-se para gerar uma queda no valor do coeficiente de arrasto total. Este comportamento é razoável nas condições estudadas, dado que os efeitos viscosos são menos representativos a Reynolds mais elevados. Esta diminuição no arrasto pode estar relacionada com a mudança da bolha de separação apresentada no extradorso do aerofólio próximo ao bordo de fuga.

Por outro lado, uma análise detalhada das linhas de corrente sobre a superfície do fólio inclinado a dez graus mostra que acontece descolamento da camada limite, tendo como conseqüência uma queda no valor da sustentação total em relação ao Reynolds. Adicionalmente, encontrou-se que o tamanho da região de separação na parte superior do fólio cresce com o aumento de Re, o qual gera uma zona cuja pressão cai enquanto o Reynolds é acrescentado. O aumento da pressão no extradorso do aerofólio é finalmente responsável da queda na sustentação, já que a distribuição de pressão no intradorso do 
aerofólio é praticamente idêntica em todos os casos estudados.

Já para as simulações do NACA inclinado a vinte graus, pode-se observar que nos regimes estudados há desprendimento massivo de vórtices e uma esteira periódica no tempo.

A partir do comportamento do coeficiente de sustentação deste sistema, pode-se observar que o máximo valor médio da sustentação se apresenta no caso em que o NACA 0012 está em um escoamento cujo Reynolds é Re $=600$. Este comportamento é comprovado pela distribuição de pressão na superfície do corpo. A partir de tal distribuição, nota-se que a maior área encerrada pelas curvas se apresenta quando $\operatorname{Re}=600$ e a menor quando $\operatorname{Re}=400$, gerando-se um aumento na sustentação na medida em que o Reynolds aumenta. Para justificar o fato da sustentação aumentar em relação ao Reynolds quando o sistema se encontra em estol, se analisaram os contornos de vorticidade e linhas de corrente ao redor do fólio. Observa-se que a região de formação de esteira está cada vez mais a montante do bordo de fuga na medida em que o Re aumenta. Esta proximidade da esteira somada com o fato de ter desprendimento de vórtices, faz com que a sustentação total no aerofólio aumente apesar da camada limite estar completamente descolada. Ressalta-se também que, devido ao estol e ao aparecimento de uma bolha de recirculação na parte superior do fólio quando o corpo esta inclinado a vinte graus, a distribuição de pressão na superfície do NACA 0012 não é homogênea, afastando-se daquele comportamento monotônico apresentado quando o ângulo é de dez graus.

Analisando o coeficiente de arrasto para o mesmo sistema, podemos notar que esta grandeza aumenta levemente quando o Reynolds é aumentado. Isto 
é devido à separação da camada limite apresentada em todas as simulações estudadas. Separando o coeficiente de arrasto na componente de pressão e na componente viscosa, vemos que o coeficiente de arrasto devido a efeitos de pressão aumenta com o Reynolds, enquanto o coeficiente de arrasto devido a efeitos viscosos diminui, devido à existência de uma bolha no extradorso do fólio que faz uma força viscosa na direção oposta ao escoamento, cujo tamanho se torna cada vez menor à medida que o Re aumenta. Finalmente os efeitos devidos à pressão terminam dominando no escoamento, fazendo com que o arrasto médio total aumente.

Uma visualização detalhada do escoamento ao redor do perfil inclinado a vinte graus, mostra que quanto maior o valor de Re mais próximo do bordo de fuga o primeiro vórtice é formado, fazendo com que o Strouhal da esteira gerada pelo aerofólio aumente. Este tipo de comportamento foi encontrado também por Carmo ${ }^{12}$ no escoamento ao redor de um cilindro.

Dado que o sistema formado pelo fólio a vinte graus apresenta uma esteira periódica no tempo, foi feito a análise de estabilidade de Floquet. Com este fim, foram obtidas as curvas de variação do módulo do multiplicador de Floquet em relação ao número de onda em $z$ da perturbação, para diferentes números Reynolds. Fica claro que o sistema é estável ante perturbações tridimensionais infinitesimais na faixa $450 \leq R e<454$ (o módulo do multiplicador é menor que 1 para todos os números de onda).

Um estudo da curva de estabilidade neutra do sistema mostra que dois diferentes modos instáveis se apresentam na faixa de Reynolds estudada. A bifurcação do primeiro modo instável (o modo de número de onda mais alto) ocorre a $\mathrm{Re}=454$. O comprimento de onda de máxima taxa de cresci- 
mento para este modo é ao redor de $\lambda / c=0.57$. Uma análise do escoamento remontado a partir do campo base bidimensional e das perturbações tridimensionais, mostra que as tridimensionalidades são mais fortes nas regiões que interligam os vórtices que nos núcleos deles. Também pode-se notar que o modo tridimensional de maior número de onda tem período $2 T$, conseqüência do multiplicador de Floquet ser um real negativo, sendo, portanto, um modo subharmônico. Tal modo se assemelha ao modo $C$ que acontece geralmente em esteiras não simétricas.

Um segundo modo instável surge para $\operatorname{Re}=582$, com comprimento de onda de máximo crescimento de $\lambda / c=2.1$. Este modo apresenta multiplicadores de Floquet complexos, sendo, portanto, um modo quase-periódico. Este fato faz com que as componentes tridimensionais do escoamento tenham um período de desprendimento diferente do período de desprendimento do campo base. Conclui-se que o aerofólio NACA 0012 inclinado a vinte graus se comporta como um corpo rombudo assimétrico, pois os modos que surgem ao redor deste corpo (modo subharmônico e quase-periódico), diferem das características espaço temporais apresentadas pelos modos A e B de instabilidade encontrados no escoamento ao redor de cilindros circulares, mas são parecidos aos modos que acontecem no escoamento ao redor de cilindros com seção transversal quadrada e com ângulo de ataque diferente de zero e outras geometrias não simétricas. 


\section{Caso aerofólio em interferência com cilindro}

Assim como no caso do aerofólio isolado, as linhas de corrente ao redor do fólio a zero grau alinhado com o cilindro, deixam suavemente a superfície do perfil sem presença de desprendimento de vórtices. Observou-se a formação de um par de vórtices simétricos na região intersticial antes do bordo de ataque, o que faz com que o regime de interferência se assemelhe ao regime $C$ que acontece no escoamento ao redor de pares de cilindros alinhados, então o cilindro se comporta como um corpo rombudo nessa disposição geométrica, onde seu diâmetro é da mesma ordem de magnitude da espessura do aerofólio.

Dos resultados das forças aerodinâmicas para este sistema, pode-se observar que a sustentação total sobre o aerofólio é praticamente nula. Isso acontece porque apesar do aerofólio estar com interferência, as linhas de corrente que circundam a superfície superior e inferior do NACA 0012 exibem uma simetria que faz com que o corpo não apresente sustentação. Essa simetria é só possível no caso em que o fólio tem ângulo de ataque nulo.

Analisando os valores das componentes do coeficiente de arrasto médio viscoso e de pressão para o cilindro e aerofólio, observa-se que estas duas quantidades decaem com o Reynolds, de maneira que o arrasto médio total nos dois corpos diminui com este parâmetro, dado que o valor do $C_{d}$ total é dado pela soma da componente de pressão na direção do escoamento $\left(C_{d p}\right)$ e pelo valor das tensões de cisalhamento $\left(C_{d v}\right)$.

O caso do aerofólio inclinado a dez graus em interferência oferece um cenário bastante diferente, já que o regime de desprendimento de vórtices muda significativamente na faixa de Reynolds estudada. Para Re $=400$ 
a esteira ainda não passou pela transição primária, pois as duas camadas cisalhantes de vorticidade oposta não se misturaram nem variam no tempo. Para $\operatorname{Re}=500$ e $\operatorname{Re}=600$ há oscilação na esteira, mas no caso $\operatorname{Re}=500 \mathrm{a}$ desestabilização acontece mais afastada do aerofólio.

Para uma distância de três diâmetros entre o cilindro e o aerofólio, não há desprendimento de vórtices na região entre os corpos, mas se apresenta uma região de concentrada vorticidade no bordo de ataque do aerofólio. Este fenômeno faz com que a pressão dinâmica do escoamento que atinge o fólio seja menor em relação às condições de fluxo livre, gerando uma queda no valor da sustentação para todos os casos de interferência comparados com as simulações feitas para o aerofólio isolado.

Analisando as forças de arrasto para o aerofólio a dez graus em interferência, vemos que o arrasto médio total diminui com o Reynols, o qual permite inferir que seu comportamento é determinado principalmente pela variação do coeficiente de arrasto viscoso. Pois enquanto o $C_{d v}$ tem um comportamento decrescente com Re, $C_{d p}$ tem um salto em $\mathrm{Re}=600$. Adicionalmente observou-se uma diminuição na pressão com o aumento do Re na região entre o cilindro e o aerofólio. Este efeito é causado porque se aumenta a vorticidade das camadas cisalhantes, intensificando a recirculação do fluido apresentada no sistema.

Nos regimes $\operatorname{Re}=500$ e $\operatorname{Re}=600$ do mesmo sistema (cilindro com fólio a dez graus) há oscilação na esteira, mas no caso $R e=500$ a desestabilização acontece mais afastada do aerofólio gerando uma sustentação menor em relação ao caso $R e=600$, já que a flutuação da esteira é menos sentida no aerofólio. Uma inspeção do comportamento da distribuição de pressão na su- 
perfície do fólio revela que para $\operatorname{Re}=400$ e $\operatorname{Re}=600$, a pressão debaixo e em cima do aerofólio são quase iguais, por tal motivo $\left.C_{l}\right|_{R e}=400$ e $\left.C_{l}\right|_{R e}=600$ tem quase o mesmo valor.

Nos regimes estudados o Strouhal do cilindro aumenta com o Reynolds, tal como no caso de dois corpos rombudos em interferência. Como o Strouhal do cilindro está acoplado com o Strouhal do aerofólio, a freqüência de desprendimento de vórtices da esteira do fólio termina apresentando um comportamento crescente com o Re.

Da análise de estabilidade de Floquet para o cilindro em interferência com o fólio a dez graus, se conclui que não há modos instáveis na faixa de Reynolds estudada.

Para todos os regimes estudados no caso de um aerofólio inclinado a vinte graus alinhado com o cilindro, observa-se desprendimento massivo da camada limite. Dos resultados obtidos para as forças aerodinâmicas deste sistema, vê-se que o $C_{d}$ do aerofólio cresce com o número de Reynolds enquanto o $C_{d}$ do cilindro decresce. Para entender melhor estas tendências, usou-se a mesma filosofia de separar o arrasto total numa componente devida à pressão $\left(C_{d p}\right)$ e outra devida a efeitos viscosos $\left(C_{d v}\right)$. No caso do cilindro, $C_{d v}$ e $C_{d p}$ decrescem com o aumento do número de Reynolds, portanto estas duas grandezas combinadas provocam uma queda no valor do arrasto total. Por outro lado o caso do aerofólio foi diferente, pois enquanto o $C_{d v}$ decresce com o Reynolds o $C_{d p}$ cresce com este parâmetro, permitindo inferir que os efeitos de pressão dominam sobre os efeitos viscosos desencadeando um acréscimo no valor médio total de arrasto. Este acréscimo no arrasto é consistente com o fato de se apresentar separação da camada limite e escoamento reverso. 
A separação da camada limite é a causa do fenômeno de estol apresentado nos regimes $\operatorname{Re}=400, \operatorname{Re}=500, \operatorname{Re}=600$, além do acréscimo no arrasto nas três simulações. Nestas condições o aerofólio se comporta praticamente como um corpo rombudo.

Da distribuição de pressão na superfície do perfil, podemos observar que a diferença de pressão entre o lado superior e inferior do fólio aumenta com o Reynolds, gerando-se um aumento na sustentação em relação ao Reynolds. Este fenômeno pode ser justificado pelo fato da esteira ficar mais próxima ao bordo de fuga quando o Reynolds é aumentado. Dado que o número de Strouhal aumenta com o Reynolds, as camadas cisalhantes se mexem de maneira mais vigorosa, afetando a maneira na qual a pressão se distribui na superfície do aerofólio.

Na configuração de interferência entre um cilindro e um fólio inclinado a vinte graus, o número de Strouhal aumenta em relação ao número de Reynolds. Semelhante ao caso do NACA 0012 com ângulo de ataque de dez graus, o desprendimento de vórtices nos dois corpos está acoplado, fazendo com que o Strouhal do sistema aumente dado que o Strouhal do cilindro cresce com o Reynolds.

Observando os resultados da análise de estabilidade, nota-se que para $\operatorname{Re}=400$ o escoamento é estável, para $R e \approx 418$ se dá inicio às instabilidades secundárias e fica instável a Reynolds mais elevados.

Somente um modo acontece na faixa de Reynolds estudada, e o número de onda adimensional de máximo crescimento para este modo tem multiplicador de Floquet real e negativo, exibindo as mesmas características de simetria temporal do modo subharmônico apresentado no caso do aerofólio 
isolado com ângulo de ataque de vinte graus. De maneira similar ao modo subharmônico do aerofólio isolado, as estruturas tridimensionais não são mais fortes nos núcleos dos vórtices, mas sim nas regiões que os interligam.

Da análise de estabilidade neutra pode-se observar que o início da instabilidade secundária deve acontecer para um regime $R e<450$ então o cilindro no caso de interferência adianta o início da instabilidade para o modo subharmônico do aerofólio, enquanto estabiliza o sistema em relação ao modo quaseperiódico, pois as curvas de Floquet mostraram somente um modo instável. 


\section{Apêndice A}

\section{Descrição do Método de}

\section{Elementos Finitos Espectrais}

O método de elementos finitos espectrais (SEM) provém da combinação entre o método de elementos finitos com a precisão das técnicas espectrais. Do método espectral, o SEM herda a alta ordem das funções de aproximação, o qual garante alta resolução e convergência exponencial, enquanto que do método de elementos finitos toma a divisão do domínio em pequenos subdomínios, o qual permite o estudo de geometrias complexas e o refinamento das áreas de interesse. A convergência do método depende da refinação da malha (refinamento $h$ ) e do grau do polinômio usado como base da expansão (refinamento $p$ ), pelo que é denominado método $h p$.

No SEM as bases utilizadas na discretização são definidas em termos dos polinômios de Legendre, além do uso de eficientes quadraturas Gaussianas associadas com operações de integração. As bases empregadas no método são $C^{\circ}$ continuas permitindo fazer um ensamble global da solução em cada 
subdomínio. Adicionalmente, o conceito de decomposição contorno-interior é utilizado, além de polinômios gerais de Jacobi que permitem acomodar quadraturas numéricas exatas.

Neste apêndice serão expostos alguns dos fundamentos matemáticos mais importantes, nos quais esta baseado o método SEM. Todos os conceitos apresentados são baseados no trabalho de Karniadakis e Sherwin ${ }^{11}$.

\section{Método dos pesos residuais}

Nos métodos de aproximação numérica se substitui uma expansão infinita por uma representação finita. Isso implica que a equação diferencial não pode ser satisfeita em todo o domínio, de modo que só se podem cumprir um número finito de condições. Estas condições definem o método numérico. Por exemplo, no método de colocação, a equação diferencial é satisfeita epenas num conjunto finito de pontos em vez do domínio completo.

O método de pesos residuais ilustra como a eleição de um conjunto de funções de pesos na versão integral da equação diferencial, podem ser usados para construir diferentes métodos numéricos.

Para descrever o método de pesos residuais consideramos uma equação diferencial linear num domínio $\Omega$ denotada por $L(u)=0$, em que $L$ é um operador. Propõe-se uma solução aproximada da forma

$$
u^{\delta}(\mathbf{x}, t)=u_{0}(\mathbf{x}, t)+\sum_{i=1}^{N_{\text {dof }}} \hat{u}_{i}(t) \Phi_{i}(\mathbf{x})
$$

Onde $\Phi_{i}(\mathbf{x})$ são funções de expansão, $\hat{u}_{i}(t)$ e $N_{d o f}$ são coeficientes indeterminados e $u_{0}(\mathbf{x}, t)$ cumpre com as condições iniciais e de fronteira de maneira 
que a função $\Phi_{i}(\mathbf{x})$ satisfaz as condições de Dirichlet.

Substituindo $u^{\delta}(\mathbf{x}, t)$ na equação diferencial obtém-se $L\left(u^{\delta}\right)=R\left(u^{\delta}\right)$, onde $R$ é o residual. Os coeficientes $\hat{u}_{i}(t)$ e $N_{\text {dof }}$ podem ser determinados através da restrição $\left(v_{j}(\mathbf{x}), R\right)=0, j=1,2, \ldots . . N_{d o f}$. Com o produto interno de Legendre $(f, g)=\int_{\Omega} f(\mathbf{x}) g(\mathbf{x}) \mathbf{d x}$. As funções $v_{j}(R)$ denominam-se de peso. Como $\left(v_{j}(\mathbf{x}), R\right)=0$ então $R \rightarrow 0$ cumprindo-se a equação diferencial $L\left(u^{\delta}\right)=R\left(u^{\delta}\right)=0$.

Existem diversas funções de peso e de expansão que definem a natureza do método numérico. Por exemplo, pode-se supor que as funções de peso são as mesmas bases com as quais se faz a expansão, ou seja, $v_{j}(\mathbf{x})=\Phi_{j}$. Este método tem por nome Budov-Galerkin e será o método empregue neste trabalho.

\section{Expansão Unidimensional}

Nesta seção se descreverá a formulação de Galerkin unidimensional com uma solução de elementos finitos. A Figura A.1 mostra a expansão em modos sobre três domínios elementares, onde se pode perceber que o tamanho de cada domínio elementar não é necessariamente o mesmo. Adicionalmente, cada modo tem valor unitário ou nulo nos extremos de cada domínio elementar. A partir da Figura A.1 fica claro que, em cada domínio elementar, os modos consistem de duas funções $\varphi_{0}, \varphi_{1}$, podendo ser definir um elemento unidimensional local $\Omega_{s t}$ tal que $\Omega_{s t}=\{\xi \mid-1 \leq \xi \leq 1\}$. 
De acordo à forma de $\varphi_{0}$ e $\varphi_{1}$ temos que

$$
\varphi_{0}(\xi)=\left\{\begin{array}{cc}
\frac{1-\xi}{2}, & \xi \in \Omega_{s t} \\
0, & \xi \notin \Omega_{s t}
\end{array}\right\}, \varphi_{1}(\xi)=\left\{\begin{array}{cc}
\frac{1+\xi}{2}, & \xi \in \Omega_{s t} \\
0, & \xi \notin \Omega_{s t}
\end{array}\right\}
$$

O elemento standard $\Omega_{s t}$ pode-se mapear para qualquer domínio $\Omega^{e}$ por meio da transformação

$$
\chi=\chi^{e}(\xi)=\frac{1-\xi}{2} x_{e-1}+\frac{1+\xi}{2} x_{e}, \xi \in \Omega_{s t}
$$

A qual expressa as variáveis globais $x$ em termos das funções locais $\xi$.

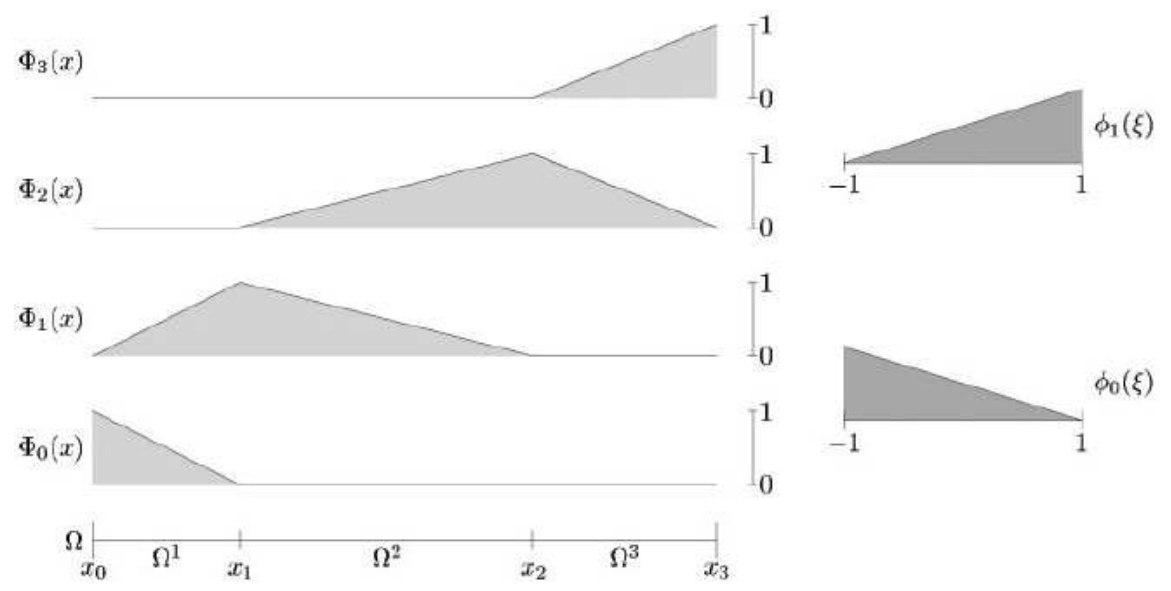

Figura A.1: Divisão do domínio solução $\Omega$ em três elementos $\Omega^{1}, \Omega^{2}, \Omega^{3}$. Se mostram também os modos globais $\Phi_{0}(x), \Phi_{1}(x), \Phi_{2}(x), \Phi_{3}(x)$ e as bases locais $\varphi_{0}(\xi)$, $\varphi_{0}(\xi)$. Extraído de Karniadakis e Sherwin ${ }^{11}$

\section{Ensamble Global}

Para relacionar expansões locais e globais precisamos introduzir o conceito de expansão global. Nesta seção mostrar-se-à o método com uma base 
unidimensional linear. Contudo, a mesma idéia pode ser empregue em expansões de ordem maior em múltiplas dimensões.

A aproximação de elementos finitos $u^{\delta}$ em termos dos modos globais é dada por

$$
u^{\delta}=\sum_{i=1}^{N_{\text {dof }}} \hat{u}_{i}(t) \Phi_{i}(\mathbf{x})
$$

De modo similar a função $u^{\delta}$ pode ser expandida nas bases locais $\varphi_{p}(\xi)$ a partir de

$$
u^{\delta}(x)=\sum_{e=1}^{N_{\text {dom }}} \sum_{p=0}^{P} u_{p}^{e} \varphi_{P}^{e}
$$

Na expressão anterior para $u^{\delta}$ aparece um novo conjunto de coeficientes $u_{p}^{e}$ que tem mais elementos que os coeficientes originais $\hat{u}_{i}(t)$. Para acoplar estes coeficientes são usadas as condições de contorno, já que os modos globais são de classe $C^{\circ}$ continua no domínio completo. No caso ilustrado na Figura A.2 vê-se que, por exemplo, $\hat{u}_{1}^{1}=\hat{u}_{0}^{2}=\hat{u}_{1}, \hat{u}_{1}^{2}=\hat{u}_{0}^{3}=\hat{u}_{2}, \hat{u}_{0}^{1}=\hat{u}_{0}, \hat{u}_{1}^{3}=\hat{u}_{3}$.

Quando organizarmos os coeficientes do vetor de coeficientes globais como $\hat{u}_{g}=\left[\hat{u}_{0}, \ldots \hat{u}_{N}\right]^{T}$ e os coeficientes $\hat{u}_{l}$ (coeficientes locais) como $\hat{u}_{l}=\left[\hat{u}^{0}, \ldots \hat{u}^{N}\right]^{T}$ podemos relacioná-los da forma $\hat{u}_{l}=[A] \hat{u}_{g}$. Onde $\hat{u}^{e}=\left(\hat{u}_{0}^{e}, \hat{u}_{1}^{e}\right)$ e $[A]$ é a matriz de ensamble global. A matriz de ensamble global representa uma das operações mais importantes na construção do método de Galerkin espectral $h p$, pois permite definir uma série de expansões locais que posteriormente podem ser ensambladas para obter uma descrição global. 


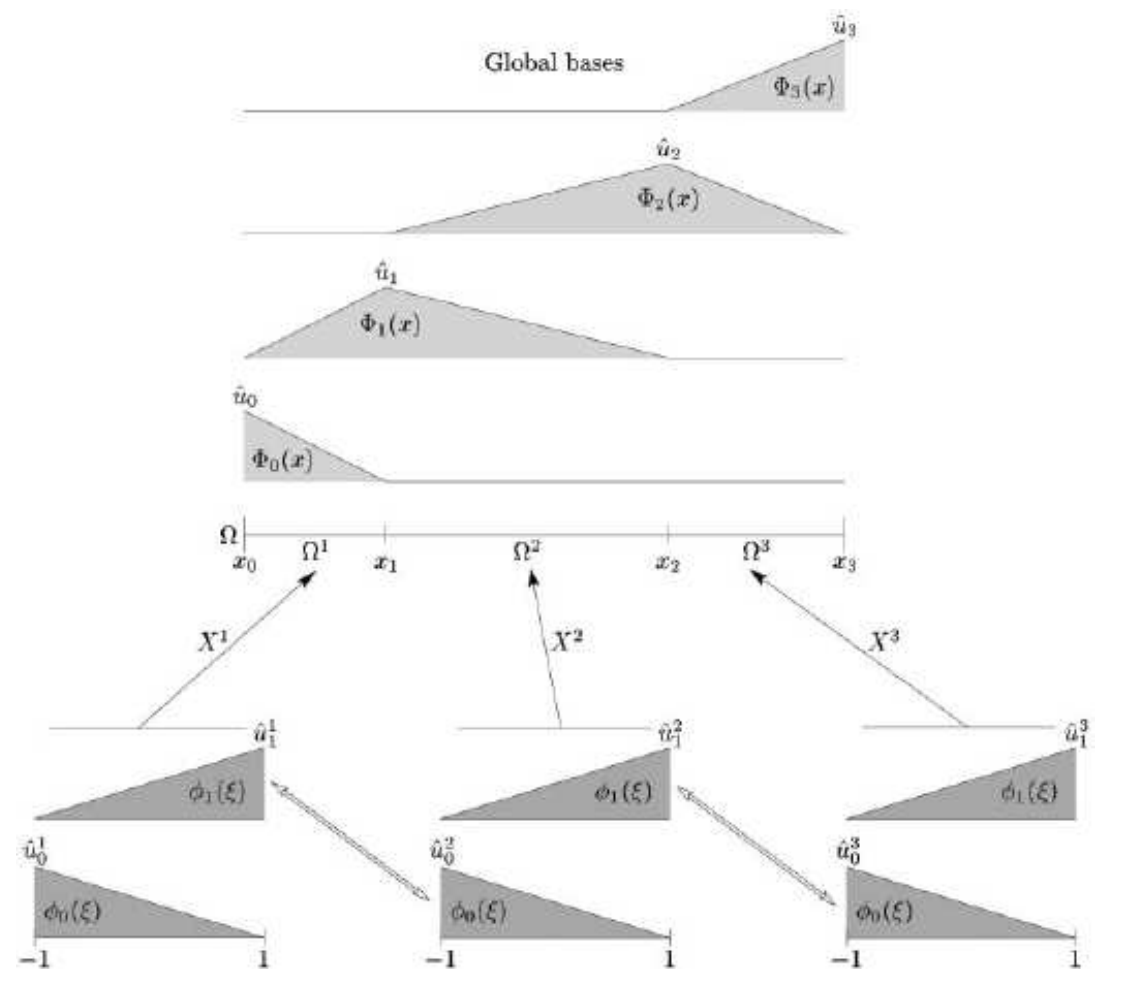

Figura A.2: Coeficientes de expansão locais e globais em três domínios elementares. Extraído de Karniadakis e Sherwin ${ }^{11}$

\section{Expansões modais e nodais}

Antes de discutir os benefícios dos diferentes tipos de expansões polinomiais, se introduzir-se-à o conceito de bases modais e nodais. Para tal definem-se os seguintes conjuntos de expansão:

$$
\begin{aligned}
\Phi_{p}^{A}(x) & =x^{p}, p=0,1, \ldots ., P \\
\Phi_{p}^{B}(x) & =\frac{\prod_{q=0, q \neq p}^{P}\left(x-x_{q}\right)}{\prod_{q=0, q \neq p}^{P}\left(x_{p}-x_{q}\right)}, p=0,1, \ldots ., P \\
\Phi_{p}^{C}(x) & =L_{p}(x), p=0,1, \ldots ., P
\end{aligned}
$$


A primeira base incrementa $x$ de uma forma monomial e é denominada como expansão modal. A segunda base polinomial é de Lagrange, baseada numa série de $P+1$ pontos nodais $x_{q}$, previamente definidos. Os po-

linômios de Lagrange têm a propriedade $\Phi_{p}^{B}\left(x_{q}\right)=\delta_{p q}$, o que implica que $u^{\delta}\left(x_{q}\right)=\sum_{p=0}^{P} \hat{u}_{p} \Phi_{p}^{B}\left(x_{q}\right)=\sum_{p=0}^{P} \hat{u}_{p} \delta_{p q}=\hat{u}_{q}$, ou seja, os coeficientes de expansão $\hat{u}_{p}$ podem ser determinados a partir das soluções nos pontos nodais $x_{q}$. Os elementos finitos lineares são um exemplo de expansões nodais onde os pontos nodais estão nos extremos do domínio. Nesses pontos nodais a solução aproximada não satisfaz necessariamente com exatidão a equação diferencial. A terceira expansão, denominada de Legendre, é também modal e é por definição ortogonal com o produto interno de Legendre, o qual tem interessantes implicações no método de Galerkin. Explicitamente a ortogonalidade é dada por

$$
\left(L_{p}(x), L_{q}(x)\right)=\int_{-1}^{1} L_{p}(x), L_{q}(x) d x=\frac{2}{2 p+1} \delta_{p q}
$$

\section{Eleição dos Conjuntos de Expansão}

A eleição de um bom conjunto usado como base de expansão depende fundamentalmente de três parâmetros: Eficiência numérica, condicionamento, e independência linear das bases.

A projeção de Galerkin $L^{2}$ de uma função suave $f(x)$ no domínio $\Omega_{s t}$ sobre a expansão polinomial $u^{\delta}(x)$ resulta da solução do problema

$$
\left(v^{\delta}, u^{\delta}\right)=\left(v^{\delta}, f\right)
$$


Com o produto interno de Legendre. Este problema pode ser expresso de forma equivalente a partir do sistema matricial

$$
\hat{\mathbf{v}}^{T}[\mathbf{M} \hat{\mathbf{u}}=\mathbf{f}] \rightarrow \mathbf{M} \hat{\mathbf{u}}=\mathbf{f}
$$

Onde $[\mathbf{M}]$ é definida como matriz de massa.

A eficiência numérica de uma base depende da construção e inversão da matriz de massa $[\mathbf{M}]$ definida por $M_{p q}=\left(\Phi_{p}, \Phi_{q}\right)$ com o produto interno de Legendre. O condicionamento da matriz de massa está relacionado com a independência linear da expansão, definido pelo número $\kappa=\|M\| \cdot\|M\|^{-1}$. Este parâmetro é muito importante para a inversão da matriz de massa.

\section{Decomposição em Fronteiras}

As funções base são escolhidas como $C^{\circ}$ continuas, ou seja, são continuas nas fronteiras entre domínios elementares. A condição que permite acoplar todos os graus de liberdade de um elemento com os modos do elemento ad-

jacente pode-se expressar como $\sum_{p=0}^{P} u_{p}^{e} \phi_{p}^{e}(1)=\sum_{p=0}^{P} u_{p}^{e+1} \phi_{p}^{e+1}(-1)$. Esta condição tem uma dificuldade inerente já que destrói a estrutura da matriz de massa global (Karniadakis ${ }^{11}$ 1999). Por isso motivo construi-se uma expansão local diferente que permite garantir continuidade $C^{\circ}$ fazendo com que alguns dos modos (não todos) se acoplem nas fronteiras. Para tal define-se uma expansão elementar $\varphi_{p}(\xi)$ na região $-1 \leq \xi \leq 1$ onde

$$
\varphi_{p}(-1)=\left\{\begin{array}{cc}
1, & p=0 \\
0, & p \neq 0
\end{array}\right\}, \varphi_{p}(1)=\left\{\begin{array}{ll}
1, & p=P \\
0, & p \neq P
\end{array}\right\}
$$


Então a continuidade $C^{\circ}$ é conseguida se $\hat{u}_{P}^{e} \varphi_{P}^{e}(1)=\hat{u}_{0}^{e+1} \varphi_{0}^{e+1}(-1)$. Este método é denominado decomposição de fronteiras ou decomposição interior. Os modos de fronteira têm magnitude unitária nos extremos do elemento local e são nulos em outras fronteiras. Os modos interiores (algumas vezes denominados modos borbulha) têm magnitude não nula no interior do elemento.

Para decompor uma base nodal em modos interiores e de fronteira só precisamos assegurar que os pontos nodais se encontram ao longo da fronteira do elemento (no caso unidimensional seriam os extremos do elemento)

\section{Bases Modais Tipo P}

No intervalo $\Omega_{s t}=\{\xi \mid-1 \leq \xi \leq 1\}$ denota-se por $\psi_{p}(\xi)$ a expansão modal tipo $\mathrm{P}$

$$
\varphi_{p}(\xi) \rightarrow \psi_{p}(\xi)=\left\{\begin{array}{cl}
\frac{1-\xi}{2}, & p=0 \\
\left(\frac{1-\xi}{2}\right)\left(\frac{1+\xi}{2}\right) P_{p-1}^{1,1}(\xi), & 0<p<P \\
\frac{1+\xi}{2}, & p=P
\end{array}\right\}
$$

Com $P_{p-1}^{1,1}$ o polinômio de Jacobi. A forma dos modos de expansão é mostrada na Figura A.3. Pode-se observar que os modos de fronteira $\psi_{0}, \psi_{P}$ têm valor unitário nos extremos do domínio, enquanto os modos interiores são nulos nos extremos. O uso dos polinômios de Jacobi na construção das bases modais tipo $\mathrm{P}$ permite manter um alto grau de ortogonalidade, gerando uma matriz de massa local pentagonal. 

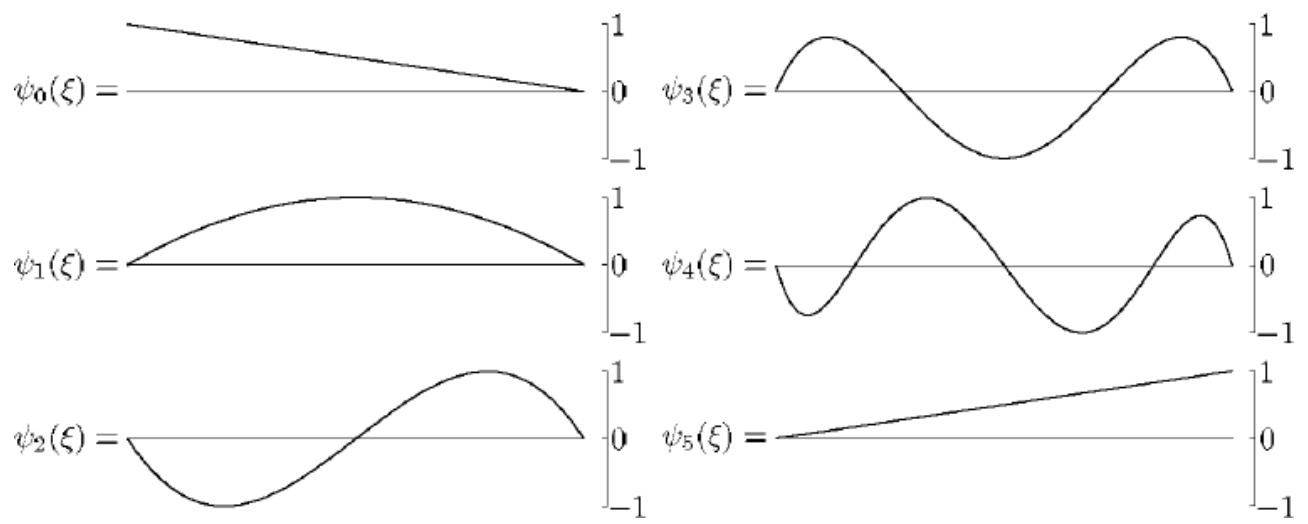

Figura A.3: Expansão modal para um polinômio de grau 5. Extraído de Karniadakis e Sherwin ${ }^{11}$

\section{Expansões polinomiais nodais}

Como já foi discutido, as expansões nodais estão baseadas nos polinômios de Lagrange associados a um conjunto de pontos nodais. Os pontos nodais devem incluir os extremos do domínio elementar para permitir a decomposição de fronteiras. À parte desta restrição, há uma completa liberdade na escolha da posição dos modos interiores, no entanto a eleição destes pontos é muito importante pois a estabilidade do sistema depende do conjunto de pontos escolhido. Uma solução estável é conseguida usando-se os pontos nodais nos zeros da regra de integração de Gauss-Lobatto-Legendre.

\section{Polinômios de Lagrange}

Dado um conjunto de $P+1$ pontos nodais denotados por $x_{q}(0 \leq q \leq P)$, os polinômios de Lagrange $h_{p}(x)$ têm a propriedade $h_{p}\left(x_{p}\right)=1, h_{p}\left(x_{q}\right)=$ $0,(q \neq p)$, ou seja, $h_{p}\left(x_{q}\right)=\delta_{p q}$. Formalmente os polinômios apresentam a 
forma

$$
h_{p}(x)=\frac{\prod_{q=0, q \neq P}^{P}\left(x-x_{q}\right)}{\prod_{q=0, q \neq P}^{P}\left(x_{p}-x_{q}\right)}
$$

Mas podem ser definidos de forma equivalente como

$$
h_{p}(x)=\frac{g(x)}{g^{\prime}\left(x_{p}\right)\left(x-x_{p}\right)}
$$

Neste caso $g(x)$ é um polinômio de ordem $P+1$ com zeros nos nodos $x_{q}$. O fato dos polinômios de Lagrange terem implícito a função $\delta$ faz com que eles sejam muito úteis como polinômios interpoladores, pois cumprem $L u(x)=$ $\sum_{p=0}^{P} \hat{u}_{p} h_{p}(x), L u\left(x_{q}\right)=u\left(x_{q}\right), L u\left(x_{q}\right)=\hat{u}_{p} \rightarrow u\left(x_{q}\right)=\hat{u}_{p}$.

\section{Elementos Espectrais}

A classe de elementos nodais do tipo $\mathrm{P}$ foi definida como elementos espectrais por Patera. Este método utiliza polinômios de Lagrange com zeros nos polinômios de Gauss- Lobatto, usando $P+1$ pontos nodais nas raízes do polinômio $g(\xi)=(1-\xi)(1+\xi) L_{p}^{\prime}(\xi)$, o qual permite obter soluções estáveis já que foi inspirado na solução de um problema de estabilidade eletrostática. Usando a função $g(\xi)$ e considerando que $g^{\prime}(\xi)=-P(P+1) L_{p}(\xi)$ e $h_{p}(\xi)=g(\xi) /\left(g^{\prime}\left(\xi_{p}\right)\left(\xi-\xi_{p}\right)\right)$ então podemos substituir na equação A.9 para obter

$$
\varphi_{p}(\xi) \rightarrow h_{p}(\xi)=\left\{\begin{array}{cl}
1, & \xi=\xi_{p} \\
\frac{(\xi-1)(\xi+1) L_{p}^{\prime}(\xi)}{P(P+1) L_{p}\left(\xi_{p}\right)\left(\xi_{p}-\xi\right)}, & \text { outro } \xi
\end{array}\right\}
$$

A derivada dos polinômios $L_{p}^{\prime}(\xi)$ pode ser relacionada com os polinômios de Jacobi $P_{p-1}^{1,1}$, de maneira que o método de elementos finitos espectrais 
utilize polinômios de Lagrange com nodos nas raízes do polinômio $g(\xi)=$ $(1-\xi)(1+\xi) P_{p-1}^{1,1}(\xi)$. A forma destes polinômios até $P=5$ é mostrada na Figura A.4. Pode-se perceber que os modos cumprem com a condição de $C^{\circ}$ continuidade onde os modos interiores são nulos na fronteira.

Os elementos da matriz de massa podem ser avaliados usando a regra de quadratura de Gauss

$$
M^{e}[p][q]=\left(h_{p}, h_{q}\right) \approx \sum_{i=0}^{P} w_{i} h_{p}\left(\xi_{i}\right) h_{q}\left(\xi_{i}\right)=\sum_{i=0}^{P} w_{i} \delta_{p i} \delta_{q i}=w_{p} \delta_{p q}
$$

onde $w_{p}$ são pesos que podem ser calculados somando as linhas da matriz de massa, pois

$$
\sum_{q=0}^{P} M^{e}[p][q]=\sum_{q=0}^{P}\left(h_{p}(\xi), h_{q}(\xi)\right)=\left(h_{p}(\xi), \sum_{q=0}^{P} h_{q}(\xi)\right)=\left(h_{q}(\xi), 1\right)
$$

A equação anterior é justamente a definição de $w_{p}$. Este procedimento tem por nome "Lumping matrix"

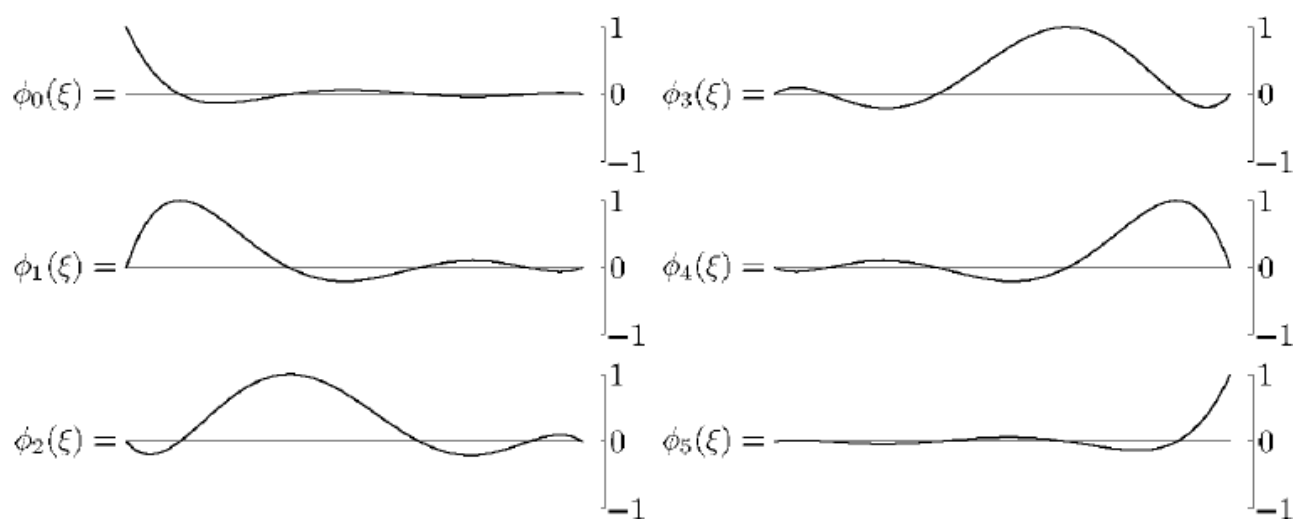

Figura A.4: Expansão nodal de modos para um polinômio de grau 5. Extraído de Karniadakis e Sherwin ${ }^{11}$ 


\section{Operações elementares}

Em seções anteriores mostrou-se como uma expansão global é decomposta em expansões dentro de subdomínios elementares que podem ser mapeados para regiões standard. As bases polinomiais são, então, definidas nessas regiões standard. Para completar a formulação de Galerkin deve-se mostrar como derivar e integrar os polinômios base nas regiões standard. Estes conceitos serão discutidos nas duas seções seguintes.

\section{Integração Numérica e Quadratura Gaussiana}

Os polinômios de Lagrange são amplamente usados como funções de interpolação. Suponhamos que uma função $u(x)$ se pode expandir como $u(x)=\sum_{p=0}^{P} u_{p} h_{p}(x)$. Agora assume-se que se conhecem certos valores $u\left(x_{i}\right)$, devido à propriedade $h_{p}\left(x_{i}\right)=\delta_{p i}$ temos que $u_{p}=u\left(x_{i}\right)$. Inspirado nesse conceito pode-se assumir que

$$
u(\xi)=\sum_{i=0}^{Q-1} u\left(\xi_{i}\right) h_{i}(\xi)+\varepsilon(u)
$$

ou seja, é possível expandir a função $u(\xi)$ numa série de potencias cuja base são os polinômios de Lagrange e cujos coeficientes dependem do valor da função em certas abscissas. $\varepsilon(u)$ representa uma função de erro. A integral da expressão anterior é

$$
\int_{-1}^{1} u(\xi) d \xi=\sum_{i=0}^{Q-1} w_{i} u\left(\xi_{i}\right)+R(u)
$$


onde $w_{i}=\int_{-1}^{1} h_{i}(\xi) d \xi$ e $R(u)=\int_{-1}^{1} \varepsilon(u) d \xi$. A função de erro é minimizada quando a função $u(\xi)$ é avaliada no i-ésimo zero do polinômio $\alpha, \beta$ da ordem $P$ de Jacobi, ou seja, quando os pontos cumprem $P_{P}^{\alpha, \beta}\left(\xi_{i}\right)=0$.

A escolha dos zeros e pesos depende do método usado. Os métodos mais usuais são: Gauss-Legendre que usa zeros no intervalo $-1<\xi_{i}<1, i=$ $0,1, \ldots Q-1$. Gauss-Radau o qual inclui um extremo que usualmente é $\xi=-1$ e Gauss-Lobatto que inclui os dois extremos $\xi= \pm 1$. Os valores de zeros e pesos podem ser encontrados em Karnaiadakis ${ }^{11}$ (1999) para cada um dos métodos mencionados.

\section{Diferenciação}

Toma-se de novo a expansão do campo $u(\xi)$ em série de potencias $u(\xi)=\sum_{i=0}^{Q-1} u\left(\xi_{i}\right) h_{j}(\xi)$, onde $h_{j}(\xi)$ é dado pela equação A.8. A derivada dessa expressão é dada por $\frac{d u(\xi)}{d \xi}=\sum_{j=0}^{Q-1} u\left(\xi_{j}\right) \frac{d h_{j}(\xi)}{d \xi}$ que avaliada em certos pontos nodais $\left.\frac{d u(\xi)}{d \xi}\right|_{\xi=\xi_{i}}$ toma a forma $\frac{d u(\xi)}{d \xi}=\sum_{j=0}^{Q-1} d_{i j} u\left(\xi_{j}\right)$ com $\left.d_{i j} \equiv \frac{d h_{j}(\xi)}{d \xi}\right|_{\xi=\xi_{i}}$. Para fazer a derivada dos polinômios de Lagrange utilizase a expressão $h_{j}(\xi)=\frac{g_{Q}(\xi)}{g_{Q}^{\prime}\left(\xi_{j}\right)\left(\xi-\xi_{j}\right)} \operatorname{com} g_{Q}(\xi)=\prod_{i=0}^{Q-1}\left(\xi-\xi_{i}\right)$, então $d_{i j}=$ $\frac{g_{Q}^{\prime}\left(\xi_{i}\right)}{g_{Q}^{\prime}\left(\xi_{j}\right)\left(\xi_{i}-\xi_{j}\right)}, \quad i \neq j$. No caso $i=j$ temos uma indeterminação podendo-se usar a regra de L'hopital, obtendo-se $d_{i j}=\frac{g_{Q}^{\prime \prime}\left(\xi_{i}\right)}{2 g_{Q}^{\prime}\left(\xi_{j}\right)}$. A derivada completa será

$$
d_{i j}=\left\{\begin{array}{c}
\frac{g_{Q}^{\prime}\left(\xi_{i}\right)}{g_{Q}^{\prime}\left(\xi_{j}\right)\left(\xi_{i}-\xi_{j}\right)}, i \neq j \\
\frac{g_{Q}^{\prime \prime}\left(\xi_{i}\right)}{2 g_{Q}^{\prime}\left(\xi_{j}\right)}, i=j
\end{array}\right\}
$$

De novo as abscissas $\xi_{i}$ e os valores matriciais $d_{i j}$ dependem dos pontos de quadratura empregados. Os valores destas quantidades estão tabelados em 
Karniadakis ${ }^{11}$ (1999) para diferentes métodos.

\section{Expansão em Bases Multidimensionais}

Nas seções anteriores foi introduzida a técnica de Galerkin para a discretização espectral $h p$ no caso unidimensional. Usando esta construção, ilustrou-se como uma expansão $C^{\circ}$ continua pode ser decomposta em expansões modais ou nodais numa região standard. Nas seções seguintes estenderse-aõ estes conceitos para sistemas bidimensionais.

As bases tensoriais empregadas serão denotadas por $\varphi_{p q}\left(\xi_{1}, \xi_{2}\right)$ (no caso bidimensional) com $\xi_{1}, \xi_{2}$ as coordenadas cartesianas standard. Esta notação refere-se a expansões modais e nodais sem ser necessário marcar uma diferença entre elas, ou seja

$$
\begin{aligned}
& \varphi_{p q}\left(\xi_{1}, \xi_{2}\right)=\psi_{p}^{a}\left(\xi_{1}\right) \psi_{q}^{a}\left(\xi_{2}\right) \\
& \varphi_{p q}\left(\xi_{1}, \xi_{2}\right)=h_{p}\left(\xi_{1}\right) h_{q}\left(\xi_{2}\right)
\end{aligned}
$$

\section{Expansões e produtos tensoriais em quadriláteros}

A extensão dos conceitos usados no caso unidimensional pode ser feito de uma forma relativamente natural para o caso bidimensional. Começaremos definindo os domínios elementares bidimensionais numa região standard $Q^{2}$ como $\Omega_{s t}=Q^{2}=\left\{-1 \leq \xi_{1}, \xi_{2} \leq 1\right\}$.

Numa seção anterior definiu-se uma variedade de expansões tipo P as quais foram referidas como $\varphi_{p}(\xi)$. Duas das bases mais usadas são: 
Base modal

$$
\varphi_{p}(\xi)=\left\{\begin{array}{cl}
\psi_{0}^{a}(\xi)=\frac{1-\xi}{2}, & p=0 \\
\psi_{p}^{a}(\xi)=\left(\frac{1-\xi}{2}\right)\left(\frac{1+\xi}{2}\right) P_{p-1}^{1,1}(\xi), & 0<p<P \\
\psi_{P}^{a}(\xi)=\frac{1+\xi}{2}, & p=P
\end{array}\right\}
$$

Base nodal

$$
\varphi_{p}(\xi)=\frac{(\xi-1)(\xi+1) L_{p}^{\prime}(\xi)}{P(P+1) L_{p}\left(\xi_{p}\right)\left(\xi_{p}-\xi\right)}, 0 \leq p \leq P
$$

As bases bidimensionais são definidas como

$$
\varphi_{p q}\left(\xi_{1}, \xi_{2}\right)=\varphi_{p}\left(\xi_{1}\right) \varphi_{q}\left(\xi_{2}\right) ; 0 \leq p, q ; p \leq P_{1} ; q \leq P_{2}
$$

Para os dois casos anteriores as expansões foram denotadas pelo índice $p$ e podem ser consideradas como um tensor unidimensional. As bases bidimensionais podem ser construídas pelo produto de dois tensores unidimensionais, cada um ao longo de um eixo coordenado (equação A.14).

A Figura A.5 mostra uma representação do produto tensorial para gerar expansões bidimensionais numa região standard em forma de quadrilátero

\section{Construção de Expansões Locais}

Consideremos a base bidimensional $\varphi_{p q}\left(\xi_{1}, \xi_{2}\right)$ como um arranjo bidimensional expandido num quadrilátero, tal como mostrado em Figura A.6. Os índices dos modos dependerão de sua posição no arranjo. Definam-se os 

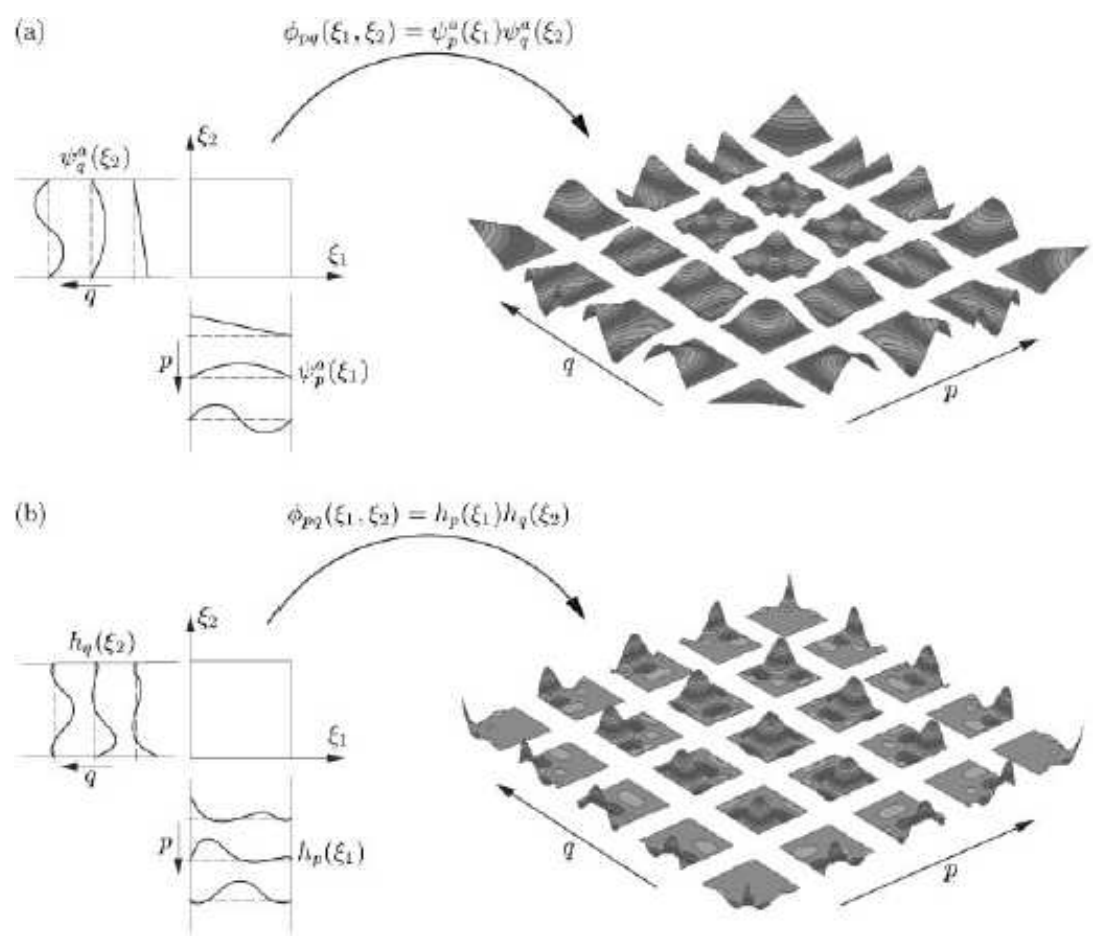

Figura A.5: Construção de uma base bidimensional a partir do produto de duas expansões unidimensionais de ordem 4. a) Expansão modal. b) Expansão nodal. Extraído de Karniadakis e Sherwin ${ }^{11}$

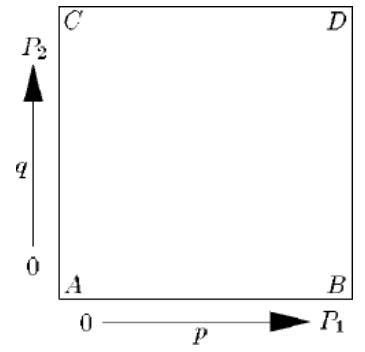

Figura A.6: Definição de arranjo de índices para uma expansão tensorial bidimensional. Extraído de Karniadakis ${ }^{11}$ (1999)

modos de vértice A,B,C,D como

$$
\begin{aligned}
& A=\varphi_{0,0}\left(\xi_{1}\right)\left(\xi_{2}\right)=\psi_{0}^{a}\left(\xi_{1}\right) \psi_{0}^{a}\left(\xi_{2}\right) \\
& B=\varphi_{P_{1}, 0}\left(\xi_{1}\right)\left(\xi_{2}\right)=\psi_{P_{1}}^{a}\left(\xi_{1}\right) \psi_{0}^{a}\left(\xi_{2}\right) \\
& C=\varphi_{0, P_{2}}\left(\xi_{1}\right)\left(\xi_{2}\right)=\psi_{0}^{a}\left(\xi_{1}\right) \psi_{P_{2}}^{a}\left(\xi_{2}\right) \\
& D=\varphi_{P_{1}, P_{2}}\left(\xi_{1}\right)\left(\xi_{2}\right)=\psi_{P_{1}}^{a}\left(\xi_{1}\right) \psi_{P_{2}}^{a}\left(\xi_{2}\right)
\end{aligned}
$$


Os modos de lado AB, CD, AC, BD como

$$
\begin{aligned}
& A B=\varphi_{p, 0}\left(\xi_{1}\right)\left(\xi_{2}\right)=\psi_{p}^{a}\left(\xi_{1}\right) \psi_{0}^{a}\left(\xi_{2}\right), 0<p<P_{1} \\
& C D=\varphi_{p, P_{2}}\left(\xi_{1}\right)\left(\xi_{2}\right)=\psi_{p}^{a}\left(\xi_{1}\right) \psi_{P_{2}}^{a}\left(\xi_{2}\right), 0<p<P_{1} \\
& A C=\varphi_{0, q}\left(\xi_{1}\right)\left(\xi_{2}\right)=\psi_{0}^{a}\left(\xi_{1}\right) \psi_{q}^{a}\left(\xi_{2}\right), 0<q<P_{2} \\
& B D=\varphi_{P_{1}, q}\left(\xi_{1}\right)\left(\xi_{2}\right)=\psi_{P_{1}}^{a}\left(\xi_{1}\right) \psi_{q}^{a}\left(\xi_{2}\right), 0<q<P_{2}
\end{aligned}
$$

Finalmente os modos interiores por

$$
\varphi_{p, q}\left(\xi_{1}\right)\left(\xi_{2}\right)=\psi_{p}^{a}\left(\xi_{1}\right) \psi_{q}^{a}\left(\xi_{2}\right), 0<p, q ; p<P_{1} ; q<P_{2}
$$

\section{Expansões $C^{\circ}$ contínuas modificadas}

Embora as funções $\varphi_{p q}\left(\xi_{1}\right)\left(\xi_{2}\right)$ sejam ortogonais, devem ser modificadas para que sejam $C^{\circ}$ continuas entre domínios elementares. De modo Similar ao que aconteceu no caso unidimensional pode-se desenvolver uma expansão modificada que força a $C^{\circ}$ continuidade, decompondo a expansão ortogonal em modos interiores e de fronteira. Mais uma vez é requerido que os modos interiores ou de borbulha sejam nulos nas fronteiras dos domínios elementares. A expansão ficará completa adicionando modos de vértice e de lado. Os modos de vértice têm valor unitário num vértice e decaem para zero nos outros vértices; os modos de lado são nulos em outros lados e nos vértices. Usando esta decomposição a $C^{\circ}$ continuidade pode ser assegurada. 
Análogo ao caso de expansões ortogonais definem-se as funções principais:

$$
\psi_{i j}^{b}(z)=\left\{\begin{array}{c}
\psi_{j}^{a}(z), i=0,0 \leq j \leq J \\
\left(\frac{1-z}{2}\right)^{i+1}, j=0,1 \leq i \leq I \\
\left(\frac{1-z}{2}\right)^{(i+1)}\left(\frac{1+z}{2}\right) P_{j-1}^{(2 i+1), 1}(z), 1 \leq i \leq I, 1 \leq j \leq J \\
\psi_{j}^{a}(z), i=I, 0 \leq j \leq J
\end{array}\right\}
$$

Pode-se observar que os modos interiores são multiplicados pelo fator $\left(\frac{1-z}{2}\right)\left(\frac{1-z}{2}\right)$, com o objetivo de que os modos sejam nulos nos extremos do domínio.

\section{Operações elementares locais}

Análogo ao caso unidimensional, as operações de integração e diferenciação de uma função conhecida serão feitas num nível elementar, de forma a que possam ser consideradas como operações elementares locais. Nas seguintes seções estenderam-se os conceitos de integração e diferenciação numa região standard bidimensional.

\section{Integração em regiões bidimensionais}

A extensão da regra de quadratura para o caso bidimensional numa região standard bidimensional pode ser feita de uma maneira natural. A integração sobre o domínio $Q^{2}=\left\{-1 \leq \xi_{1}, \xi_{2} \leq 1\right\}$ é matematicamente definido por

$$
\int_{Q^{2}} u\left(\xi_{1}, \xi_{2}\right) d \xi_{1} d \xi_{2}=\int_{-1}^{1}\left\{\left.\int_{-1}^{1} u\left(\xi_{1}, \xi_{2}\right)\right|_{\xi_{2}} d \xi_{1}\right\} d \xi_{2}
$$


Substituindo a regra de quadratura obtêm-se

$$
\int_{Q^{2}} u\left(\xi_{1}, \xi_{2}\right) d \xi_{1} d \xi_{2} \approx \sum_{i=0}^{Q_{1}-1} w_{i}\left\{\sum_{j=0}^{Q_{2}-1} w_{j} u\left(\xi_{1 i}, \xi_{2 j}\right)\right\}
$$

Na equação anterior $Q_{1}, Q_{2}$ são os pontos de quadratura nas direções $\xi_{1}$ e $\xi_{2}$.

\section{Derivadas numa região standard $\Omega_{s t}$}

Em problemas diferenciais usualmente surgem derivadas do tipo $\frac{\partial u}{\partial x}$. Um caminho para avaliar estas derivadas consiste em mapear uma região elementar $x \in \Omega_{e}$, para uma região standard $\xi \in \Omega_{s t}$, empregando a regra da cadeia $\frac{\partial u}{\partial x_{1}}=\frac{\partial u}{\partial \xi_{1}} \frac{\partial \xi_{1}}{\partial x_{1}}+\frac{\partial u}{\partial \xi_{2}} \frac{\partial \xi_{2}}{\partial x_{1}}$. As derivadas $\frac{\partial \xi_{i}}{\partial x_{i}}$ são fatores de forma que serão abordados na seção de integração dentro de uma região de forma arbitrária. Nesta seção discutir-se-à inicialmente como derivar funções polinomiais numa região local $\Omega_{s t}$ para avaliar derivadas da forma $\frac{\partial u}{\partial \xi_{1}}, \frac{\partial u}{\partial \xi_{2}}, \ldots$ Tal como no caso unidimensional as derivadas serão feitas no espaço físico, ou seja, a função polinomial será representada pelos polinômios de Lagrange através de um conjunto de pontos discretos que são tipicamente os pontos de quadratura. Consideremos então a expansão $u^{\delta}(\xi)=\sum_{p=0}^{P} \hat{u}_{p} h_{p}(\xi)$. Onde $h_{p}(\xi)$ é o polinômio de Lagrange, o qual passa através de um conjunto de $P+1$ pontos nodais. Os coeficientes de amplitude podem ser avaliados usando a propriedade de colocação que cumprem os polinômios de Lagrange $h_{i}\left(\xi_{j}\right)=\delta_{i j}$ quando são avaliados nos pontos nodais. Utilizando essa condição obtemos $u_{p}=u^{\delta}\left(\xi_{p}\right)$, o que permite expandir também as derivadas em função de 
polinômios de Lagrange

$$
\frac{\partial u^{\delta}(\xi)}{\partial \xi}=\sum_{p=0}^{P} u_{p} \frac{\partial h_{p}(\xi)}{\partial \xi}=\sum_{p=0}^{P} u_{p}^{\prime} h_{p}(\xi)
$$

Com $u_{p}^{\prime}=\left.\sum_{q=0}^{P} u_{q} \frac{\partial h_{q}(\xi)}{\partial \xi}\right|_{\xi_{p}}$. Este resultado permite avaliar os termos não lineares na equação de Navier-Stokes nos pontos nodais como

$$
\begin{array}{r}
u^{\delta}\left(\xi_{i}\right) \frac{\partial u^{\delta}\left(\xi_{i}\right)}{\partial \xi}=\left(\sum_{p=0}^{P} u_{p} h_{p}\left(\xi_{i}\right)\right)\left(\sum_{q=0}^{P} u_{q} \frac{\partial h_{q}\left(\xi_{i}\right)}{\partial \xi}\right) \\
u^{\delta}\left(\xi_{i}\right) \frac{\partial u^{\delta}\left(\xi_{i}\right)}{\partial \xi}=\left(\sum_{p=0}^{P} u_{p} h_{p}\left(\xi_{i}\right)\right)\left(\sum_{q=0}^{P} u_{q}^{\prime} h_{q}\left(\xi_{i}\right)\right)=u_{i} u_{i}^{\prime}
\end{array}
$$

Então $u^{\delta}(\xi) \frac{\partial u^{\delta}(\xi)}{\partial \xi} \approx \sum_{p=0}^{P} u_{p} u_{p}^{\prime} h_{p}(\xi)$.

Apesar deste resultado ter sido derivado para o caso unidimensional, as mesmas propriedades podem ser aplicadas em sistemas de múltiplas dimensões que são representados por produtos tensoriais de polinômios de Lagrange.

\section{Derivadas bidimensionais em regiões standard $\Omega_{s t}$ com forma de quadrilátero}

Para derivar uma expansão dentro de uma região standard da forma $u^{\delta}\left(\xi_{1}, \xi_{2}\right)=\sum_{p=0}^{P_{1}} \sum_{q=0}^{P_{2}} \hat{u}_{p q} \varphi_{p q}\left(\xi_{1}, \xi_{2}\right)$ a função é representada em termos dos polinômios de Lagrange $u^{\delta}\left(\xi_{1}, \xi_{2}\right)=\sum_{p=0}^{Q_{1}-1} \sum_{q=0}^{Q_{2}-1} u_{p q} h_{p}\left(\xi_{1}\right) h_{q}\left(\xi_{2}\right)$. Onde os coeficientes de amplitude são $u_{p q}=u^{\delta}\left(\xi_{1 p}, \xi_{2 q}\right)$, e $\xi_{p}, \xi_{q}$ são zeros de uma 
quadratura apropriada. A derivada da função em relação a $\xi_{1}$ é

$$
\frac{\partial u^{\delta}}{\partial \xi_{1}}\left(\xi_{1}, \xi_{2}\right)=\sum_{p=0}^{P_{1}} \sum_{q=0}^{P_{2}} u_{p q} \frac{d h_{p}\left(\xi_{1}\right)}{d \xi_{1}} h_{q}\left(\xi_{2}\right)
$$

As derivadas dos polinômios de Jacobi $\frac{d h_{p}\left(\xi_{1}\right)}{d \xi_{1}}$ foram tratadas anteriormente. Quando as derivadas são avaliadas em pontos nodais reduz-se a soma de termos da ordem $O\left(P^{2}\right)$ a termos da ordem $O(P)$, pois

$$
\frac{\partial u^{\delta}}{\partial \xi_{1}}\left(\xi_{1 i}, \xi_{2 j}\right)=\sum_{p=0}^{P_{1}} \sum_{q=0}^{P_{2}}\left\{\left.u_{p q} \frac{d h_{p}\left(\xi_{1}\right)}{d \xi_{1}}\right|_{\xi_{1 i}} \delta_{q j}\right\}=\left.\sum_{p=0}^{P_{1}} u_{p j} \frac{d h_{p}\left(\xi_{1}\right)}{d \xi_{1}}\right|_{\xi_{1 i}}
$$

De maneira análoga cumpre-se uma equação para a derivada em relação a $\xi_{2}$, que pode ser calculada como

$$
\frac{\partial u^{\delta}}{\partial \xi_{2}}\left(\xi_{1 i}, \xi_{2 j}\right)=\left.\sum_{q=0}^{P_{2}} u_{i q} \frac{d h_{q}\left(\xi_{2}\right)}{d \xi_{2}}\right|_{\xi_{2 j}}
$$

\section{Integração dentro de uma região elementar de forma ar- bitrária}

As regiões $\Omega^{e}$ são domínios que estão em função das coordenadas cartesianas globais $\left(x_{1}, x_{2}\right)$ para o caso bidimensional. Para integrar sobre $\Omega^{e}$ transforma-se esta região numa região standard $\Omega_{s t}$ definida em termos das coordenadas locais $\left(\xi_{1}, \xi_{2}\right)$, de modo que a integral seja dada por

$$
\int_{\Omega^{e}} u\left(x_{1}, x_{2}\right) d x_{1} d x_{2}=\int_{\Omega_{s t}} u\left(\xi_{1}, \xi_{2}\right)\left|J_{2 D}\right| d \xi_{1} d \xi_{2}
$$


Onde $J_{2 D}$ é o Jacobiano da transformação definido como

$$
J_{2 D}=\left|\begin{array}{ll}
\frac{\partial x_{1}}{\partial \xi_{1}} & \frac{\partial x_{1}}{\partial \xi_{2}} \\
\frac{\partial x_{2}}{\partial \xi_{1}} & \frac{\partial x_{2}}{\partial \xi_{2}}
\end{array}\right|
$$

Supondo-se que a transformação $\left(x_{1}, x_{2}\right) \rightarrow\left(\xi_{1}, \xi_{2}\right)$ é conhecida, então é possível avaliar todas as derivadas parciais requeridas no cálculo do Jacobiano. Usualmente as integrais no novo espaço (espaço $\xi_{1}, \xi_{1}$ ) são feitas com o método de quadraturas Gaussianas, o que implica avaliar o jacobiano nos pontos de quadratura.

\section{Derivação dentro de uma região elementar de forma ar- bitrária}

Para derivar uma função numa região elementar $\Omega^{e}$ de forma arbitrária aplicamos de novo a regra da cadeia

$$
\nabla=\left(\begin{array}{c}
\frac{\partial}{\partial x_{1}} \\
\frac{\partial}{\partial x_{2}}
\end{array}\right)=\left(\begin{array}{c}
\frac{\partial \xi_{1}}{\partial x_{1}} \frac{\partial}{\partial \xi_{1}}+\frac{\partial \xi_{2}}{\partial x_{1}} \frac{\partial}{\partial \xi_{2}} \\
\frac{\partial \xi_{1}}{\partial x_{2}} \frac{\partial}{\partial \xi_{1}}+\frac{\partial \xi_{2}}{\partial x_{2}} \frac{\partial}{\partial \xi_{2}}
\end{array}\right)
$$

As derivadas $\frac{\partial}{\partial \xi}$ podem ser avaliadas usando a representação em polinômios

de Lagrange exposta anteriormente, enquanto as derivadas $\frac{\partial \xi}{\partial x}$ são fatores de forma que para o caso de mapeamentos lineares podem ser expressas de maneira analítica. Para tal expressam-se as derivadas parciais como $\partial \xi_{i} / \partial x_{i}$ em termos de $\xi$. Para uma função $u\left(\xi_{1}, \xi_{2}\right)$ podemos aplicar a regra da cadeia 
para calcular a derivada total como

$$
d u\left(\xi_{1}, \xi_{2}\right)=\frac{\partial u}{\partial \xi_{1}} d \xi_{1}+\frac{\partial u}{\partial \xi_{2}} d \xi_{2}
$$

Substituindo a função $u\left(\xi_{1}, \xi_{2}\right)$ por $x_{1}=\chi_{1}\left(\xi_{1}, \xi_{2}\right), x_{2}=\chi_{2}\left(\xi_{1}, \xi_{2}\right)$ obtemos

$$
\left(\begin{array}{c}
d x_{1} \\
d x_{2}
\end{array}\right)=\left(\begin{array}{ll}
\frac{\partial x_{1}}{\partial \xi_{1}} & \frac{\partial x_{1}}{\partial \xi_{2}} \\
\frac{\partial x_{2}}{\partial \xi_{1}} & \frac{\partial x_{2}}{\partial \xi_{2}}
\end{array}\right)\left(\begin{array}{c}
d \xi_{1} \\
d \xi_{2}
\end{array}\right)
$$

Esta equação pode ser invertida para obter

$$
\left(\begin{array}{c}
d \xi_{1} \\
d \xi_{2}
\end{array}\right)=\frac{1}{J}\left(\begin{array}{cc}
\frac{\partial x_{2}}{\partial \xi_{2}} & -\frac{\partial x_{1}}{\partial \xi_{2}} \\
-\frac{\partial x_{2}}{\partial \xi_{1}} & \frac{\partial x_{1}}{\partial \xi_{2}}
\end{array}\right)\left(\begin{array}{c}
d x_{1} \\
d x_{2}
\end{array}\right)
$$

Por outro lado a transformação (função que faz o mapeamento) $\xi_{1}=\left(\chi_{1}\right)^{-1}\left(x_{1}, x_{2}\right)$ é conhecida, então temos que

$$
\left(\begin{array}{c}
d \xi_{1} \\
d \xi_{2}
\end{array}\right)=\left(\begin{array}{ll}
\frac{\partial \xi_{1}}{\partial x_{1}} & \frac{\partial \xi_{1}}{\partial x_{2}} \\
\frac{\partial \xi_{2}}{\partial x_{1}} & \frac{\partial \xi_{2}}{\partial x_{2}}
\end{array}\right)\left(\begin{array}{c}
d x_{1} \\
d x_{2}
\end{array}\right)
$$

Comparando A.23 com A.24 obtemos $\frac{\partial \xi_{1}}{\partial x_{1}}=\frac{1}{J} \frac{\partial x_{2}}{\partial \xi_{2}}, \frac{\partial \xi_{1}}{\partial x_{2}}=-\frac{1}{J} \frac{\partial x_{1}}{\partial \xi_{2}}, \frac{\partial \xi_{2}}{\partial x_{1}}=$ $-\frac{1}{J} \frac{\partial x_{2}}{\partial \xi_{1}}, \frac{\partial \xi_{2}}{\partial x_{2}}=\frac{1}{J} \frac{\partial x_{1}}{\partial \xi_{1}}$. Desta forma é possível avaliar o gradiente dado na equação A.21, já que todas as derivadas estão em função de $\xi$ e podem ser calculadas usando uma representação em polinômios de Lagrange. 


\section{Matrizes elementares e notação vetorial}

A formulação em múltiplas dimensões utiliza diferentes tipos de bases de expansão, precisando do uso de uma grande quantidade de índices na notação. Para simplificar esta notação se introduzir-se-à uma nova notação vetorial e matricial para representar diferentes operações, tais como derivadas e integrais.

Usualmente se requer a avaliação de uma função num conjunto de pontos nodais (em expansões tensoriais estes pontos usualmente são os pontos de

quadratura) $\overrightarrow{\xi_{m}}$. Defina-se então o vetor $\mathbf{u}$ que denota a função $u(\vec{\xi})$ avaliada nesse pontos, ou seja, $\mathbf{u}[m]=u\left(\overrightarrow{\xi_{m}}\right) \operatorname{com} \vec{\xi}=\left[\xi_{1}, \xi_{2}\right]$. O índice $m$ é uma função de $i, j$. Considerando que $Q_{1}, Q_{2}$ são pontos de quadratura ao longo de cada direção ter-se-à que $m(i, j)=i+j \cdot Q_{1}$, onde os índices $i, j$ percorrem os intervalos $0 \leq i \leq Q_{1}-1,0 \leq j \leq Q_{2}-1$. Por convenção conta-se primeiro a coordenada $\xi_{1}$ e depois a coordenada $\xi_{2}$. Portanto o vetor explicitamente estará dado por $\mathbf{u}=\left[u\left(\xi_{10}, \xi_{20}\right), \ldots, u\left(\xi_{1 Q_{1}}, \xi_{20}\right), u\left(\xi_{10}, \xi_{21}\right), \ldots, u\left(\xi_{1 Q_{1}}, \xi_{2 Q_{2}}\right)\right]$.

Para o caso dos coeficientes de expansão adota-se a convenção $\hat{u}[m]=\hat{u}_{m}$ que explicitamente assume a forma $\hat{u}=\left[\hat{u}_{00}, \hat{u}_{01}, \ldots ., \hat{u}_{0 P_{2}}, \hat{u}_{10}, \ldots, \hat{u}_{P_{1} P_{2}}\right]^{T}$

\section{Matrizes de peso e base}

Define-se uma matriz de peso $\mathbf{W}$ como uma matriz diagonal que contém os pesos de quadratura gaussiana multiplicados pelo jacobiano avaliado em tais pontos, ou seja, $\mathbf{W}[m(i j)][n(r s)]=J_{i j} w_{i} w_{j} \delta_{m n}$. Aqui $J_{i j}$ representa $J\left(\xi_{1 i}, \xi_{2 j}\right)$ e $m(i, j)=i+j \cdot Q_{1}$. A matriz $\mathbf{B}$ é uma espécie de matriz de Vandermonde cujas colunas são as bases de expansão avaliadas nos pontos 
nodais $\mathbf{B}[m][n]=\varphi_{n}\left(\overrightarrow{\xi_{m}}\right), \vec{\xi}=\left(\xi_{1}, \xi_{2}\right)$. A matriz é formulada de maneira que as colunas são arrumadas segundo $\mathbf{u}$ e as filas segundo $\hat{\mathbf{u}}$, termo a termo a matriz está dada por

$$
\mathbf{B}=\left(\begin{array}{ccc}
\varphi_{00}\left(\xi_{10}, \xi_{20}\right) \cdots & \varphi_{0 P_{2}}\left(\xi_{10}, \xi_{20}\right) \cdots & \varphi_{P_{1} P_{2}}\left(\xi_{10}, \xi_{20}\right) \\
\vdots & \vdots & \vdots \\
\varphi_{00}\left(\xi_{1 Q_{1}}, \xi_{20}\right) \cdots & \varphi_{0 P_{2}}\left(\xi_{1 Q_{1}}, \xi_{20}\right) \cdots & \varphi_{P_{1} P_{2}}\left(\xi_{1 Q_{1}}, \xi_{20}\right) \\
\vdots & \vdots & \vdots \\
\varphi_{00}\left(\xi_{1 Q_{1}}, \xi_{2 Q_{2}}\right) \cdots & \varphi_{0 P_{2}}\left(\xi_{1 Q_{1}}, \xi_{2 Q_{2}}\right) \cdots & \varphi_{P_{1} P_{2}}\left(\xi_{1 Q_{1}}, \xi_{2 Q_{2}}\right)
\end{array}\right)
$$

\section{Matriz derivada}

A matriz final que precisamos para completar o conjunto de operadores discretos é uma matriz que represente a diferenciação.

A derivada de uma função em relação a $\xi_{1}$ no espaço físico avaliada num ponto de quadratura está dada por

$$
\frac{\partial u}{\partial \xi_{1}}\left(\xi_{1 i}, \xi_{2 j}\right)=\left.\sum_{r=0}^{Q_{1}} \sum_{s=0}^{Q_{2}} \frac{d h_{r}\left(\xi_{1}\right)}{d \xi_{1}}\right|_{\xi_{1 i}} h_{s}\left(\xi_{2 j}\right) u_{r s}
$$

onde $u_{r s}=u\left(\xi_{1 r}, \xi_{2 s}\right)$. Pode-se definir um operador $\mathbf{D}_{\xi_{1}}$ que atua sobre $\mathbf{u} \mathrm{e}$ representa a derivada de uma função avaliada nos pontos de quadratura, ou seja,

$$
\frac{\partial \mathbf{u}}{\partial \xi_{1}}=\mathbf{D}_{\xi_{1}} \mathbf{u}
$$

com

$$
\mathbf{D}_{\xi_{1}}[m(i j)]\left[m^{\prime}(r s)\right]=\left.\frac{d h_{r}\left(\xi_{1}\right)}{d \xi_{1}}\right|_{\xi_{1 i}} h_{s}\left(\xi_{2 j}\right)
$$


e $m(i j)=m^{\prime}(i j)=i+j \cdot Q_{1}$. Isto sugere que é possível calcular a derivada da base $\varphi_{n}$ em relação a $\xi_{1}$ avaliada nos pontos de quadratura $\xi_{m(i j)}$ fazendo uso da matriz B, portanto a expressão final fica da forma

$$
\frac{\partial \varphi_{n}}{\partial \xi_{1}}\left(\vec{\xi}_{m}\right)=\left(\mathbf{D}_{\xi_{1}} \mathbf{B}\right)[m][n]
$$

$\operatorname{com} \vec{\xi}_{m(i j)}=\left[\xi_{1 i}, \xi_{2 j}\right]$

\section{Matriz $\Lambda$ de coeficientes diagonais}

Previamente mostrou-se que a derivada em relação às coordenadas globais $x_{1}, x_{2}, x_{3}$ podem ser obtidas usando a regra da cadeia a partir das derivadas em relação às coordenadas locais (equação A.21). A matriz equivalente requererá então pré-multiplicar as matriz derivada por uma matriz diagonal que contém os fatores de forma $\partial \xi_{1} / \partial x_{1}, \partial \xi_{1} / \partial x_{2}, \partial \xi_{1} / \partial x_{3}, \ldots .$. avaliados nos pontos de quadratura. Para definir essa matriz diagonal introduz-se a notação $\Lambda\left(f\left(\xi_{1}, \xi_{2}\right)\right)$ que representa uma função $f$ avaliada nos pontos de quadratura, ou seja

$$
\boldsymbol{\Lambda}\left(f\left(\xi_{1}, \xi_{2}\right)\right)[m(i j)][n(r s)]=f\left(\xi_{1 i}, \xi_{2 j}\right) \delta_{m n}
$$

com $m(i j)=n(i j)=i+j \cdot Q_{1}$, de maneira que a derivada

$$
\frac{\partial u}{\partial x_{1}}=\frac{\partial \xi_{1}}{\partial x_{1}} \frac{\partial u}{\partial \xi_{1}}+\frac{\partial \xi_{2}}{\partial x_{1}} \frac{\partial u}{\partial \xi_{2}}
$$

pode se escrever como

$$
\frac{\partial \mathbf{u}}{\partial x_{1}}=\left[\boldsymbol{\Lambda}\left(\frac{\partial \xi_{1}}{\partial x_{1}}\right) \mathbf{D}_{\xi_{1}}+\boldsymbol{\Lambda}\left(\frac{\partial \xi_{2}}{\partial x_{1}}\right) \mathbf{D}_{\xi_{2}}\right]
$$




\section{Transformação Backward}

A transformação backward entre o espaço de coeficientes e o espaço físico está dada por

$$
u^{\delta}(\mathbf{x})=\sum_{m=0}^{N_{m}-1} \hat{u}_{m} \varphi_{m}(\vec{\xi})=\sum_{m(p q)=0}^{N_{m}-1} \hat{u}_{p q} \varphi_{p q}(\vec{\xi})
$$

Neste caso $m(p q)$ representa a conexão entre os índices tensoriais $p q$ e o índice global $m$. Avaliando a função nos pontos de quadratura obtém-se

$$
u^{\delta}\left(\xi_{1 i}, \xi_{2 j}\right)=\sum_{m(p q)} \hat{u}_{p q} \varphi_{p q}\left(\xi_{1 i}, \xi_{2 j}\right)
$$

Esta expressão pode se escrever em termos de notação matricial como

$$
\mathbf{u}=\mathbf{B} \hat{\mathbf{u}}
$$

\section{Transformação Forward}

Este método consiste em que dada uma função continua $u(\vec{\xi})$ ou discreta $u^{\delta}(\vec{\xi})$ se podem determinar os coeficientes de amplitude $\hat{u}$ por meio do método de pesos residuais.

Quando a função $u^{\delta}(\vec{\xi})$ não coincidir com o espaço polinomial das bases usadas na expansão, surgirá um erro dado por

$$
u^{\delta}\left(\xi_{1}, \xi_{2}\right)-u\left(\xi_{1}, \xi_{2}\right)=R(u)
$$


ou equivalentemente

$$
\sum_{p q} \hat{u}_{p q} \varphi_{p q}\left(\xi_{1}, \xi_{2}\right)-u\left(\xi_{1}, \xi_{2}\right)=R(u)
$$

Usando o método dos pesos residuais se obtém

$$
\left(v, \sum_{p q} \hat{u}_{p q} \varphi_{p q}\right)-(v, u)=(v, R(u))
$$

Assumindo $(v, R(u))=0$ se chega à expressão

$$
\left(v, \sum_{p q} \hat{u}_{p q} \varphi_{p q}\right)=(v, u)
$$

Existe certa liberdade no momento de escolher as funções $v(\vec{\xi})$. No caso do método de colocação (interpolação) se escolhe $v_{m}=\delta\left(\vec{\xi}_{m}\right)$ de maneira que

$$
\int_{\Omega} v_{m} u^{\delta}(\vec{\xi}) \overrightarrow{d \xi}=\int_{\Omega} v_{m} \sum_{n=1}^{N_{m}-1} \hat{u}_{n} \varphi_{n}(\vec{\xi}) \overrightarrow{d \xi}, m=0, \ldots, N_{m}-1
$$

Então

$$
u^{\delta}\left(\vec{\xi}_{m}\right)=\sum_{n=1}^{N_{m}-1} \hat{u}_{n} \varphi_{n}\left(\overrightarrow{\xi_{m}}\right) \longrightarrow \mathbf{u}=\mathbf{B}_{\eta} \hat{\mathbf{u}}
$$

$\operatorname{com} \mathbf{B}_{\eta}[m][n]=\varphi_{n}\left(\overrightarrow{\xi_{m}}\right)$

\section{Projeção discreta de Galerkin}

Na projeção discreta de Galerkin a função $v$ que surge no método de pesos residuais (ver transformação forward) é substituída pela mesma base usada 
na expansão, resultando no sistema

$$
\left(\varphi_{r s}, \sum_{p q} \hat{u}_{p q} \varphi_{p q}\right)=\left(\varphi_{r s}, u\right)
$$

Dado que os coeficientes $\hat{u}_{p q}$ são independentes das coordenadas $\xi_{1}, \xi_{2}$ o sistema dado em A.37 pode se escrever como

$$
\sum_{p q}\left(\varphi_{r s}, \varphi_{p q}\right) \hat{u}_{p q}=\left(\varphi_{r s}, u\right)
$$

A equação A.38 é a representação de um sistema linear o qual pode ser resolvido para determinar os coeficientes $\hat{u}_{p q}$, onde os termos $\left(\varphi_{r s}, \varphi_{p q}\right)$ representam as componentes da matriz de massa M. A equação A.38 define a transformação forward.

Para construir a versão discreta da equação A.38 consideremos inicialmente o produto interno entre duas funções $u$ e $v$ dado por

$$
(v, u)=\int v\left(\xi_{1}, \xi_{2}\right) u\left(\xi_{1}, \xi_{2}\right)|J| d \xi_{1} d \xi_{2}
$$

Usando o método de quadratura gaussiana se obtém uma solução aproximada da equação A.39 como

$$
(v, u)_{\delta}=\sum_{i=0}^{Q_{1}-1} \sum_{j=0}^{Q_{2}-1} w_{i} w_{j} v\left(\xi_{i 1}, \xi_{2 j}\right) u\left(\xi_{i 1}, \xi_{2 j}\right)\left|J_{i j}\right|
$$

Em notação matricial a anterior expressão toma a forma

$$
(v, u)_{\delta}=\mathbf{V}^{T} \mathbf{W} \mathbf{U}
$$


Para escrever a parte direita da equação A.38 em notação matricial note-se que $v$ é um vetor conformado pela função avaliada nos pontos nodais então $\mathbf{V}^{T}=\mathbf{B}^{T}$, portanto o lado direito de A.38 está dado por

$$
\mathbf{B}^{T} \mathbf{W} \mathbf{U}=\left(\varphi_{r s}, u\right)
$$

e o lado esquerdo de A.38 será

$$
\left(\varphi_{r s}, \sum_{p q} \hat{u}_{p q} \varphi_{p q}\right)=\left(\mathbf{B}^{T} \mathbf{W B}\right) \hat{\mathbf{U}}
$$

De maneira que a equação A.38 em notação matricial tem a forma

$$
\left(\mathbf{B}^{T} \mathbf{W B}\right) \hat{\mathbf{U}}=\mathbf{B}^{T} \mathbf{W} \mathbf{U}
$$

Então os valores de uma função nos pontos de quadratura podem ser determinados por

$$
\hat{\mathbf{U}}=\left(\mathbf{B}^{T} \mathbf{W B}\right)^{-1} \mathbf{B}^{T} \mathbf{W} \mathbf{U}=(\mathbf{M})^{-1} \mathbf{B}^{T} \mathbf{W} \mathbf{U}
$$

Esta equação define a transformação discreta forward com projeção de Galerkin.

\section{Operadores diferenciais: Weak laplacian}

Nesta seção ilustrar-se-à como construir um sistema matricial para um problema diferencial, por tal motivo vamos considerar a aproximação de Galerkin para o problema bidimensional de Poisson $\nabla^{2} u(\mathbf{x})=f(\mathbf{x}), \mathbf{x}=$ 
$\left(x_{1}, x_{2}\right) \in \Omega^{e}$. Usando a aproximação de Galerkin tomamos o produto interno em relação a uma função continua $v(\mathbf{x})$ que leva à condição $\left(v, \nabla^{2} u\right)=(v, f)$. Aplicando o teorema da divergência ao lado esquerdo da equação anterior obtemos

$$
(\nabla v, \nabla u)=\int_{\partial \Omega} v \nabla u \cdot \hat{n} d s-(v, f)
$$

O termo $(\nabla v, \nabla u)$ tem por nome weak laplacian e explicitamente está dado por

$$
\left(\frac{\partial v}{\partial x_{1}} \hat{e_{1}}+\frac{\partial v}{\partial x_{2}} \hat{e_{2}}, \frac{\partial u}{\partial x_{1}} \hat{e_{1}}+\frac{\partial u}{\partial x_{2}} \hat{e_{2}}\right)=\left(\frac{\partial v}{\partial x_{1}}, \frac{\partial u}{\partial x_{1}}\right)+\left(\frac{\partial v}{\partial x_{2}}, \frac{\partial u}{\partial x_{2}}\right)
$$

Para este caso tanto $v$ como $u$ são aproximados com a mesma função. Considerando que $(v, u)_{\delta}=\mathbf{V}^{T} \mathbf{W} \mathbf{U}$ então

$$
\mathbf{L}^{e}=\left(\frac{\partial \mathbf{B}}{\partial x_{1}}\right)^{T} \mathbf{W}\left(\frac{\partial \mathbf{B}}{\partial x_{1}}\right)+\left(\frac{\partial \mathbf{B}}{\partial x_{2}}\right)^{T} \mathbf{W}\left(\frac{\partial \mathbf{B}}{\partial x_{2}}\right)
$$

Lembrando que a derivada de uma função $\mathbf{U}$ é

$$
\frac{\partial \mathbf{U}}{\partial x_{1}}=\left[\boldsymbol{\Lambda}\left(\frac{\partial \xi_{1}}{\partial x_{1}}\right) \mathbf{D}_{\xi_{1}}+\boldsymbol{\Lambda}\left(\frac{\partial \xi_{2}}{\partial x_{1}}\right) \mathbf{D}_{\xi_{2}}\right] \mathbf{U}
$$

chega-se à expressão

$$
\begin{aligned}
\mathbf{L}^{e}= & \mathbf{B}^{T}\left[\mathbf{D}_{\xi_{1}}^{T} \boldsymbol{\Lambda}\left(\frac{\partial \xi_{1}}{\partial x_{1}}\right)+\mathbf{D}_{\xi_{2}}^{T} \boldsymbol{\Lambda}\left(\frac{\partial \xi_{2}}{\partial x_{1}}\right)\right] \mathbf{W}\left[\mathbf{D}_{\xi_{1}} \boldsymbol{\Lambda}\left(\frac{\partial \xi_{1}}{\partial x_{1}}\right)+\mathbf{D}_{\xi_{2}} \boldsymbol{\Lambda}\left(\frac{\partial \xi_{2}}{\partial x_{1}}\right)\right] \mathbf{B}+ \\
\mathbf{B}^{T} & {\left[\mathbf{D}_{\xi_{1}}^{T} \boldsymbol{\Lambda}\left(\frac{\partial \xi_{1}}{\partial x_{2}}\right)+\mathbf{D}_{\xi_{2}}^{T} \boldsymbol{\Lambda}\left(\frac{\partial \xi_{2}}{\partial x_{2}}\right)\right] \mathbf{W}\left[\mathbf{D}_{\xi_{1}} \boldsymbol{\Lambda}\left(\frac{\partial \xi_{1}}{\partial x_{2}}\right)+\mathbf{D}_{\xi_{2}} \boldsymbol{\Lambda}\left(\frac{\partial \xi_{2}}{\partial x_{2}}\right)\right] \mathbf{B} }
\end{aligned}
$$




\section{Operações globais}

Todas as operações descritas até agora foram locais no sentido que elas estão definidas em domínios elementares. No entanto em geral tem-se interesse em resolver sistemas de equações diferenciais parciais que requerem continuidade entre regiões elementares. Para construir um sistema global $C^{\circ}$ continuo a partir de contribuições locais, se deve definir um processo de ensamble global que será introduzido a seguir.

\section{Ensamble global e conectividade}

Para ter um ensamble global é necessário definir os modos de expansão local $\varphi_{p q}\left(\xi_{1}, \xi_{2}\right)$ dentro de uma região global $\Omega$. No caso de $\Omega$ ser dividido em $N_{e l}$ elementos contíguos denotados por $\Omega^{e}$, os $\operatorname{modos} \varphi_{p q}^{e}\left(\xi_{1}, \xi_{2}\right)$ serão definidos como

$$
\varphi_{p q}^{e}\left(\xi_{1}, \xi_{2}\right)= \begin{cases}\varphi_{p q}\left(\xi_{1}, \xi_{2}\right), & \left(x_{1}, x_{2}\right) \in \Omega^{e} \\ 0, & \text { outro caso }\end{cases}
$$

onde as variáveis globais e locais estão relacionadas pela transformação $\xi_{1}=$ $\left[\chi_{1}^{e}\right]^{-1}(x 1, x 2), \xi_{2}=\left[\chi_{2}^{e}\right]^{-1}(x 1, x 2)$. Desde um ponto de vista prático o que deve-se fazer é realizar todas as operações num domínio elementar $\Omega^{e}$ e construir um mapeamento para um ensamble global. Para tal fim definam-se como graus de liberdade locais o número de coeficientes de expansão $\hat{u} \mathrm{em}$ cada região elementar $e$, desta maneira o vetor que determina todos os grados 
de liberdade do sistema $\hat{u}_{l}$ estará dado por

$$
\hat{u_{l}}=\underline{\hat{u}^{e}}\left(\begin{array}{c}
\hat{u}^{1} \\
\hat{u}^{2} \\
\vdots \\
\hat{u}^{N_{e l}}
\end{array}\right)
$$

O índice superior nesta notação especifica a região elementar e a linha debaixo implica que se faz uma extensão a todos os domínios elementares. Por outro lado defina-se $\hat{u}_{g}$ como o vetor composto por todos os graus de liberdade globais do sistema. A transformação que liga os graus de liberdade locais e globais consegue-se por meio da matriz de ensamble $\mathbf{A}$ que cumpre $\hat{u}_{l}=\mathbf{A} \hat{u}_{g}$. Consideremos como exemplo uma expansão em dois triângulos até $P_{1}=P_{2}=$ 2 que só contém modos de fronteira. O sistema estará definido por $N_{m}=$ $\frac{\left(P_{1}+1\right)\left(P_{2}+2\right)}{2}=6$ modos. Na Figura A.7 (a) pode-se observar o esquema de numeração local de modos. Este esquema depende da orientação do sistema coordenado local em cada região elementar. Neste caso se numeraram os modos de acordo à convenção na qual os modos de vértice são numerados primeiro, seguidos dos modos de lado e finalmente os modos interiores (neste exemplo não há modos interiores). Em cada região elementar (cada um dos triângulos) há seis graus de liberdade, de maneira que no domínio global $\Omega$ se tem doze graus de liberdade. Para ensamblar os dois triângulos deve-se segurar $C^{\circ}$ continuidade, a qual se consegue mudando o esquema de graus de liberdade tal como mostrado em Figura A.7 (b). A nova numeração para o domínio global $\Omega$ conserva o padrão standard, já que primeiro se enumeram 
os modos de vértice, depois os modos de lado e finalmente os interiores. O ensamble global para este sistema obtém-se da seguinte forma

(a)

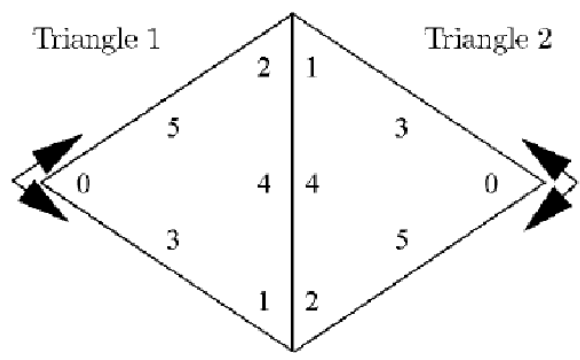

(b)

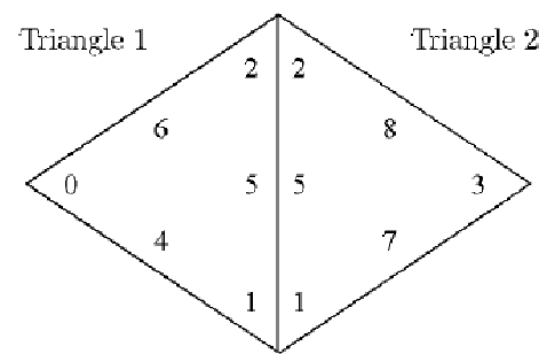

Figura A.7: Ilustração dos esquemas de numeração local (a) e global (b) para uma região composta por dois triângulos elementares. Extraído de Karniadakis e Sherwin ${ }^{11}$

$$
\hat{u}_{l}=\left[\begin{array}{c}
\hat{u}^{1}[0] \\
\hat{u}^{1}[1] \\
\hat{u}^{1}[2] \\
\hat{u}[3] \\
\hat{u}^{1}[4] \\
\hat{u}^{1}[5] \\
\hat{u}^{2}[0] \\
\hat{u}^{2}[1] \\
\hat{u}^{2}[2] \\
\hat{u}^{2}[3] \\
\hat{u}^{2}[4] \\
\hat{u}^{2}[5]
\end{array}\right]=\left(\begin{array}{lllllllll}
1 & 0 & 0 & 0 & 0 & 0 & 0 & 0 & 0 \\
0 & 1 & 0 & 0 & 0 & 0 & 0 & 0 & 0 \\
0 & 0 & 1 & 0 & 0 & 0 & 0 & 0 & 0 \\
0 & 0 & 0 & 0 & 1 & 0 & 0 & 0 & 0 \\
0 & 0 & 0 & 0 & 0 & 1 & 0 & 0 & 0 \\
0 & 0 & 0 & 0 & 0 & 0 & 1 & 0 & 0 \\
0 & 0 & 0 & 1 & 0 & 0 & 0 & 0 & 0 \\
0 & 0 & 1 & 0 & 0 & 0 & 0 & 0 & 0 \\
0 & 1 & 0 & 0 & 0 & 0 & 0 & 0 & 0 \\
0 & 0 & 0 & 0 & 0 & 0 & 0 & 0 & 1 \\
0 & 0 & 0 & 0 & 1 & 0 & 0 & 0 & 0 \\
0 & 0 & 0 & 0 & 0 & 0 & 0 & 1 & 0
\end{array}\right)\left[\begin{array}{c}
\hat{u}_{g}[0] \\
\hat{u}_{g}[1] \\
\hat{u}_{g}[2] \\
\hat{u}_{g}[3] \\
\hat{u}_{g}[4] \\
\hat{u}_{g}[5] \\
\hat{u}_{g}[6] \\
\hat{u}_{g}[7] \\
\hat{u}_{g}[8]
\end{array}\right]
$$

Observe-se que, por exemplo, o modo 5 no triângulo 1 deve ser mapeado ao modo 6 no domínio global, por tal motivo existe o número 1 na sétima fila 
da matriz de ensamble global.

Finalmente consideremos o produto interior entre a função $u\left(x_{1}, x_{2}\right)$ com as bases globais $\Phi_{n}\left(x_{1}, x_{2}\right)$ dado por $\hat{\mathbf{I}}_{g}[n]=\int_{\Omega} u\left(x_{1}, x_{2}\right) \Phi_{n}\left(x_{1}, x_{2}\right) d x_{1} d x_{2}$. Esta integral pode-se escrever de forma equivalente como

$$
\hat{\mathbf{I}}_{g}[n]=\int_{\Omega} u\left(x_{1}, x_{2}\right) \Phi_{n}\left(x_{1}, x_{2}\right) d x_{1} d x_{2}=\int_{\Omega^{e}} u\left(x_{1}, x_{2}\right) \varphi_{m}\left(x_{1}, x_{2}\right) d x_{1} d x_{2}
$$

onde $n=n(m, e)$ depende do modo e da região elementar. Em notação matricial a operação tem a forma $\hat{\mathbf{I}}_{g}=\mathbf{A}^{T} \hat{\mathbf{I}}_{l}=\mathbf{A}^{T} \hat{\mathbf{I}}^{e}$, com

$$
\hat{\mathbf{I}}^{e}[m]=\int_{\Omega^{e}} u\left(x_{1}, x_{2}\right) \varphi_{m}\left(x_{1}, x_{2}\right) d x_{1} d x_{2}
$$

Computacionalmente não é desejável construir a matriz A explicitamente. A operação pode ser implementada numericamente utilizando o arranjo $n(e, i)=$ map $[e][i]$. Este novo arranjo contém o valor global do i-ésimo coeficiente de expansão no e-ésimo elemento, no citado exemplo dos triângulos o arranjo está dado por

$$
\operatorname{map}[1][i]=\left(\begin{array}{c}
0 \\
1 \\
2 \\
4 \\
5 \\
6
\end{array}\right), \operatorname{map}[2][i]=\left(\begin{array}{c}
3 \\
2 \\
1 \\
8 \\
5 \\
7
\end{array}\right)
$$


que pode ser implementado computacionalmente como

$$
\left\{\begin{array}{l}
\text { do } e=1, N_{e l} \\
\text { do } i=0, N_{m}^{e}-1 \\
\hat{u}^{e}[i]=\operatorname{sign}[e][i] \cdot \hat{u}_{g}[\operatorname{map}[e][i]] \Longleftrightarrow \hat{u}_{l}=\mathbf{A} \hat{u}_{g} \\
\text { continue } \\
\text { continue }
\end{array}\right.
$$

Por exemplo, se $e=1$ e $i=3$ então map [1][3] = 4. A função sign $[m][n]$ tem valor 1 ou -1 mas em expansões nodais sempre tem valor unitário, considerando este fato se obtém $\hat{u}^{1}[3]=\hat{u}_{g}[4]$, que é exatamente o mapeamento do triângulo local para o domínio global.

\section{Matriz de ensamble global}

Nesta seção se apresentar-se-à uma maneira de ensamblar um sistema global a partir de um sistema local, para isso deve ter-se em conta os seguintes parâmetros:

a) $\hat{\mathbf{U}}^{\mathbf{e}}$ vetor de coeficientes de expansão num domínio elementar.

b) $\mathbf{U}^{e}$ vetor que contém a função $u\left(\xi_{1}, \xi_{2}\right)$ avaliada nos pontos de quadratura

c) $\mathbf{B}^{e}$ matriz cujas colunas contêm as bases $\varphi_{p q}\left(\xi_{1}, \xi_{2}\right)$ avaliadas nos pontos de quadratura

d) $\mathbf{W}^{e}$ matriz de pesos diagonal 
e) $\hat{\mathbf{U}}_{\mathbf{g}}$ vetor que contém os coeficientes globais de expansão

f) $\hat{\mathbf{U}}_{\mathbf{l}}, \underline{\hat{\mathbf{U}}^{\mathrm{e}}}$ vetor formado pela concatenação de coeficientes locais

Para determinar $\hat{\mathbf{U}}^{\mathbf{e}}$ dado um vetor $\mathbf{U}^{e}$ considera-se uma transformação discreta forward a qual envolve a solução do sistema matricial

$$
\hat{\mathbf{U}}^{e}=(\mathbf{M})^{-1}\left(\mathbf{B}^{e}\right)^{T} \mathbf{W}^{e} \mathbf{U}^{e} \Rightarrow \mathbf{M}^{e} \hat{\mathbf{U}}^{e}=\left(\mathbf{B}^{e}\right)^{T} \mathbf{W}^{e} \mathbf{U}^{e}
$$

De forma equivalente pode-se definir uma transformação forward global ensamblando matrizes da forma

$$
\begin{aligned}
& \underline{\mathbf{M}}^{e}=\left(\begin{array}{cccc}
\mathbf{M}^{1} & 0 & 0 & 0 \\
0 & \mathbf{M}^{2} & 0 & 0 \\
0 & 0 & \ddots & 0 \\
0 & 0 & 0 & \mathbf{M}^{N_{e l}}
\end{array}\right) \\
& \left(\mathbf{B}^{e}\right)^{T} \mathbf{W}^{e}=\left(\begin{array}{cccc}
\left(\mathbf{B}^{1}\right)^{T} \mathbf{W}^{1} & 0 & 0 & 0 \\
0 & \left(\mathbf{B}^{2}\right)^{T} \mathbf{W}^{2} & 0 & 0 \\
0 & 0 & \ddots & 0 \\
0 & 0 & 0 & \left(\mathbf{B}^{N_{e l}}\right)^{T} \mathbf{W}^{N_{e l}}
\end{array}\right)
\end{aligned}
$$

$\underline{\mathbf{M}}^{e}$ significa armar uma matriz diagonal cujas entradas são blocos de matrizes. Isto é equivalente à concatenação de $\hat{\mathbf{U}}^{\mathrm{e}}$ e $\mathbf{U}^{e}$ para $\mathbf{U}_{l}=\underline{\mathbf{U}^{e}}$ e $\hat{\mathbf{U}}_{l}=\underline{\mathbf{U}^{e}}$ respectivamente, resultando no sistema matricial

$$
\underline{\mathbf{M}^{e}} \hat{\mathbf{U}}_{l}=\underline{\left(\mathbf{B}^{e}\right)^{T} \mathbf{W}^{e} \mathbf{U}_{l}}
$$


A equação A.56 representa a transformação forward sobre todos os elementos $N_{e l}$. Considerando que $\hat{\mathbf{U}}_{l}=\mathbf{A} \hat{\mathbf{U}}_{g}$ determina os graus de liberdade locais a partir dos graus de liberdade globais, podemos substituir na equação A.56 para obter

$$
\underline{\mathbf{M}}^{e} \mathbf{A} \hat{\mathbf{U}}_{g}=\underline{\left(\mathbf{B}^{e}\right)^{T} \mathbf{W}^{e} \mathbf{U}_{l}}
$$

A matriz $\mathbf{M}^{e} \mathbf{A}$ não é quadrada, para ter esta propriedade se pré-multiplica a equação A.57 por $\mathbf{A}^{T}$ para obter o sistema o sistema global quadrado

$$
\left[\mathbf{A}^{T} \underline{\mathbf{M}}^{e} \mathbf{A}\right] \hat{\mathbf{U}}_{g}=\mathbf{A}^{T} \underline{\left(\mathbf{B}^{e}\right)^{T} \mathbf{W}^{e} \mathbf{U}_{l}}
$$

Este sistema pode ser resolvido usando uma transformação forward. A matriz em colchetes quadrados representa a matriz de massa global $\mathbf{M}$ dada por $\mathbf{M}=\mathbf{A}^{T} \underline{\mathbf{M}}^{e} \mathbf{A}$.

O sistema resultante de ensamblar a matriz global $\mathbf{M}$ a partir de matrizes locais $\mathbf{M}^{e}$ pode resultar muito espalhado, sendo muito difícil de inverter e inclusive de factorizar. Na próxima seção se mostrará uma metodologia que permite reduzir este sistema global em pequenas componentes baseado na decomposição característica do método $h p$.

\section{Condensação estática}

Os coeficientes do sistema global podem ser determinados a partir da expressão A.58. Esta equação é do tipo

$$
\mathbf{M x}=\mathbf{A}^{T} \underline{\mathbf{M}}^{e} \mathbf{A x} \equiv \mathbf{f}
$$


Com f uma função conhecida. A matriz $\mathbf{M}$ tipicamente é muito espalhada sendo muito ineficiente tentar inverte-la. Uma aproximação mais eficiente usa a estrutura da discretização espectral a qual é a motivação do método de condensação estática.

Cada uma das matrizes elementares $\mathbf{M}^{e}$ pode ser decomposta no seguinte sistema formado por componentes interiores e de fronteira, ou seja

$$
\mathbf{M}^{e}=\left(\begin{array}{cc}
\mathbf{M}_{b}^{e} & \mathbf{M}_{c}^{e} \\
\left(\mathbf{M}_{c}^{e}\right)^{T} & \mathbf{M}_{i}^{e}
\end{array}\right)
$$

Aqui $\mathbf{M}_{b}^{e}$ representa as componentes de $\mathbf{M}^{e}$ resultantes da interação entre modos de fronteira, $\mathbf{M}_{c}^{e}$ representa as componentes de $\mathbf{M}^{e}$ resultantes do acoplamento entre modos de fronteira e interiores, e $\mathbf{M}_{i}^{e}$ representa as componentes de $\mathbf{M}^{e}$ resultantes das interações entre modos interiores.

O ensamble $\mathbf{A}^{T}$ pode ser visto como um mapeamento no qual se tem completa liberdade para especificar o ordenamento do sistema global. O sistema pode ser arrumado listando primeiro os modos globais de fronteira (construídos a partir dos modos de fronteira locais), posteriormente são listados os graus de liberdade interiores (construídos a partir dos modos locais interiores) enumerados de forma consecutiva. Adotando este arranjo se chega ao sistema mostrado na Figura A.8 Agora se descompõe $\mathbf{x}$ e f em componentes interiores e de fronteira, ou seja

$$
\mathrm{x}=\left(\begin{array}{c}
\mathrm{x}_{\mathrm{b}} \\
\mathrm{x}_{\mathrm{i}}
\end{array}\right), \mathrm{f}=\left(\begin{array}{c}
\mathrm{f}_{\mathrm{b}} \\
\mathrm{f}_{\mathrm{i}}
\end{array}\right)
$$




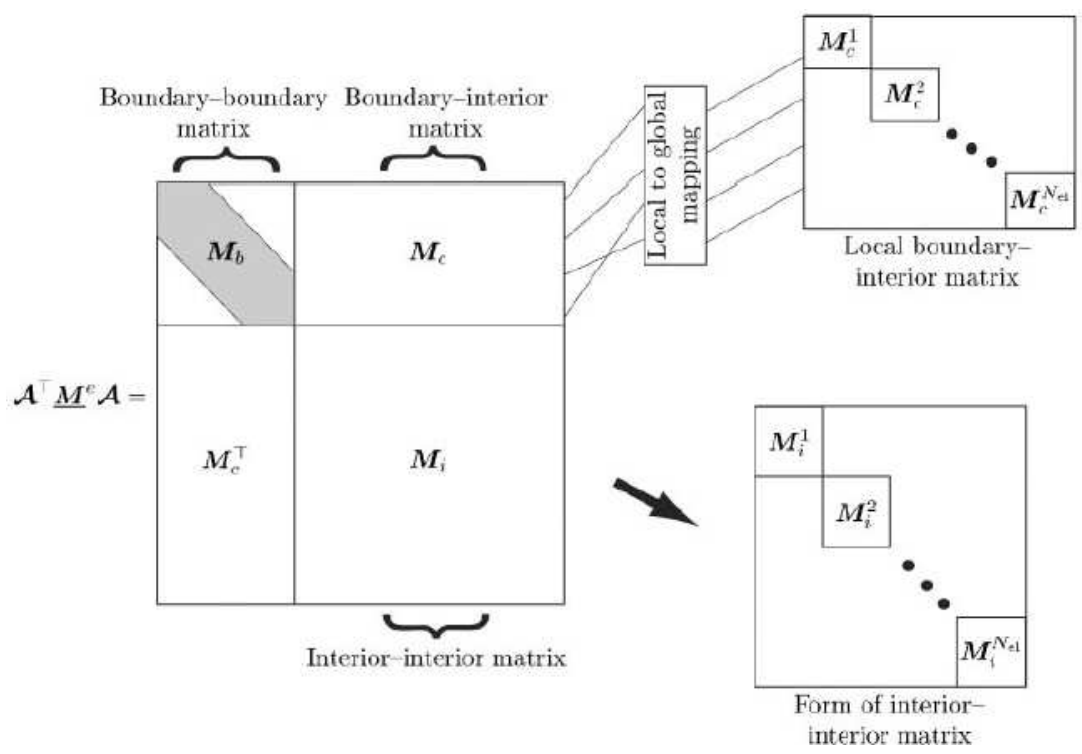

Figura A.8: Forma da matriz de massa global M. Extraído de Karniadakis e Sherwin ${ }^{11}$

Então a equação A.59 fica da forma

$$
\left(\begin{array}{cc}
\mathbf{M}_{b} & \mathbf{M}_{c} \\
\mathbf{M}_{c}^{T} & \mathbf{M}_{i}
\end{array}\right)\left(\begin{array}{c}
\mathbf{x}_{\mathbf{b}} \\
\mathbf{x}_{\mathbf{i}}
\end{array}\right)=\left(\begin{array}{c}
\mathbf{f}_{\mathbf{b}} \\
\mathbf{f}_{\mathbf{i}}
\end{array}\right)
$$

Para resolver este sistema se pré-multiplica pela matriz

$$
\left(\begin{array}{cc}
\mathbf{I} & -\mathbf{M}_{c} \mathbf{M}_{i}^{-1} \\
0 & \mathbf{I}
\end{array}\right)
$$

para chegar à expressão

$$
\left(\begin{array}{cc}
\mathbf{M}_{b}-\mathbf{M}_{c} \mathbf{M}_{i}^{-1} \mathbf{M}_{c}^{T} & 0 \\
\mathbf{M}_{c}^{T} & \mathbf{M}_{i}
\end{array}\right)\left(\begin{array}{c}
\mathbf{x}_{\mathbf{b}} \\
\mathbf{x}_{\mathbf{i}}
\end{array}\right)=\left(\begin{array}{c}
\mathbf{f}_{\mathbf{b}}-\mathbf{M}_{c} \mathbf{M}_{i}^{-1} \mathbf{f}_{\mathbf{i}} \\
\mathbf{f}_{\mathbf{i}}
\end{array}\right)
$$


A equação para as fronteiras será

$$
\left(\mathbf{M}_{b}-\mathbf{M}_{c} \mathbf{M}_{i}^{-1} \mathbf{M}_{c}^{T}\right) \mathbf{x}_{\mathbf{b}}=\mathbf{f}_{\mathbf{b}}-\mathbf{M}_{c} \mathbf{M}_{i}^{-1} \mathbf{f}_{\mathbf{i}}
$$

Uma vez conhecido $\mathbf{x}_{\mathbf{b}}$ pode-se determinar $\mathbf{x}_{i}$ como

$$
\mathbf{x}_{\mathbf{i}}=\mathbf{M}_{i}^{-1} \mathbf{f}_{\mathbf{i}}-\mathbf{M}_{i}^{-1} \mathbf{M}_{c}^{T} \mathbf{x}_{\mathbf{b}}
$$

Desta forma a solução de A.59 foi dividida em três partes. Primeiro deve-se avaliar e inverter o sistema $\mathbf{M}_{b}-\mathbf{M}_{c} \mathbf{M}_{i}^{-1} \mathbf{M}_{c}^{T}$ conhecido como complemento Schur, na segunda parte deve-se avaliar $\mathbf{M}_{i}^{-1}$ e na operação final deve-se avaliar $\mathbf{M}_{c} \mathbf{M}_{i}^{-1}=\left[\mathbf{M}_{i}^{-1} \mathbf{M}_{c}^{T}\right]^{T}$. A segunda e terceira operação podem ser levadas a cabo num nível elementar. Como $\mathbf{M}_{i}$ esta composta por blocos de matrizes diagonais $\mathbf{M}_{i}^{e}$ (ou seja $\mathbf{M}_{i}=\mathbf{M}_{i}^{e}$ ), a matriz inversa de $\mathbf{M}_{i}$ é $\mathbf{M}_{i}^{-1}=\left[\underline{\mathbf{M}_{i}^{e}}\right]^{-1}$. Os produtos $\mathbf{M}_{c} \mathbf{M}_{i}^{-1} \mathbf{f}_{\mathbf{i}}$ e $\mathbf{M}_{i}^{-1} \mathbf{M}_{c}^{T} \mathbf{x}_{\mathbf{b}}$ podem ser tratados também como operações locais.

Defina-se a matriz $\mathbf{A}_{b}$ como a versão de fronteira de $\mathbf{A}$. Então a operação $\mathbf{A}_{b}$ liga os graus de liberdade de fronteira globais com os graus de liberdade de fronteira locais e está dada por

$$
\left(\begin{array}{c}
\mathbf{x}_{\mathbf{b}}{ }^{1} \\
\mathbf{x}_{\mathbf{b}}{ }^{2} \\
\vdots \\
\mathbf{x}_{\mathbf{b}}{ }^{N_{e l}}
\end{array}\right)=\mathbf{A}_{b} \mathbf{x}_{\mathbf{b}}
$$


Onde $\mathbf{x}_{\mathbf{b}}{ }^{e}$ contém as componentes de $\mathbf{x}_{\mathbf{b}}$ no elemento $e$. A matriz de fronteira interior $\mathbf{M}_{c}$ pode-se escrever como $\mathbf{M}_{c}=\mathbf{A}_{b}^{T} \mathbf{M}_{c}^{e}$ então os produtos $\mathbf{M}_{c} \mathbf{M}_{i}^{-1} \mathbf{f}_{\mathbf{i}}$ e $\mathbf{M}_{i}^{-1} \mathbf{M}_{c}^{T} \mathbf{x}_{\mathbf{b}}$ se tornam

$$
\begin{aligned}
\mathbf{M}_{c} \mathbf{M}_{i}^{-1} & =\mathbf{A}_{b}^{T} \underline{\mathbf{M}_{c}^{e}}\left[\underline{\mathbf{M}_{i}^{e}}\right]^{-1} \mathbf{f}_{\mathbf{i}} \\
\mathbf{M}_{i}^{-1} \mathbf{M}_{c}^{T} & =\underline{\left[\mathbf{M}_{i}^{e}\right]^{-1}}\left(\underline{\mathbf{M}_{c}^{e}}\right)^{T} \mathbf{A}_{b} \mathbf{x}_{\mathbf{b}}
\end{aligned}
$$

As matrizes $\underline{\left[\mathbf{M}_{i}^{e}\right]^{-1}}$ e $\underline{\mathbf{M}}_{c}^{e}$ são matrizes locais cujas operações são feitas num nível local.

A operação de ensamble das matrizes de fronteira é feita por $\mathbf{M}_{b}=\mathbf{A}_{b}^{T} \underline{\mathbf{M}_{b}}{ }^{e} \mathbf{A}_{b}$, então o complemento Shur fica como

$$
\begin{aligned}
\mathbf{M}_{b}-\mathbf{M}_{c} \mathbf{M}_{i}^{-1} \mathbf{M}_{c}^{T} & =\mathbf{A}_{b}^{T} \underline{\mathbf{M}_{b}^{e}} \mathbf{A}_{b}-\mathbf{A}_{b}^{T} \underline{\mathbf{M}_{c}^{e}} \underline{\left[\mathbf{M}_{i}^{e}\right]^{-1}} \underline{\left[\mathbf{M}_{c}^{e}\right]^{T}} \mathbf{A}_{b} \\
& =\mathbf{A}_{b}^{T}\left[\mathbf{M}_{b}^{e}-\mathbf{M}_{c}^{e}\left[\mathbf{M}_{i}^{e}\right]^{-1}\left(\mathbf{M}_{c}^{e}\right)^{T}\right] \mathbf{A}_{b}
\end{aligned}
$$

A equação A.69 mostra que o complemento Schur pode ser gerado a partir do complemento Schur local $\left[\mathbf{M}_{b}^{e}-\mathbf{M}_{c}^{e}\left[\mathbf{M}_{i}^{e}\right]^{-1}\left(\mathbf{M}_{c}^{e}\right)^{T}\right]$. Pode-se apreciar que a operação de ensamble global só precisa do sistema de fronteira quando a condensação estática é empregada. Uma vez a solução de fronteira é conhecida a solução para os modos interiores é dada pela equação A.65 que pode ser feita num nível elementar.

\section{Sistema de numeração global de fronteiras}

Numa seção anterior discutiram-se os aspectos relacionados com a numeração local de modos num domínio elementar, com o objetivo de permitir 
um ensamble global de modos usando $C^{\circ}$ continuidade. Este ensamble foi feito através do esquema map $[e][i]$. Nesta seção será discutido um esquema de ordenamento de modos que inclui as condições de fronteira de Dirichlet. O procedimento que permite arrumar os modos de fronteira é mostrado na

(a)

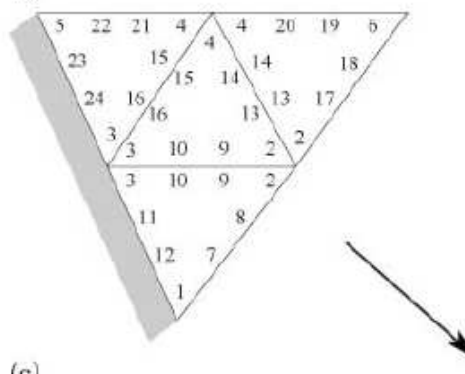

(c)

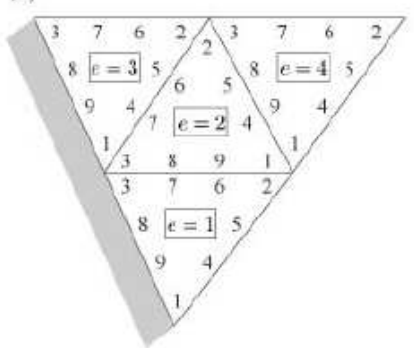

(b)

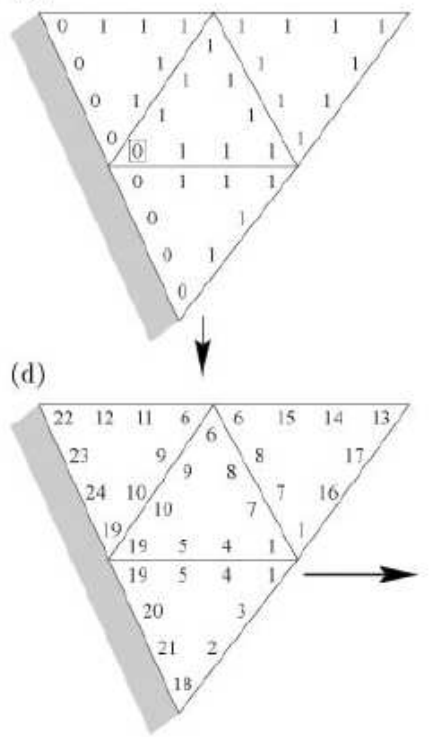

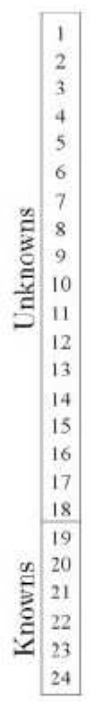

Figura A.9: Esquema de numeração global (a). Esquema de numeração na fronteira incluindo condições de Dirichlet (b). Ordenamento local de graus de liberdade (c). Ordenamento do sistema tal que os graus de liberdade conhecidos na fronteira de Dirichlet são listados depois dos graus desconhecidos (d). Extraído de Karniadakis e Sherwin ${ }^{11}$

Figura A.9. Neste exemplo se considera uma malha composta por quatro elementos triangulares. Na Figura A.9 se mostra o esquema de numeração global de modos para uma expansão polinomial da ordem três. Esta numeração global é obtida a partir do arranjo bmap $[e][i]$ o qual relaciona todos os graus de liberdade de fronteira locais (Figura A.9 (c)) com os globais. Se assume que os graus de liberdade de fronteira locais nos vértices são numerados primeiro, seguido dos graus de liberdade nos lados tal como ilustrado 
em Figura A.9 (c). Então o arranjo bmap $[e][i]$ pode ser definido como

$$
\begin{aligned}
\operatorname{bmap}[1][i] & \Rightarrow[1,2,3,7,8,9,10,11,12] \\
\text { bmap }[2][i] & \Rightarrow[2,4,3,13,14,15,16,10,9] \\
\text { bmap }[3][i] & \Rightarrow[3,4,5,16,15,21,22,23,24] \\
\text { bmap }[4][i] & \Rightarrow[2,6,4,17,18,19,20,14,13]
\end{aligned}
$$

Se tivermos uma condição de fronteira do tipo Dirichlet, o mais desejável é posicionar todos os graus de liberdade globais ao longo desta fronteira, na parte final de um novo sistema global de numeração.

Desde o ponto de vista da implementação, uma maneira conveniente de especificar as condições de fronteira é identificar nos elementos locais quais lados tocam a fronteira de Dirichlet. Então é possível identificar os graus de liberdade ao longo destas fronteiras e associar para eles um arranjo definido como mask $[e][i]$, e mostrado na Figura A.9 (b). Neste arranjo todos os graus de liberdade de Dirichlet têm uma entrada de 0, enquanto os outros graus de liberdade têm uma entrada de 1 . Finalmente, usando o arranjo mask podemos arrumar o sistema de numeração global incluindo as fronteiras a partir de um sistema local e outro sistema global. Pode-se definir um arranjo global Gbmap $[i]$ construído a partir de mask $[e][i]$ que mapea os índices da Figura A.9 (c) para aqueles da Figura A.9 (d). O arranjo em forma de algoritmo 
está dado por (o arranjo global Gbmap [i] é iniciado em zero)

$$
\left\{\begin{array}{c}
\text { let } n_{1}=n_{2}=1 \\
d o e=1, N_{e l} \\
\text { do } i=0, n_{b}[e]-1 \\
\text { if }(G b m a p[b m a p[e][i]]=0) \\
\text { if }(\text { mask }[e][i]=1) \\
\left(G b m a p[b m a p[e][i]]=n_{1}\right) \\
n_{1}=n_{1}+1 \\
\text { else } \\
\left(\text { Gbmap }[\text { bmap }[e][i]]=n_{2}+N_{b}\right) \\
n_{2}=n_{2}+1 \\
\text { continue } \\
\text { continue }
\end{array}\right.
$$

Onde $N_{b}$ é o número de graus de liberdade de fronteira desconhecidos. A forma final do esquema de ordenamento global é feito por bmap [e][i] que tem a estrutura dada na equação A.71. Com este esquema obtemos um ordenamento de graus de liberdade tal como mostrado no extremo direito da Figura A.9. No novo esquema os graus desconhecidos são listados primeiro 
seguidos dos graus conhecidos.

$$
\left\{\begin{array}{l}
d o e=1, N_{e l} \\
d o i=0, n_{b}[e]-1 \\
\quad b m a p[e][i]=\text { Gbmap }[\text { bmap }[e][i]] \\
\text { continue } \\
\text { continue }
\end{array}\right.
$$

\section{Transformação Elemental de fronteiras}

Dada uma condição de fronteira de Dirichlet $g_{D}(\mathbf{x})$ onde $\mathbf{x} \in \partial \Omega$, precisamos um método de aproximação de fronteira em termos de uma expansão discreta. Em geral se requere que a aproximação discreta da fronteira permaneça $C^{\circ}$ continua. A metodologia usada consiste, então, numa projeção de Galerkin modificada para segurar $C^{\circ}$ continuidade. Em duas dimensões esta projeção modificada pode ser vista como uma projeção de colocação nos vértices, seguida de uma projeção $L^{2}$ sobre os lados e finalmente numa projeção $L^{2}$ sobre a função remanente.

Para ilustrar a projeção modificada de Galerkin se considerar-se-à o caso mostrado na Figura A.10. Deseja-se projetar uma condição de contorno conhecida $g_{D}(\mathbf{x})$ sobre uma fronteira de um elemento $e$ ao longo de $\partial \Omega$. A solução discreta $u^{\delta}(x 1, x 2)$ ao longo da fronteira é

$$
u^{\delta}\left(x_{1}, x_{2}\right)=\sum_{p q} \hat{u}_{p q}^{e} \varphi_{p q}^{e}\left(\xi_{1},-1\right)=\sum_{p=0}^{P_{1}} \hat{u}_{p 0}^{e} \varphi_{p 0}^{e}\left(\xi_{1},-1\right)
$$


Se a expansão for do tipo modal ter-se-à $\varphi_{p 0}\left(\xi_{1},-1\right)=\psi_{p}^{a}\left(\xi_{1}\right) \psi_{0}^{a}(-1)=$

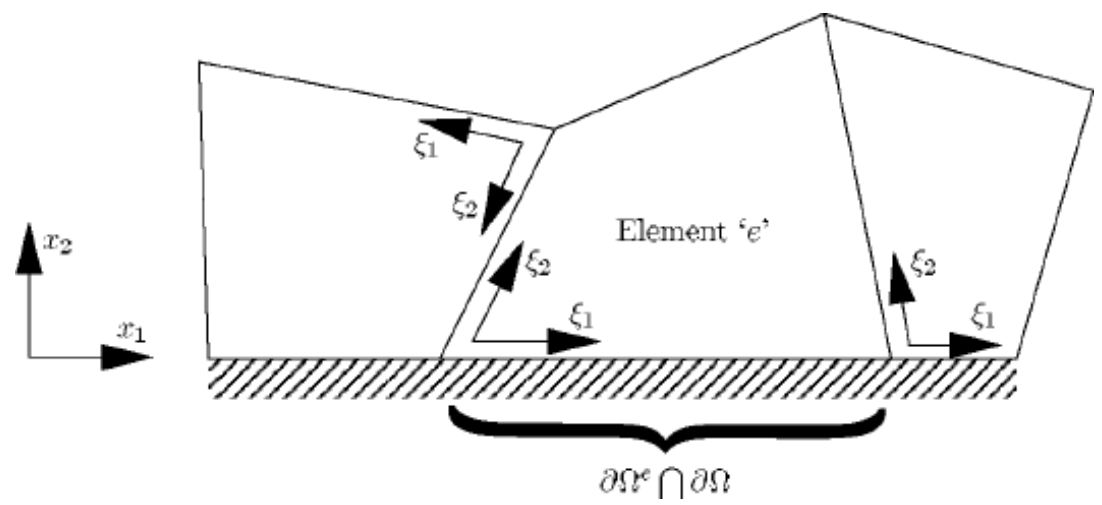

Figura A.10: Intersecção da fronteira do elemento e com a fronteira $\partial \Omega$. Extraído de Karniadakis $^{11}(1999)$

$\psi_{p}^{a}\left(\xi_{1}\right)$, se for do tipo nodal ter-se-à então $\varphi_{p 0}\left(\xi_{1},-1\right)=h_{p}\left(\xi_{1}\right)$. Para o caso modal (funciona igualmente para o caso nodal) se deseja determinar os coeficientes $\hat{u}_{p 0}^{e}$ que cumprem com a condição

$$
\sum_{p=0}^{P_{1}} \hat{u}_{p 0}^{e} \psi^{a}\left(\xi_{1}\right) \approx g_{D}\left(\chi_{1}^{e}\left(\xi_{1},-1\right)\right)
$$

As funções de vértice têm por definição um valor unitário nos extremos do lado enquanto os outros modos de fronteira são nulos. A $C^{\circ}$ continuidade se consegue com as condições

$$
\begin{aligned}
\hat{u}_{00}^{e} & =g_{D}\left(\chi_{1}^{e}(-1,-1)\right) \\
\hat{u}_{P_{1}, 0}^{e} & =g_{D}\left(\chi_{1}^{e}(1,1)\right)
\end{aligned}
$$

Os coeficientes restantes desconhecidos na fronteira podem ser determinados 
a partir de

$$
\sum_{p=1}^{P_{1}-1} \hat{u}_{p 0}^{e} \psi^{a}\left(\xi_{1}\right) \approx g_{D}\left(\chi_{1}^{e}\left(\xi_{1},-1\right)\right)-\hat{u}_{00}^{e} \psi_{0}^{a}\left(\xi_{1}\right)-\hat{u}_{P_{1} 0}^{e} \psi_{P_{1}}^{a}\left(\xi_{1}\right)
$$

Tais coeficientes podem ser calculados usando a projeção de Galerkin

$$
\left(\varphi_{i}, \sum_{p=1}^{P_{1}-1} \hat{u}_{p 0}^{e} \varphi_{p}\right)=\left(\varphi_{i}, g_{D}-\hat{u}_{00}^{e} \psi_{0}^{a}-\hat{u}_{P_{1} 0}^{e} \psi_{P_{1}}^{a}\right)
$$

Para todo $i, 0 \leq i \leq P_{1}-1$ 



\section{Apêndice B}

\section{Aplicação do método de}

\section{elementos finitos espectrais às}

\section{equações incompressíveis de}

\section{Navier-Stokes}

A solução numérica das equações de Navier-Stokes que governa fluidos viscosos requer discretização espacial e temporal. A discretização espacial está ligada com a resolução das pequenas escalas do escoamento como a camada limite. Por outro lado a discretização temporal está relacionada com fenômenos de instabilidade e também com a forma das equações semi-discretas que devem ser resolvidas. Em particular, a discretização temporal determina a forma da equação de pressão.

A pressão representa um ponto muito importante nas equações de fluxo incompressível dado que ela deve ser sempre compatível com a condição de livre 


\section{Aplicação do método de elementos finitos espectrais às equações 156 incompressiveis de Navier-Stokes}

divergência no campo de velocidades. É muito comum utilizar uma equação de Poisson para a pressão derivada da equação de momento com condição de incompressibilidade, no entanto não é claro a condição de contorno ótima a ser empregada. Trabalhos feitos por Orzsag et al. ${ }^{40}$ concluíram que uma condição de fronteira de tipo Neumann derivada da equação de momento leva a resultados certos na solução para a pressão.

O objetivo deste apêndice é mostrar a implementação de esquemas splitting no contexto da discretização espacial espectral para a resolução das equações de Navier-Stokes, no caso de escoamento incompressível. Os resultados apresentados estão baseados nos trabalhos de Carmo ${ }^{12}$, Karniadakis et al. ${ }^{41}$ e Orzsag et al. ${ }^{40}$.

Antes de tentar resolver numericamente as equações de Navier-Stokes devem ser definidas condições de contorno apropriadas para o sistema. Começando com a velocidade pode-se dizer que ao longe não há influência do corpo nem da esteira formada por ele, então pode-se considerar que a velocidade longe dos corpos é igual à velocidade do escoamento livre $U_{\infty}$. Nas paredes é imposta uma condição de não escorregamento, ou seja, a velocidade é nula. Na região de saída do fluido, se impôs a condição na qual a derivada da velocidade na direção normal é nula $\partial \mathbf{u} / \partial \mathbf{n}=0$. Para a pressão na saída também se impôs uma condição de contorno tipo Neumann, isto é $\partial p / \partial \mathbf{n}=0$. Enquanto à condição de contorno da pressão na parede ainda existe um debate na literatura. Os problemas para fixar tal condição radicam especialmente no fato de não existir uma equação para a pressão e, portanto, a pressão numa parede é conseqüência do escoamento. A seguir será exposta uma condição de contorno do tipo Neumann de alta ordem que é derivada da equação de 
equilíbrio do momento linear na direção normal na fronteira do domínio, esta metodologia foi proposto por Karniadakis et al. ${ }^{41}$.

Consideremos um fluxo incompressível governado pela equação de NavierStokes adimensional

$$
\frac{\partial \mathbf{u}}{\partial t}=-\nabla p+\frac{1}{R e} \mathbf{L}(\mathbf{u})+\mathbf{N}(\mathbf{u})
$$

Que cumpre com a condição de incompressibilidade $\nabla \cdot \mathbf{u}=0$. Nesta equação u é o vetor velocidade, $p$ é a pressão estática e Re é o número de Reynolds. Aqui L e $\mathbf{N}$ representam um operador linear e não linear respectivamente, definidos como

$$
\begin{gathered}
\mathbf{L}(\mathbf{u}) \equiv \nabla^{2} \mathbf{u}=\nabla(\nabla \cdot \mathbf{u})-\nabla \times(\nabla \times \mathbf{u}) \\
\mathbf{N}(\mathbf{u}) \equiv-\frac{1}{2}[\mathbf{u} \cdot \nabla \mathbf{u}+\nabla(\mathbf{u} \cdot \mathbf{u})]
\end{gathered}
$$

O termo não linear ou convectivo é implementado dessa forma com o intuito de diminuir os efeitos de aliasing. Para integrar a equação B.1 utilizamse esquemas de passo de tempo de alta ordem usualmente empregados na resolução de equações diferenciais ordinárias.

Integrando a equação B.1 num passo de tempo $\Delta t$ obtemos

$$
\mathbf{u}^{n+1}-\mathbf{u}^{n}=-\int_{t_{n}}^{t_{n}+1} \nabla p d t+\frac{1}{R e} \int_{t_{n}}^{t_{n}+1} \mathbf{L}(\mathbf{u}) d t+\int_{t_{n}}^{t_{n}+1} \mathbf{N}(\mathbf{u}) d t
$$


Aplicação do método de elementos finitos espectrais às equações 158 incompressiveis de Navier-Stokes

Onde $n$ se refere ao passo de tempo, pois $t_{n}=n \Delta t$. O termo que inclui a pressão pode-se reescrever como

$$
\int_{t_{n}}^{t_{n}+1} \nabla p d t=\Delta t \nabla \bar{p}^{n+1}
$$

Então $\bar{p}^{n+1}$ é um campo escalar que segura que o campo de velocidades final seja incompressível no passo de tempo $(n+1)$. Por motivos de eficiência aproxima-se o termo não linear com um esquema explícito que pode ser o esquema $J_{e}$ da família de Adams-Bashford como

$$
\int_{t_{n}}^{t_{n}+1} \mathbf{N}(\mathbf{u}) d t=\Delta t \sum_{q=0}^{J_{e}-1} \beta_{q} \mathbf{N}\left(\mathbf{u}^{n-q}\right)
$$

Onde $\beta_{q}$ são pesos devidamente escolhidos mostrados na Tabela.5.1. Por motivos de estabilidade o termo linear é aproximado com um esquema implícito que pode ser o esquema $J_{i}$ da família Adams-Moulton dado por

$$
\int_{t_{n}}^{t_{n}+1} \mathbf{L}(\mathbf{u}) d t=\Delta t \sum_{q=0}^{J_{i}-1} \gamma_{q} \mathbf{L}\left(\mathbf{u}^{n+1-q}\right)
$$

Similarmente $\gamma_{q}$ são pesos devidamente escolhidos e mostrados também na Tabela.B.1.

Usando tais esquemas a equação de Navier-Stokes pode ser resolvida em três etapas

$$
\begin{gathered}
\frac{\hat{\mathbf{u}}-\mathbf{u}^{n}}{\Delta t}=\sum_{q=0}^{J_{e}-1} \beta_{q} \mathbf{N}\left(\mathbf{u}^{n-q}\right) \\
\frac{\hat{\mathbf{u}}-\hat{\mathbf{u}}}{\Delta t}=-\nabla \bar{p}^{n+1}
\end{gathered}
$$




\begin{tabular}{|c||c||c||c||c||}
\hline \hline Esquema & Coeficiente & $1^{a}$ ordem & $2^{a}$ ordem & $3^{a}$ ordem \\
\hline \hline Adams-Bashford & $\beta_{0}$ & 1 & $3 / 2$ & $23 / 12$ \\
\hline Adams-Bashford & $\beta_{1}$ & 0 & $-1 / 2$ & $-16 / 12$ \\
\hline Adams-Bashford & $\beta_{2}$ & 0 & 0 & $5 / 12$ \\
\hline Adams-Moulton & $\gamma_{0}$ & 1 & $1 / 2$ & $5 / 12$ \\
\hline Adams-Moulton & $\gamma_{1}$ & 0 & $1 / 2$ & $8 / 12$ \\
\hline Adams-Moulton & $\gamma_{2}$ & 0 & 0 & $-1 / 12$ \\
\hline
\end{tabular}

Tabela B.1: Coeficientes das famílias de Adams-Bashford e Adams-Moulton. Tomada de Carmo ${ }^{12}$

$$
\frac{\mathbf{u}^{n+1}-\hat{\hat{\mathbf{u}}}}{\Delta t}=\nu \sum_{q=0}^{J_{i}-1} \gamma_{q} \mathbf{L}\left(\mathbf{u}^{n+1-q}\right)
$$

Com condições de Dirichlet $\mathbf{u}^{n+1}=\mathbf{u}_{0}$ sobre $\partial \Omega$. Aqui $\hat{\mathbf{u}}, \hat{\hat{\mathbf{u}}}$ são velocidades intermediárias definidas em B.8 e B.9. A equação B.8 pode ser resolvida para obter $\hat{\mathbf{u}}$, conhecendo esta variável pode-se obter $\hat{\hat{\mathbf{u}}}$ a partir de B.9 para finalmente determinar $\mathbf{u}^{n+1}$ com a equação B.10. Só resta saber como resolver B.9 já que $\hat{\mathbf{u}}$ e $\bar{p}^{n+1}$ são incógnitas. A solução deste sistema se consegue assumindo que o campo $\hat{\hat{\mathbf{u}}}$ satisfaz a condição de incompressibilidade

$$
\nabla \cdot \hat{\hat{\mathbf{u}}}=0 \quad \text { em } \Omega
$$

Substituindo a equação B.11 em B.9 se chega a uma equação para a pressão dada por

$$
\nabla^{2} \bar{p}^{n+1}=\nabla \cdot\left(\frac{\hat{\mathbf{u}}}{\Delta t}\right) \quad e m \Omega
$$

Para resolver esta equação deve-se impor uma condição de contorno conveniente. O método splitting clássico utiliza a hipótese de que $\hat{\hat{\mathbf{u}}}$ satisfaz a 


\section{Aplicação do método de elementos finitos espectrais às equações} 160 incompressiveis de Navier-Stokes

condição de fronteira de Dirichlet na direção normal

$$
\hat{\hat{\mathbf{u}}} \cdot \mathbf{n}=\mathbf{u}_{0} \cdot \mathbf{n}
$$

Apesar de esta condição levar a um conjunto de equações que podem ser resolvidas de forma eficiente, resultados dados por Karniadakis et al. ${ }^{41}$ mostram que a condição de contorno B.13 é incorreta no sentido que ela é inconsistente com as equações B.1. Para resolver este problema Karniadakis et al. ${ }^{41}$ utilizam uma solução alternativa na qual se toma a equação B.1 no contorno $\partial \Omega$ integrada no tempo, multiplicando todos os termos de B.1 pelo vetor normal n se obtém

$$
\int_{t_{n}}^{t_{n+1}} \frac{\partial \mathbf{u}}{\partial t} \cdot \mathbf{n} d t=-\int_{t_{n}}^{t_{n+1}} \nabla p \cdot \mathbf{n} d t+\frac{1}{R e} \int_{t_{n}}^{t_{n+1}} \mathbf{L}(\mathbf{u}) \cdot \mathbf{n} d t+\int_{t_{n}}^{t_{n+1}} \mathbf{N}(\mathbf{u}) \cdot \mathbf{n} d t
$$

O termo dentro da integral no lado esquerdo de B.14 pode se reescrever como

$$
\frac{\partial \mathbf{u}}{\partial t} \cdot \mathbf{n}=\frac{\partial}{\partial t}(\mathbf{u} \cdot \mathbf{n})-\mathbf{u} \cdot \frac{\partial \mathbf{n}}{\partial t}
$$

O segundo termo dado em B.15 é nulo, dado que o domínio é fixo e, portanto, o vetor normal na fronteira não depende do tempo. O termo $\frac{\partial}{\partial t}(\mathbf{u} \cdot \mathbf{n})$ representa o fluxo mássico liquido no domínio. Como o sistema considerado não tem fontes nem sorvedouros a integral de contorno desse termo é nula $\left(\right.$ Carmo $\left.^{12}\right)$. Desta forma o lado esquerdo da equação B.14 é nulo. Conside- 
rando esse fato e substituindo as equações B.5, B.6, B.7 chega-se a

$$
\frac{\partial \bar{p}^{n+1}}{\partial \mathbf{n}}=\mathbf{n} \cdot\left[\sum_{q=0}^{J_{e}-1} \beta_{q} \mathbf{N}\left(\mathbf{u}^{n-q}\right)+\frac{1}{R e} \sum_{q=0}^{J_{i}-1} \gamma_{q} \mathbf{L}\left(\mathbf{u}^{n+1-q}\right)\right]
$$

Pode-se observar que na equação de contorno B.16 aparecem variáveis no tempo $n+1$ que são incógnitas. Para evitar esses termos se reescreve o termo linear em termos de uma parte solenoidal e uma parte irrotacional como na equação B.2. O termo senoidal pode ser por tratado com um esquema explicito e a parte irrotacional a pode ser aproximada com um esquema implícito, obtendo-se o sistema

$$
\begin{aligned}
\frac{\partial \bar{p}^{n+1}}{\partial \mathbf{n}}= & \mathbf{n} \cdot \sum_{q=0}^{J_{e}-1} \beta_{q} \mathbf{N}\left(\mathbf{u}^{n-q}\right)+\mathbf{n} \cdot \frac{1}{R e} \sum_{q=1}^{J_{i}-1} \gamma_{q} \nabla\left(\nabla \cdot \mathbf{u}^{n+1-q}\right)+ \\
& \mathbf{n} \cdot \frac{1}{R e} \sum_{q=0}^{J_{e}-1} \beta_{q}\left(-\nabla \times\left(\nabla \times \mathbf{u}^{n-q}\right)\right)
\end{aligned}
$$

Mas o termo $\gamma_{0} \nabla\left(\nabla \cdot \mathbf{u}^{n+1}\right)$ é nulo já que se deve cumprir $\nabla \cdot \mathbf{u}^{n+1}=0$, desse modo eliminam-se as variáveis dependentes do passo $n+1$. Em resumo os passos do avanço no tempo são:

1. Calcula-se o campo de velocidades intermediário $\hat{\mathbf{u}}$ com a equação

$$
\frac{\hat{\mathbf{u}}-\mathbf{u}^{n}}{\Delta t}=\sum_{q=0}^{J_{e}-1} \beta_{q} \mathbf{N}\left(\mathbf{u}^{n-q}\right)
$$

2. Conhecendo $\hat{\mathbf{u}}$ pode-se calcular o campo de pressões $\bar{p}^{n+1}$ com a expressão

$$
\nabla^{2} \bar{p}^{n+1}=\nabla \cdot\left(\frac{\hat{\mathbf{u}}}{\Delta t}\right)
$$


Aplicação do método de elementos finitos espectrais às equações 162 incompressiveis de Navier-Stokes

com a condição de contorno

$$
\begin{aligned}
\frac{\partial \bar{p}^{n+1}}{\partial \mathbf{n}}= & \mathbf{n} \cdot \sum_{q=0}^{J_{e}-1} \beta_{q} \mathbf{N}\left(\mathbf{u}^{n-q}\right)+\mathbf{n} \cdot \frac{1}{R e} \sum_{q=1}^{J_{i}-1} \gamma_{q} \nabla\left(\nabla \cdot \mathbf{u}^{n+1-q}\right)+ \\
& \mathbf{n} \cdot \frac{1}{R e} \sum_{q=0}^{J_{e}-1} \beta_{q}\left(-\nabla \times\left(\nabla \times \mathbf{u}^{n-q}\right)\right)
\end{aligned}
$$

3. Como $\hat{\mathbf{u}}$ e $\bar{p}^{n+1}$ são conhecidos se calcula $\hat{\hat{\mathbf{u}}}$ a partir de

$$
\frac{\hat{\mathbf{u}}-\hat{\mathbf{u}}}{\Delta t}=-\nabla \bar{p}^{n+1}
$$

4. Finalmente pode-se obter o campo de velocidades $\mathbf{u}^{n+1}$ com a equação

$$
\frac{\mathbf{u}^{n+1}-\hat{\hat{\mathbf{u}}}}{\Delta t}=\nu \sum_{q=0}^{J_{i}-1} \gamma_{q} \mathbf{L}\left(\mathbf{u}^{n+1-q}\right)
$$




\section{Referências Bibliográficas}

[1] GERRARD, J. H. The mechanics of the formation region of vortices behind bluff bodies. Journal of Fluid Mechanics 25, 401-413 (1966). vii, $8,9,28$

[2] MEnEGHINI, J. R. Projetos de pesquisa no tópico de geração e desprendimento de vórtices no escoamento ao redor de cilindros. Resenha apresentada à Escola Politécnica da Universidade de São Paulo (Escola Politécnica da Universidade de São Paulo, 2002). vii, viii, 7, 8, 9, 10, $12,20,21,23,24,25,26,42$

[3] YOUNG, J. A. Viscous flow around vortex shedding flowmeters: a discrete vortex model, Ph.D. thesis (1989). vii, 10

[4] WILLIAMSON, C. H. K. 2-d and 3-d aspects of the wake of a cylinder, and their relation to wake computations,. Lect. Appl. Math 28, 719-751 (1991). vii, 11, 12, 13

[5] LEWEKE, T. \& WILliAMSON, C. H. K. Three-dimensional instabilities in wake transition. European Journal of Mechanics 17, 571-586 (1998). vii, 11, 13, 14, 15 
[6] CARMO, B. S., MENEGHINI, J. R. \& SHERWIN, S. J. Secondary instabilities in the flow around two circular cylinders in tandem. Journal of Fluid Mechanics 644, 395-431 (2010). vii, viii, 16, 19, 27, 28

[7] BARKLEY, D. \& HENDERSON, R. D. Three-dimensional floquet stability analysis of the wake of a circular cylinder. Journal of Fluid Mechanics 322, 215-241 (1996). viii, 15, 16, 17, 18, 20, 52, 56, 75

[8] BASU, R. I. Aerodynamic forces on structures of circular cross section. part 1. model-scale data obtained under two-dimensional conditions in low-turbulence streams. J. Wind Engineering 21 (1985). viii, 21

[9] SCHLiCHTING, H. Boudary layer theory (Mc Graw Hill Company Books, 1968). viii, ix, 23, 24, 25, 26, 31, 40, 41

[10] MENEGHINI, J., CARMO, B., TSIlOUFAS, S., GIORIA, R. \& ARANHA, J. Wake instability issues: From circular cylinders to stalled airfoils. Journal of Fluids and Structures 27, 694 - 701 (2011). viii, ix, $5,32,33,34$

[11] KARNIADAKIS, G. E. \& SHERWIN, S. J. Spectral hp element method for CFD (Oxford University Press, 1999). xii, xiii, 7, 45, 47, 106, 108, $110,112,114,116,118,119,121,139,145,148,152$

[12] CARMO, B. S. Estudo numérico do escoamento ao redor de cilindros alinhados. Dissertação de mestrado (Escola Politécnica da Universidade de São Paulo, 2005). xv, 7, 45, 52, 56, 71, 84, 98, 156, 159, 160

[13] THEOFILIS, V. \& SHERWIN, S. J. Global instabilities in trailing-edge 
laminar separated flow on a naca 0012 airfoil. International Symposium on Air Breathing Engines (ISABE) (2001). 5

[14] ROSCHKO, A. On the drag and shedding frequency of two dimensional bluff bodies. Technical Report 3169 NACA (1954). 11

[15] WILLIAMSON, C. H. K. The existence of two stages in the transition to three-dimensionality of a cylinder wake. Physics of fluids 31, 3165-3168 (1988b). 13

[16] WILliAMSON, C. H. K. Three-dimensional wake transition. Journal of Fluid Mechanics 328, 345-407 (1996c). 13

[17] WILLIAMSON, C. H. K. Mode a secondary instability in wake transition. Physics of Fluids 8, 1680-1682 (1996b). 15

[18] WILLIAMSON, C. H. K. The existence of two stages in the transition to three-dimensionality of a cylinder wake. Physics of Fluids 31, 3165-3168 (1988). 17, 19, 29, 75

[19] WILLIAMSON, C. H. K. Oblique and parallel modes of vortex shedding in the wake of a circular cylinder at low reynolds numbers. Journal of Fluid Mechanics 206, 579-627 (1989). 20

[20] LEWEKE, T. \& PROVENSAL, M. The flow behind rings - bluff-body wakes without end effects. Journal of Fluid Mechanics 288, 265-310 (1995). 20

[21] ROSCHKO, A. Experiments on the flow past a circular cylinder at very high reynolds numbers. Journal of Fluid Mechanics 10, 354 (1961). 21 
[22] MIZUSHIMA, J. \& SUEHIRO, N. Instability and transition of flow past two tandem circular cylinders. Physics of Fluids 17 (2005). 27

[23] CARMO, B. S. \& MENEGHINI, J. R. Numerical investigation of the flow around two circular cylinders in tandem. Journal of Fluids and Structures 22, 979-988 (2006). 27

[24] CARMO, B. S., SHERWIN, S. J., BEARMAN, P. W. \& WILldEN, R. H. J. Wake transition in the flow around two circular cylinders in staggered arrangements. Journal of Fluid Mechanics 597, 1-29 (2007). $28,29,44,52,58,59,74$

[25] MONKEWITZ, P. A. A note on vortex shedding from axisymmetric bluff bodies. Journal of Fluid Mechanics 192, 561-575 (1988). 42

[26] CHOMAZ, P. H., HUERRE, P. \& REDEKOPP, L. G. Bifurcations to local and global modes in spatially-developing flows. Phys. Rev. Lett. 60, 25-28 (1988). 42

[27] SAAD, Y. Numerical methods for large eigenvalue problems (Manchester University Press, 1992). 45

[28] PATERA, A. T. A spectral element method for fluid dynamics:laminar flow in a channel expansion. Journal of Computational Physics 54, 468-488 (1984). 45

[29] KARNIADAKIS, G. E. Spectral element-fourier methods for incompressible turbulent flows. Comput. Method. Appl. Mech. Engng 80, 367-380 (1990). 46, 48 
[30] KARNIADAKIS, G. E. \& ORSZAG, S. A. High-order splitting methods for the incompressible navier-stokes equations. Journal of Computational Physics 97, 414-443 (1991). 46

[31] WARBURTON, T. C., SHERWIN, S. J. \& KARNIADAKIS, G. E. Basis functions for triangular and quadrilateral high-order elements. Journal on Scientific Computing 20, 1671-1695 (1999). 46

[32] HENDERSON, R. D. Nonlinear dynamics and pattern formation in turbulent wake transition. Journal of Fluid Mechanics 352, 65-112 (1997). 49

[33] TSILOUFAS, S. P. Estudo da estabilidade secundária do escoamento ao redor de um aerofólio. Dissertação de mestrado (Escola Politécnica da Universidade de São Paulo, 2009). 51, 52, 53

[34] TSILOUFAS, S., GIORIA, R., MENEGHINI, J. \& CARMO, B. Floquet stability analysis of the flow around an airfoil. Proceedings of the 20th International Congress of Mechanical Engineering, Gramado, Brazil. (2009). 55

[35] GIORIA, R. S. \& al. Floquet stability analysis of the flow around an oscillating cylinder. Journal of Fluid and Structures 25, 676-686 (2009). $58,59,74$

[36] ZHANG, H. \& al. On the transition of the cylinder wake. Physics of Fluids 7, 779-794 (1995). 74

[37] SHEARD, G. J., THOMPSON, M. C. \& HOURIGAN, K. From spheres 
to circular cylinders: the stability and flow structures of bluff ring wakes. Journal of Fluid Mechanics 492, 147-180 (2003). 74

[38] BlaCkBurn, H. M., MARQUES, F. \& LOPEZ, J. M. Symmetry breaking of two-dimensional time-periodic wakes. Journal of Fluid Mechanics 522, 395-411 (2005) (2005). 74

[39] IGARASHI, T. Characteristics of the flow around two circular cylinders arranged in tandem. Bulletin of JSME 24, 323-331 (1981). 77

[40] ORSZAG, S., ISRAELI, M. \& DEVILLE, M. Boundary conditions for incompressible flows. Journal of Scientific Computing (1986). 156

[41] KARNIADAKIS, G. E., ORSZAG, S. A. \& ISRAELI, M. High-order splitting methods for the incompressible Navier-Stokes equations. Journal of Computational Physics (1991). 156, 157, 160 